Edson Kenji Ueda

Determinação da Curva Aproximadora pela Composição de Curvas de Bézier e Aplicação do Recozimento Simulado 
Edson Kenji Ueda

\section{Determinação da Curva Aproximadora pela Composição de Curvas de Bézier e Aplicação do Recozimento Simulado}

Dissertação apresentada à Escola Politécnica da Universidade de São Paulo para obtenção do título de Mestre em Ciências.

Área de Concentração: Engenharia de Controle e Automação Mecânica

Orientador: Prof. Dr. Marcos de Sales Guerra Tsuzuki

São Paulo

2015 
Este exemplar foi revisado e corrigido em relação à versão original, sob responsabilidade única do autor e com a anuência de seu orientador.

São Paulo, de de

Assinatura do autor:

Assinatura do orientador:

Catalogação-na-publicação

Ueda, Edson Kenji

Determinação da curva aproximadora pela composição de curvas de Bézier e aplicação do recozimento simulado / E. K. Ueda -- versão corr. -- São Paulo, 2015.

$74 \mathrm{p}$.

Dissertação (Mestrado) - Escola Politécnica da Universidade de São Paulo. Departamento de Engenharia Mecatrônica e de Sistemas Mecânicos.

1.Curva de Bézier 2.Recozimento simulado 3.Ajuste de curvas I.Universidade de São Paulo. Escola Politécnica. Departamento de Engenharia Mecatrônica e de Sistemas Mecânicos II.t. 


\section{Agradecimentos}

Agradeço ao Prof. Dr. Marcos de Sales Guerra Tsuzuki pelas orientações durante todo o desenvolvimento deste trabalho.

Aos meus colegas do Laboratório de de Geometria Computacional, que me auxiliaram nesta jornada.

Aos meus colegas do Laboratório de Veículos Não tripulados pelo companheirismo.

E à minha família, que me ajudaram na execução deste trabalho. 


\section{Resumo}

Determinar curvas a partir de uma série da pontos é uma tarefa importante e muito utilizada em CAD. Este trabalho propõe um algoritmo para determinar uma curva aproximadora representada por diversas curvas de Bézier em sequência a partir de uma sequência de pontos. É utilizada uma abordagem de curvas de Bézier por trechos, onde cada trecho possui continuidade $C^{1}$-fraca. A otimização é feita pelo recozimento simulado com vizinhança adaptativa que minimiza a soma das distâncias de cada ponto da sequência à curva aproximadora e utiliza o comprimento da curva aproximadora como um fator de regularização. Adicionalmente, é utilizado o recozimento simulado multi-objetivo que avalia a influência da soma das distâncias de cada ponto à curva e do comprimento da curva separadamente. Também é feita uma comparação entre a técnica de ajuste de curvas e a técnica de interpolação de curvas.

Palavras-chave: Curva de Bézier, recozimento simulado, ajuste de curvas. 


\section{Abstract}

The task of determining a curve from a set of points is very important in CAD. This work proposes an algorithm to determine a sequence of Bézier curves that approximate a sequence of points. The piecewise Bézier curve is used, where each curve has $C^{1}$ weak continuity. The optimization is done using the simulated annealing with adaptive neighborhood aiming at minimizing the sum of the distances from each point of the sequence to the generated curve. The length of this curve is used as a regularization factor. In addition, it is used a multi-objective simulated annealing that evaluates the influence of the sum of the distances from each point to the generated curve, and the curve's length. It is also done a comparison between curve fitting and curve interpolation techniques.

Keywords: Bézier curve, simulated annealing, curve fitting. 


\section{Sumário}

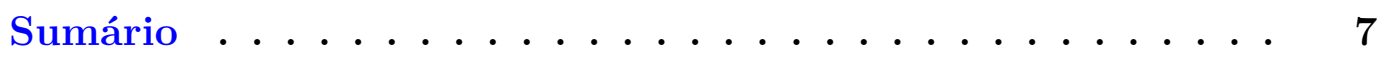

Lista de ilustrações . . . . . . . . . . . . . . 9

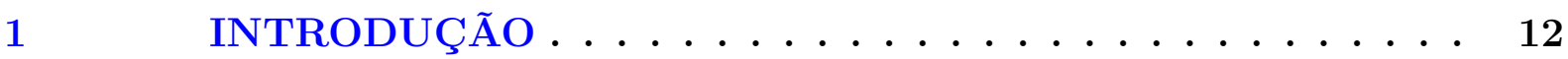

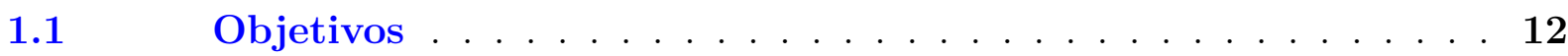

1.2 Revisão Bibliográfica . . . . . . . . . . . . . . . . 13

$1.3 \quad$ Organização do Texto . . . . . . . . . . . . . . . . . 14

2 CURVA DE BÉZIER ................. 15

$2.1 \quad$ Ajuste com uma Única Curva de Bézier . . . . . . . . . . . . . 15

2.2 Curva de Bézier por Trechos . . . . . . . . . . 18

3 RECOZIMENTO SIMULADO . . . . . . . . . . . 19

3.1 Vizinhança Adaptativa e Fator de Cristalização . . . . . . . . . 20

3.2 Programa de Resfriamento . . . . . . . . . . . . 23

4 APLICAÇÃO DO RECOZIMENTO SIMULADO NO PROBLEMA DE AJUSTE DE CURVAS . . . . . . . . . 25

4.1 Definição da Função de Custo . . . . . . . . . . . . . 25

4.2 Cálculo da Projeção . . . . . . . . . . . . . . . . . 25

4.3 Cálculo do Comprimento . . . . . . . . . . . . . . 26

4.4 Representação Paramétrica da Curva de Bézier por Trechos . . 27

4.4.1 Parâmetros Contínuos . . . . . . . . . . . . . . 27

4.4.2 Parâmetros Discretos . . . . . . . . . . . . . . . . . . 28

4.5 Determinação do Próximo Candidato . . . . . . . . . . . 28

4.6 Otimização da Busca do Ponto mais Próximo . . . . . . . . . 29

$5 \quad$ RECOZIMENTO SIMULADO MULTI-OBJETIVO . . . . . 32

$5.1 \quad$ Inicialização do Arquivo . . . . . . . . . . . . . . . . . 32

5.2 Quantidade de Dominância . . . . . . . . . . . . 34

5.3 Casos de Dominância . . . . . . . . . . . . . . . . . . 34

5.3.1 Caso 1 - a solução corrente domina a nova solução . . . . . . . . . . . 35

5.3.2 Caso 2 - não existe dominância entre a solução corrente e a nova solução 35

5.3.3 Caso 3 - a nova solução domina a solução corrente . . . . . . . . . . 36 


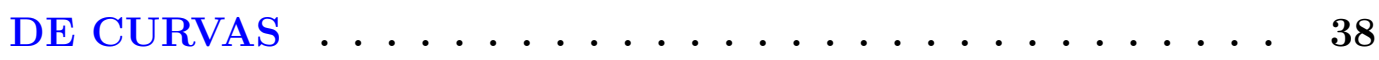

$6.1 \quad$ Funções objetivo . . . . . . . . . . . . . . . 38

6.2 Determinação do Próximo Candidato . . . . . . . . . . 38

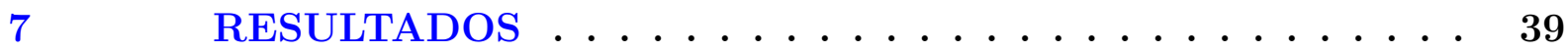

$7.1 \quad$ Parábola . . . . . . . . . . . . . . . 39

7.1.1 Interpolação . . . . . . . . . . . . . . . . . . . 39

7.1.2 Recozimento Simulado com Vizinhança Adaptativa . . . . . . . . . . 40

7.1.3 Recozimento Simulado Multi-objetivo . . . . . . . . . . . . . 41

7.2 Curva com Inflexão . . . . . . . . . . . . . . . 41

7.2.1 Interpolação . . . . . . . . . . . . . . . . . . . . 41

7.2.2 Recozimento Simulado com Vizinhança Adaptativa . . . . . . . . . . 44

7.2.3 Recozimento Simulado Multi-objetivo . . . . . . . . . . . . . 46

7.3 Curva com Auto-Intersecção . . . . . . . . . . . . . . . . . 49

7.3.1 Interpolação . . . . . . . . . . . . . . . . . . . 49

7.3.2 Recozimento Simulado com Vizinhança Adaptativa . . . . . . . . . 50

7.3.3 Recozimento Simulado Multi-objetivo . . . . . . . . . . . . 55

7.4 Fator de Cristalização, Calor Específico, Coeficiente de Resfriamento e Custos . . . . . . . . . . . . . . . . . . . 55

$8 \quad$ CONCLUSÕES ........................... 61

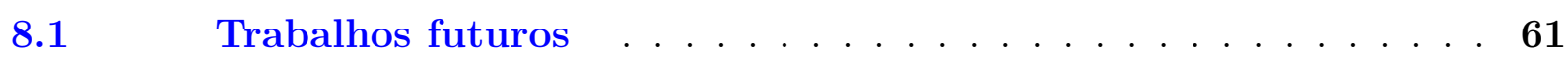

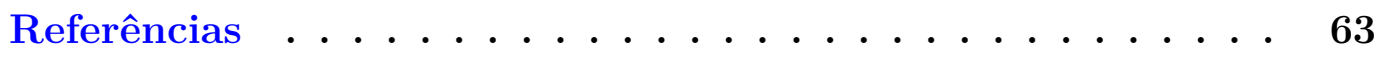

$\begin{array}{ll}\text { APENNDICES } & 65\end{array}$

APÊNDICE A-CURVA B-SPLINE . . . . . . . . 66

APÊNDICE B - INTERPOLAÇÃO DE CURVAS POR ALGORITMO GEOMÉTRICO . . . . . . 68

APÊNDICE C - VALORES DE CADA PARCELA DA FUNÇÃO CUSTO UTILIZANDO O RECOZIMENTO SIMULADO COM VIZINHANÇA ADAPTATIVA ................. 71 


\section{Lista de ilustrações}

Figura 1.1 - Curva aproximadora e curva interpoladora. . . . . . . . . . . . . . . 13

Figura 2.2 - Curva de Bézier. . . . . . . . . . . . . . . . . . . . 15

Figura 2.3 - Cálculo da distância feito com parâmetros pré-definidos (imagem traduzida de Hasegawa et al. [2013, Figura 1]). . . . . . . . . . . . . . . 16

Figura 2.4 - Cálculo da distância entre um ponto e uma curva. . . . . . . . . . . . 17

Figura 2.5 - Curva de Bézier por trechos. . . . . . . . . . . . . . . . 17

Figura 3.6 - Realimentação do fator de cristalização. . . . . . . . . . . . . . . . . 22

Figura 3.7 - Comportamento do fator de cristalização com a variação da temperatura. 22

Figura 4.8 - Cálculo da altura de um triângulo. . . . . . . . . . . . . . . . . 26

Figura 4.9 - Curva de Bézier por trechos. . . . . . . . . . . . . . . . 27

Figura 4.10-Primeiro limite de deslocamento da junção de curvas. . . . . . . . . . . 30

Figura 4.11-Segundo limite de deslocamento da junção de curvas. . . . . . . . . . . 30

Figura 4.12-Busca da menor distância entre cada ponto da sequência de pontos e curva gerada. . . . . . . . . . . . . . . . . . . . 31

Figura 4.13-Exemplo de uma curva com dois trechos. (a) Ocorre auto-intersecção; (b) Não ocorre auto-intersecção. . . . . . . . . . . . . . . . . . .

Figura 5.14-A solução nova é dominada pela solução corrente. (a) A solução nova e as soluções do arquivo são não dominantes; (b) Algumas soluções do arquivo dominam a solução nova. . . . . . . . . . . . . . . . . . 36

Figura 5.15-A nova solução e a solução corrente são não dominantes. (a) Algumas soluções do arquivo dominam a nova solução; (b) A nova solução e as soluções do arquivo são não dominantes; (c) A nova solução domina $k(k \geq 1)$ soluções do arquivo. . . . . . . . . . . . . . . . . .

Figura 5.16-A nova solução domina a solução corrente. (a) Algumas soluções do arquivo dominam a nova solução; (b) A nova solução e as soluções do arquivo são não dominantes, com exceção da solução corrente; (c) A nova solução domina algumas soluções do arquivo, excluindo a solução corrente. . . . . . . . . . . . . . . . . 37

Figura 7.17-Resultado da interpolação no exemplo da parábola. (a) Todos os pontos são interpolados; (b) 13 pontos são interpolados. . . . . . . . . . . . . . . 40

Figura 7.18-Exemplo de uma parábola com: (a) 1 curva de Bézier; (b) 2 curvas de Bézier; (c) 3 curvas de Bézier. . . . . . . . . . . . . . . . . . . 42

Figura 7.19-Resultados do exemplo da parábola: (a) W1 x Distância; (b) W1 x Comprimento; (c) W1 x Custo. . . . . . . . . . . . . . . . 43

Figura 7.20-Frente de Pareto do exemplo da curva parabólica. . . . . . . . . . . . . 44 
Figura 7.21-Alguns resultados da frente de Pareto referente ao exemplo da parábola com: (a) 1 curva de Bézier; (b) 2 curvas de Bézier; (c) 3 curvas de Bézier. A curva em vermelho é a curva que apresenta a menor distância entre sequência de pontos e curva aproximadora, e a curva em verde a curva que apresenta o menor comprimento. . . . . . . . . . . . . . . 45

Figura 7.22-Resultado da interpolação no exemplo de uma curva com inflexão. (a) Todos os pontos são interpolados; (b) 13 pontos são interpolados. . . . 46

Figura 7.23-Exemplo de uma curva com inflexão com: (a) 2 curvas de Bézier; (b) 3 curvas de Bézier; (c) 4 curvas de Bézier. . . . . . . . . . . . . . . . 47

Figura 7.24-Resultados do exemplo da curva com inflexão: (a) W1 x Distância; (b) W1 x Comprimento; (c) W1 x Custo. . . . . . . . . . . . . . . 48

Figura 7.25 -Curva com inflexão com comprimento elevado. . . . . . . . . . . . . . . 49

Figura 7.26-Frente de Pareto do exemplo da curva com inflexão. . . . . . . . . . . . 50

Figura 7.27-Alguns resultados da frente de Pareto referente ao exemplo da curva com inflexão com: (a) 2 curvas de Bézier; (b) 3 curvas de Bézier; (c) 4 curvas de Bézier. A curva em vermelho é a curva que apresenta a menor distância entre sequência de pontos e curve aproximadora, e a curva em verde a curva que apresenta o menor comprimento. . . . . . .

Figura 7.28-Resultado da interpolação no exemplo de uma curva com auto-intersecção. (a) Todos os pontos são interpolados; (b) 13 pontos são interpolados. . 52

Figura 7.29-Exemplo de uma curva com auto-intersecção com: (a) 5 curvas de Bézier; (b) 6 curvas de Bézier; (c) 7 curvas de Bézier. . . . . . . . . . . 53

Figura 7.30-Resultados do exemplo da curva com auto-intersecção : (a) W1 x Distância; (b) W1 x Comprimento; (c) W1 x Custo. . . . . . . . . . . . 54

Figura 7.31-Frente de Pareto do exemplo da curva com auto-intersecção. . . . . . . 55 Figura 7.32-Alguns resultados da frente de Pareto referente ao exemplo da curva com auto-intersecção com: (a) 5 curvas de Bézier; (b) 6 curvas de Bézier; (c) 7 curvas de Bézier. A curva em vermelho é a curva que apresenta a menor distância entre sequência de pontos e curva aproximadora, e a curva em verde a curva que apresenta o menor comprimento. . . . . . . 56

Figura 7.33-Fatores de cristalização para um exemplo com 4 parâmetros. (a) Fator $c_{0}$; (b) Fator $c_{1}$; (c) Fator $c_{2}$; (d) Fator $c_{3}$. . . . . . . . . . . . 58

Figura 7.34-Curva de custo máximo, mínimo e médio por temperatura. . . . . . . . 58

Figura $7.35-$ Curva da variância por temperatura. . . . . . . . . . . . . . . . . 59

Figura $7.36-$ Curva do calor específico por temperatura. . . . . . . . . . . . . . . . 59

Figura 7.37-Curva do fator de resfriamento $\alpha$ por temperatura. . . . . . . . . . . 60

Figura A.38-B-spline com a primeira derivada. . . . . . . . . . . . . . 67 
Figura B.39-Interpolação de curvas. (a) primeira curva utilizando a sequência de pontos como pontos e controle; (b) primeiro deslocamento dos pontos de controle; (c) curva gerada após o primeiro deslocamento dos pontos de controle; (d) curva interpoladora ao final do processo. (Extraído de Maekawa et al. [2007]) . . . . . . . . . . . . . . . . . 70 


\section{Introdução}

A técnica de determinar curvas a partir de uma sequência de pontos é muito importante na engenharia. Esta técnica pode ser útil em tarefas aplicadas à engenharia reversa, como por exemplo a reconstrução de objetos. É muito difícil reconstruir objetos somente com curvas, pois normalmente são necessárias superfícies para representar um objeto tridimensional. Porém existe um tipo específico de superfície, denominado por superfície esbelta [PIEGL; TILLER, 1996], que são construídas com o auxílio de curvas, denominadas curvas de nível. Assim, ao obter pontos na forma de curvas de nível é possível reconstruir o objeto por meio desta técnica. Objetos que possuem esta característica são inúmeros como a pá de hélice de uma turbina ou bomba, cascos de navio, entre outros [SHAMSUDDIN et al., 2006].

Outra aplicação da determinação de curvas a partir de uma sequência de pontos é no planejamento de trajetórias, definindo pontos (locais) onde o veículo deve passar e, consequentemente, a trajetória é determinada.

A tarefa de determinar uma curva a partir de uma sequência de pontos pode ser feita por duas diferentes abordagens, uma por interpolação e outra por aproximação. A primeira determina uma curva que passe por todos os pontos, enquanto a segunda determina uma curva que melhor aproxima uma sequência de pontos.

\subsection{Objetivos}

O objetivo deste trabalho é estudar a aplicação do recozimento simulado para o problema de ajuste de curvas com o intuito de criar curvas aproximadoras a uma sequência de pontos bidimensional, considerando a existência de ruído. Caso sejam utilizadas curvas interpoladoras, todos os pontos estarão sobre a curva, mas a curva pode possuir um comprimento elevado, pelo fato dela ser tortuosa, e esta característica não é desejada. Essa tortuosidade pode ser observada na Fig. 1.1, onde a sequência de pontos é mostrada por circunferências em azul, a curva aproximadora por uma linha tracejada em preto e a curva interpoladora por uma linha em vermelho.

Este efeito também pode ocorrer com curvas aproximadoras caso seja utilizado curvas de Bézier com muitos pontos de controle. Assim, este trabalho propõe uma nova função objetivo que é composto pela distância entre sequência de pontos e curva aproximadora e o comprimento desta curva, e esta função objetivo é minimizada pelo recozimento sumulado. Também é utilizado uma abordagem de curvas de Bézier por trechos para evitar a utilização de curvas de Bézier com muitos pontos de controle. 


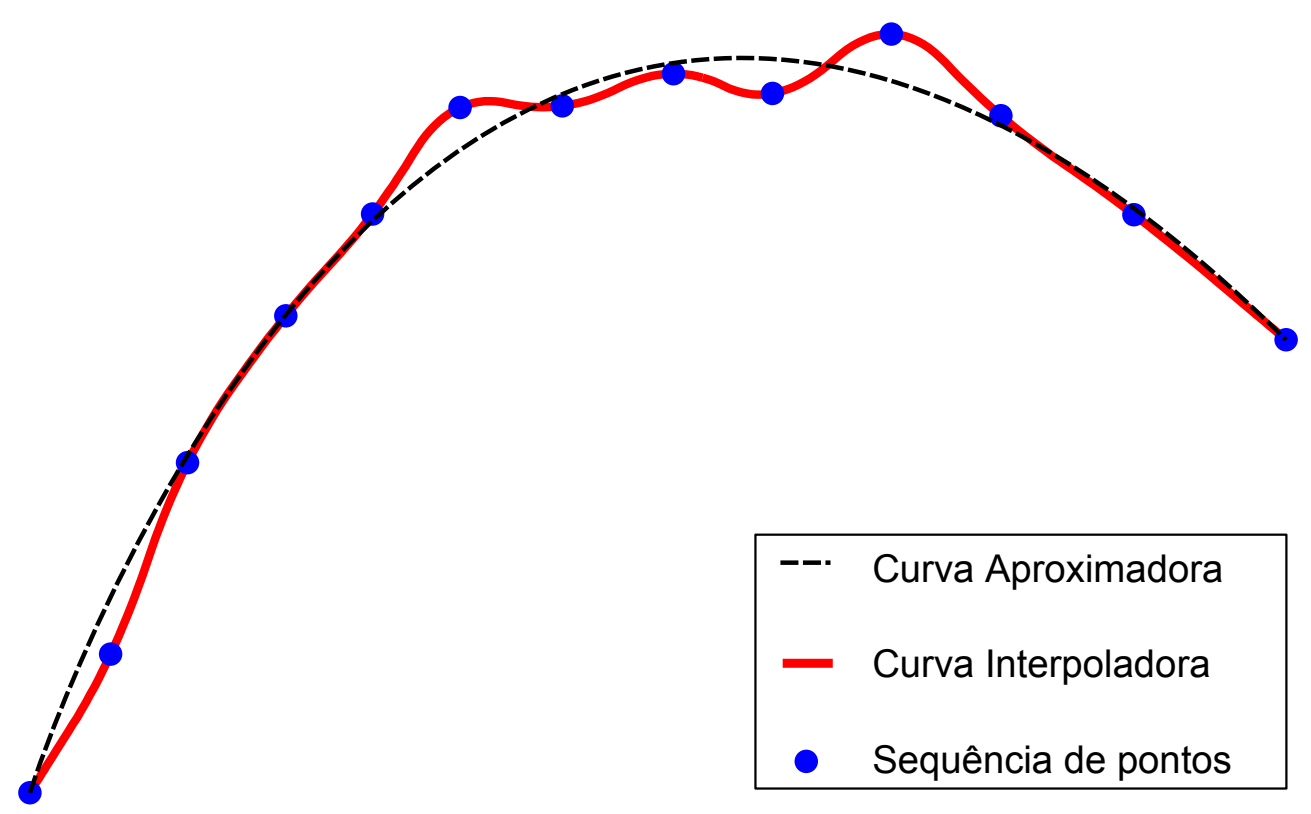

Figura 1.1 - Curva aproximadora e curva interpoladora.

\subsection{Revisão Bibliográfica}

A técnica de interpolação tem como objetivo criar curvas ou superfícies que passam por uma sequência de pontos. Existem vários algoritmos clássicos de interpolação de curvas e superfícies, onde pontos de controle são determinados pela solução de sistemas lineares [PIEGL; TILLER, 1997]. Estes algoritmos podem determinar curvas interpoladoras e também determinar os vetores tangentes da curva. Maekawa et al. [2007] desenvolveram um algoritmo geométrico que determina uma curva B-spline [PIEGL; TILLER, 1997, seção 2.2] que interpola uma sequência de pontos. Gofuku et al. [2009] aprimoraram este algorítimo ao adicionar informações sobre como o vetor tangente e/ou normal influenciam a curva interpoladora. O primeiro algoritmo pode ser aplicado para a criação de curvas no espaço tridimensional, porém o segundo algoritmo pode ser aplicado somente para criar curvas no espaço bidimensional, pois um ponto de uma curva tridimensional possuirá um plano normal, e consequentemente, existem diversos vetores normais. Desta forma, Okaniwa et al. [2012] modificaram o algoritmo para torná-lo aplicável a curvas tridimensionais, ao utilizar o vetor de curvatura no lugar do vetor normal. Todos os três algoritmos geométricos necessitam determinar o ponto mais próximo da curva até um ponto dado, que é a projeção ortogonal do ponto sobre a curva. Para se realizar esta operação, eles utilizaram o método de Newton-Raphson para curvas e também utilizaram um algoritmo de segunda ordem proposto por $\mathrm{Hu}$ e Wallner [2005] que pode ser aplicado a curvas e superfícies.

Porém o método de interpolação possui uma limitação, pois é necessário no mínimo um ponto de controle para cada ponto da sequência. Desta forma, caso a sequência de pontos possua uma grande quantidade de pontos, este método se torna inviável. Assim, o método de ajuste de curvas se torna mais viável, pois necessita de um número menor de 
pontos de controle.

Normalmente os problemas de ajuste de curvas são realizados com o auxílio de metaheurísticas. Pandunata e Shamsuddin [2010] e Hasegawa et al. [2013] utilizaram o algoritmo de evolução diferencial (ED) para resolver o problema de ajuste de curvas. Ambos os trabalhos utilizam uma única curva de Bézier [PIEGL; TILLER, 1997, seção 1.3] para definir a curva que melhor aproxima uma sequência de pontos. Hasegawa et al. [2013] fazem uma abordagem paralela utilizando um algoritmo de ED paralelo para fazer a aproximação. Ao invés de utilizar um algoritmo de ED para controlar todos os pontos de controle, cada ED controla um único ponto de controle. Sobrinho et al. [2009] utilizaram o recozimento simulado para controlar os pontos de controle de uma curva B-spline que aproxima uma sequência de pontos, e esta curva auxilia na reconstrução de uma pá de turbina. Adi et al. [2010] utilizaram a otimização por enxame de partículas para aproximar uma curva NURBS [PIEGL; TILLER, 1997, seção 4.2] a uma sequência de pontos, o algoritmo controla os pontos de controle e os pesos da curva NURBS. Tavares et al. [2011] utilizaram o recozimento simulado para realizar o planejamento de trajetória offline, onde é determinada a trajetória de um robô de forma que ele realize um percurso em um ambiente conhecido entre dois pontos sem que ocorram colisões e que alguns critérios sejam satisfeitos.

\subsection{Organização do Texto}

No capítulo 2 é apresentada a representação matemática da curva de Bézier e algumas de suas propriedades, assim como o equacionamento do problema de ajuste de curvas e a curva de Bézier por trechos. No capítulo 3 é apresentado o recozimento simulado com vizinhança adaptativa e o programa de resfriamento adotado. No capítulo 4 é apresentado como o recozimento simulado foi utilizado para resolver o problema de ajuste de curvas. Assim, a função objetivo e as variáveis a serem otimizadas são definidas. Também é apresentado como a função objetivo foi calculada. No capítulo 5 é apresentado o recozimento simulado multi-objetivo. No capítulo 6 é apresentado como o recozimento simulado multi-objetivo foi utilizado para resolver o problema de ajuste de curvas. No capítulo 7 serão apresentados alguns resultados para avaliar o método proposto. Finalmente no capítulo 8 estão as conclusões e algumas sugestões para o prosseguimento desta pesquisa. 


\section{Curva de Bézier}

A curva de Bézier $\mathbf{P}(u)$ é uma curva paramétrica dada por

$$
\mathbf{P}(u)=\sum_{i=0}^{n} \mathbf{p}_{i} B_{i, n}(u), \quad u \in[0,1]
$$

onde $\mathbf{p}_{i}$ são os pontos de controle, $n$ é o número de pontos de controle, $(n-1)$ é o grau do polinômio e $B_{i, n}(u)$ são as funções bases calculadas com o polinômio de Bernstein definidas por

$$
B_{i, n}(u)=\left(\begin{array}{c}
n \\
i
\end{array}\right) u^{i}(1-u)^{n-i}, \quad i=0, \ldots, n .
$$

onde $\left(\begin{array}{c}n \\ i\end{array}\right)$ é o binomial dado por

$$
\left(\begin{array}{l}
n \\
i
\end{array}\right)=\frac{n !}{i !(n-i) !} \quad\left(\begin{array}{l}
0 \\
0
\end{array}\right) \equiv 1 .
$$

A Fig. 2.2 mostra uma curva de Bézier com quatro pontos de controle. A curva é definida pelos pontos de controle $\mathbf{p} 0, \mathbf{p} 1, \mathbf{p} 2$ e $\mathbf{p} 3$, a curva sempre passa pelo primeiro e último pontos de controle e a curva sempre se encontra dentro do envoltório convexo [CHIYOKURA, 1988, seção 5.2.1] formado pelos pontos de controle. p1, p2 são pontos de controle internos.

\subsection{Ajuste com uma Única Curva de Bézier}

O problema de ajuste de curva tem o objetivo de encontrar uma curva que aproxime uma sequência de pontos pela determinação dos pontos de controle $\left(\mathbf{p}_{\mathbf{0}}, \ldots, \mathbf{p}_{\mathbf{n}}\right)$ da curva de Bézier aproximadora. Neste caso, a somatória da distância de cada ponto até a curva deve

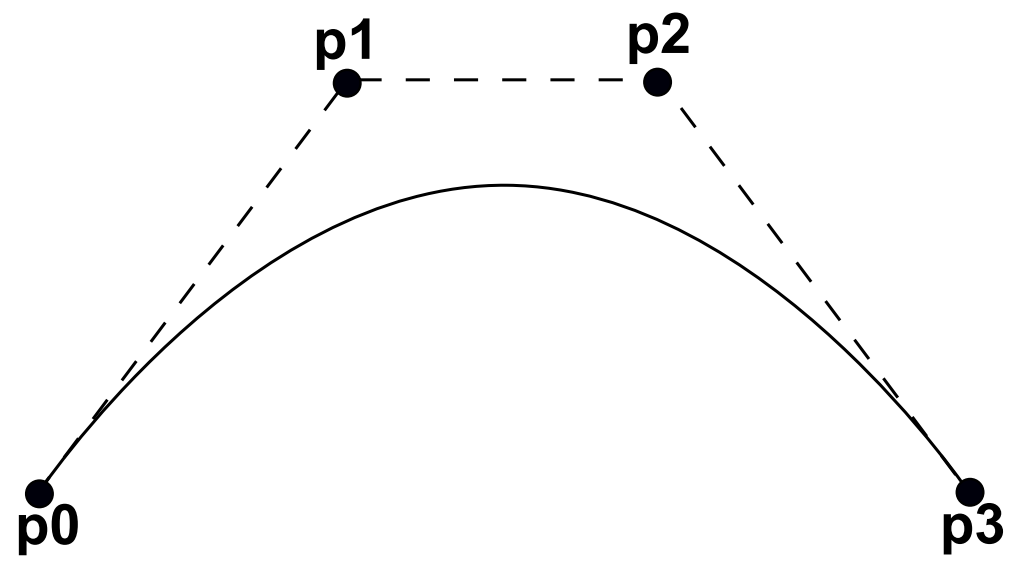

Figura 2.2 - Curva de Bézier. 


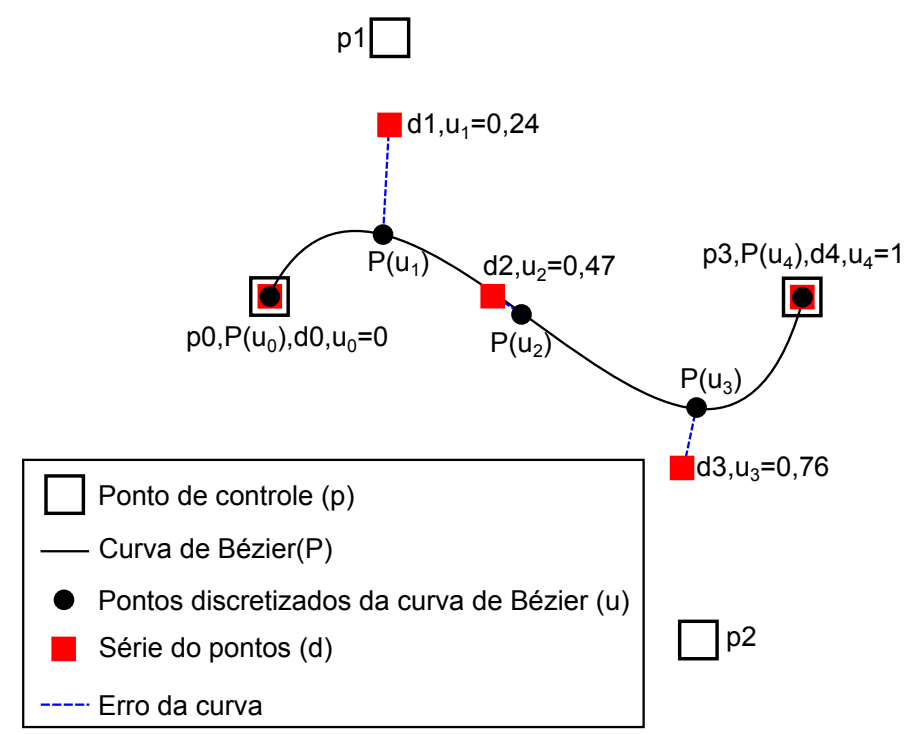

Figura 2.3 - Cálculo da distância feito com parâmetros pré-definidos (imagem traduzida de Hasegawa et al. [2013, Figura 1]).

ser minimizada. Considerando que procura-se por uma curva de Bézier única, a função que descreve a somatória das distâncias é

$$
f\left(\mathbf{p}_{\mathbf{0}}, \ldots, \mathbf{p}_{\mathbf{n}}\right)=\sum_{k=1}^{m-1}\left|\mathbf{d}_{k}-\mathbf{P}\left(u_{k}\right)\right|^{2},
$$

onde $n$ é o número de pontos de controle, $d$ é uma sequência de pontos com $m+1$ elementos e devido às características da curva de Bézier, têm-se $\mathbf{d}_{\mathbf{0}}=\mathbf{P}(0)$ e $\mathbf{d}_{\mathbf{m}}=\mathbf{P}(1)$. O termo $\left|\mathbf{d}_{k}-\mathbf{P}\left(u_{k}\right)\right|$ é a distância entre cada ponto $\mathbf{d}_{k}$ até a curva de Bézier.

A distância do ponto à curva pode ser aproximada de diversas formas, Hasegawa et al. [2013] e Pandunata e Shamsuddin [2010] calculam a distância utilizando uma parametrização pré-definida, onde para um dado ponto $\mathbf{d}_{k}$ o ponto sobre a curva mais próximo a ele é aproximado por $\mathbf{P}\left(u_{k}\right)$, onde $u_{k}$ é a razão entre o comprimento $\left|\mathbf{d}_{k}-\mathbf{d}_{k-1}\right|$ e $\sum_{i=1}^{m+1}\left|\mathbf{d}_{i}-\mathbf{d}_{i-1}\right|$. Este cálculo não garante a correta distância, uma vez que o ponto da curva de Bézier mais próximo a um ponto $\mathbf{d}_{k}$ deve variar com a modificação de pontos de controle internos. A Fig. 2.3 mostra uma curva de Bézier com 4 pontos de controle e uma sequência de pontos com 5 pontos, onde cada ponto $\mathbf{d}_{k}$ da sequência possui um ponto mais próximo $\mathbf{P}\left(u_{k}\right)$. É possível notar que no ponto $\mathbf{d} \mathbf{2}$ a distância até a curva é nula, mas ao utilizar a parametrização fixa determinou-se $\mathbf{P}\left(u_{2}\right)$ e a distância entre os dois pontos não é nula. Outra forma de se obter o ponto mais próximo a uma curva é por métodos iterativos. Como o método de Newton-Raphson utilizado por Maekawa et al. [2007] e Gofuku et al. [2009], que encontra o parâmetro associado ao ponto da curva com a menor distância entre o ponto fornecido e a curva. Este parâmetro $\mathbf{u}_{k}$ é definido ao resolver a seguinte equação

$$
\left(\mathbf{d}_{k}-\mathbf{P}\left(u_{k}\right)\right) \cdot \dot{\mathbf{P}}\left(u_{k}\right)=0 .
$$




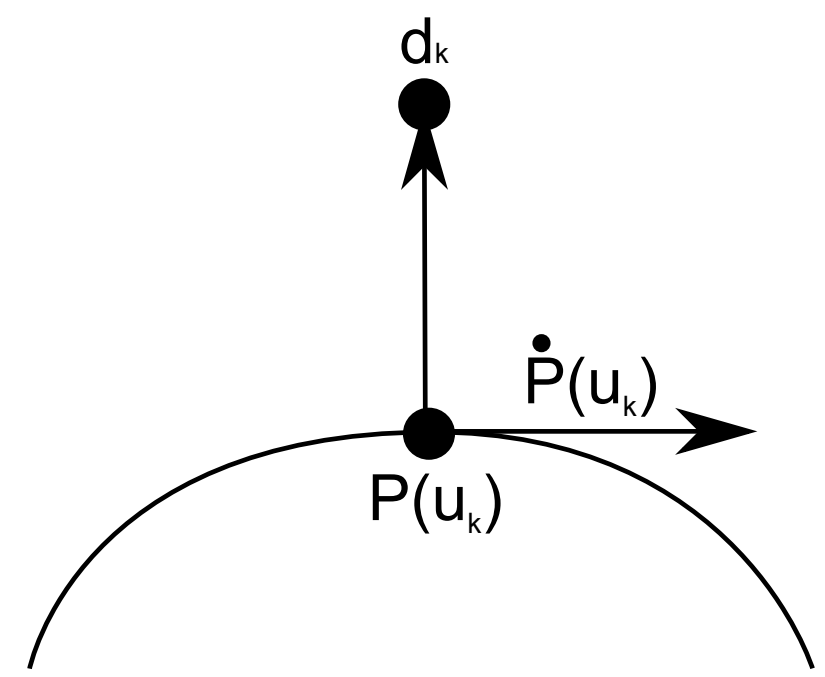

Figura 2.4 - Cálculo da distância entre um ponto e uma curva.

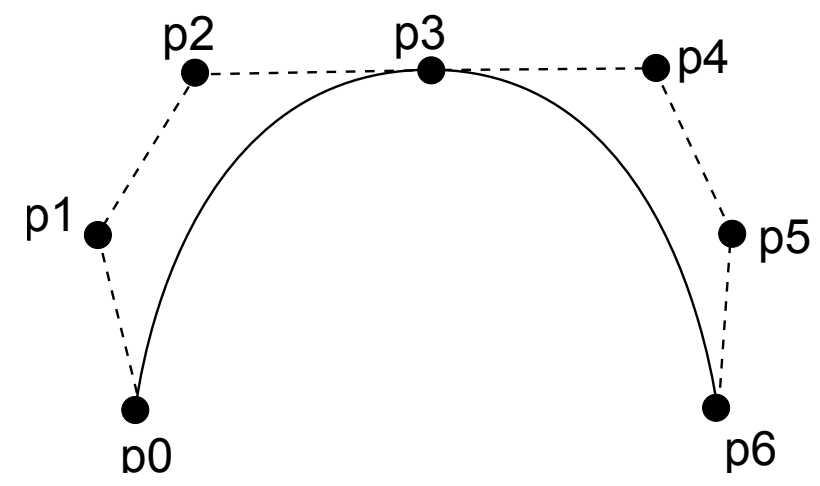

Figura 2.5 - Curva de Bézier por trechos.

A Eq. 2.5 obtém um parâmetro $u_{k}$ em que o vetor $\left(\mathbf{d}_{k}-\mathbf{P}\left(u_{k}\right)\right)$ é ortogonal à $\mathbf{P}\left(u_{k}\right)$ conforme mostra a Fig. 2.4. Outra forma iterativa de se encontrar a distância de um ponto a uma curva é o algoritmo proposto por Hu e Wallner [2005] onde se apresenta um algoritmo de primeira e segunda ordens para se encontrar a projeção ortogonal de um ponto sobre uma curva ou superfície. Assim, o problema de determinar a distância entre um ponto dado e uma curva é o mesmo que o problema de determinar a projeção de um ponto sobre a curva.

Outra forma de aproximar a projeção de um ponto a uma curva é pela discretização da curva e em seguida determinar qual ponto discretizado está mais próximo de cada ponto $\mathbf{d}_{k}$, como realizado por Tavares et al. [2011], porém de acordo com Hasegawa et al. [2013] a quantidade de pontos que discretiza a curva tem influência direta com a qualidade do resultado, quanto mais pontos melhor será o resultado. Mas quanto maior a discretização, o tempo de processamento também aumenta. 


\subsection{Curva de Bézier por Trechos}

Uma das propriedades indesejadas da curva de Bézier é que cada ponto de controle modifica toda a curva, e uma forma de amenizar este problema é utilizar sequências de curvas de Bézier, onde as curvas de Bézier tem continuidade $C^{1}$-fraca, que relaxa a condição de continuidade, onde as derivadas possuem a mesma direção, mas não necessariamente o mesmo módulo. Assim, cada ponto de controle de uma curva influenciam apenas duas curvas, a curva que ele controle a uma curva adjacente. Um exemplo de curva de Bézier cúbica por trechos é mostrado na Fig. 2.5, onde existe uma composição de duas curvas de Bézier, a primeira curva de Bézier é definida pelos pontos de controle p0, p1, p2 e p3 e a segunda curva de Bézier é definida pelos pontos de controle $\mathbf{p 3}, \mathbf{p 4}, \mathbf{p 5}$ e p6. Note que o último ponto de controle da primeira curva é o primeiro ponto de controle da segunda curva, e para garantir a continuidade $C^{1}$-fraca na junção das duas curvas o ponto de controle p4 é definido por

$$
\mathrm{p} 4=\mathrm{p} 3-\beta \cdot(\mathrm{p} 2-\mathrm{p} 3) .
$$

Esta equação faz com que a direção da derivada no final da primeira curva, definidas pelos pontos de controle $p_{0}, p_{1}, p_{2}$ e $p_{3}$, é igual à direção da derivada no início da segunda curva, definidas pelos pontos de controle $p_{3}, p_{4}, p_{5}$ e $p_{6}$, e o fator $\beta$ é um fator de proporcionalidade do módulo destas derivadas. A continuidade $C^{1}$-fraca relaxa a condição de continuidade no ponto $\mathbf{p} 3$, onde as derivadas possuem a mesma direção, mas o módulo não é necessariamente o mesmo. Desta forma é possível notar que a cada nova curva de Bézier criada, o segundo ponto de controle desta nova curva será sempre calculado pela eq. 2.6 e o primeiro ponto de controle desta nova curva é o último ponto de controle da curva anterior. Yamaguchi [1988, seção 5.1.2] faz o cálculo dos fatores de continuidade de segmentos de curvas de Bézier cúbicas com continuidade $C^{2}$, garantindo a igualdade da primeira e da segunda derivada na junção de duas curvas. 


\section{Recozimento simulado}

O recozimento simulado é uma meta-heurística probabilística muito utilizada para otimizar problemas combinatórios e problemas contínuos. Esta meta-heurística é baseada no algoritmo de Metropolis [METROPOLIS et al., 1953] que simula a recristalização atômica de um metal no processo de recozimento. Kirkpatrick et al. [1983] modificou o algoritmo de Metropolis ao adotar um programa de resfriamento para solucionar problemas de otimização combinatória. Corana et al. [1987] propuseram uma adaptação do recozimento simulado para aplicá-lo em problemas com variáveis contínuas.

No processo de recozimento ocorre a migração dos átomos resultando em uma configuração que sempre minimize a energia, que é um processo similar ao de resolver um problema de otimização, onde se minimiza uma função. No recozimento simulado, um candidato é gerado ao realizar uma modificação aleatória na solução atual e em seguida a função custo é avaliada. Caso ocorra uma melhora na solução, isto é, se o valor da nova função custo for menor que a atual, ela é aceita e o algoritmo continua avaliando a próxima iteração. Porém, se o valor da função custo aumentar, uma nova avaliação é realizada. Este candidato pode ainda ser aceito pela probabilidade, que é calculada para uma determinada temperatura $T$ pela expressão

$$
P(\Delta E)=e^{-\frac{\Delta E}{k_{b} T}}
$$

onde $k_{b}$ é a constante de Boltzman e $\Delta E$ é a variação da função custo. Se $P(\Delta E)>$ ramdom $(0,1)$, então o candidato é aceito.

Caso a solução não seja aceita, então o candidato é rejeitado e um novo candidato é gerado ao modificar aleatoriamente a solução atual. Para casos de combinações como os estudados por Kirkpatrick et al. [1983], a determinação de um novo candidato não é complexa. Um exemplo clássico de otimização combinatória é o problema do caixeiro viajante. Neste exemplo, o próximo candidato é gerado a partir de uma simples permutação das variáveis. No caso de problemas de otimização com variáveis contínuas várias estratégias podem ser adotadas. Segundo Bohachevsky et al. [1986], para se obter o próximo candidato $\mathbf{x}_{k+1}$, deve-se gerar um vetor $\mathbf{u}$ com direção aleatória e unitária $(\|\mathbf{u}\|=1)$, multiplicá-lo por passo de tamanho $\Delta r$ e somá-lo à solução atual $x_{k}$. Assim,

$$
\mathbf{x}_{k+1}=\mathbf{x}_{k}+\Delta r \cdot \mathbf{u}
$$

Diferente do método proposto por Bohachevsky et al. [1986], em que o deslocamento é unitário e constante, Corana et al. [1987] propuseram um método anisotrópico, em que 
procuraram manter o número de candidatos aceitos constante enquanto a dimensão do passo em cada direção é modificado. Desta forma o próximo candidato é gerado por

$$
\mathbf{x}_{k+1}=\mathbf{x}_{k}+v \cdot \Delta r_{i} \cdot \mathbf{e}_{\mathbf{i}}
$$

onde $\Delta r_{i}$ é o valor da passo na direção $\mathbf{e}_{\mathbf{i}}$, e $v$ é um valor aleatório dentro do intervalo $[-1,1]$.

\subsection{Vizinhança Adaptativa e Fator de Cristalização}

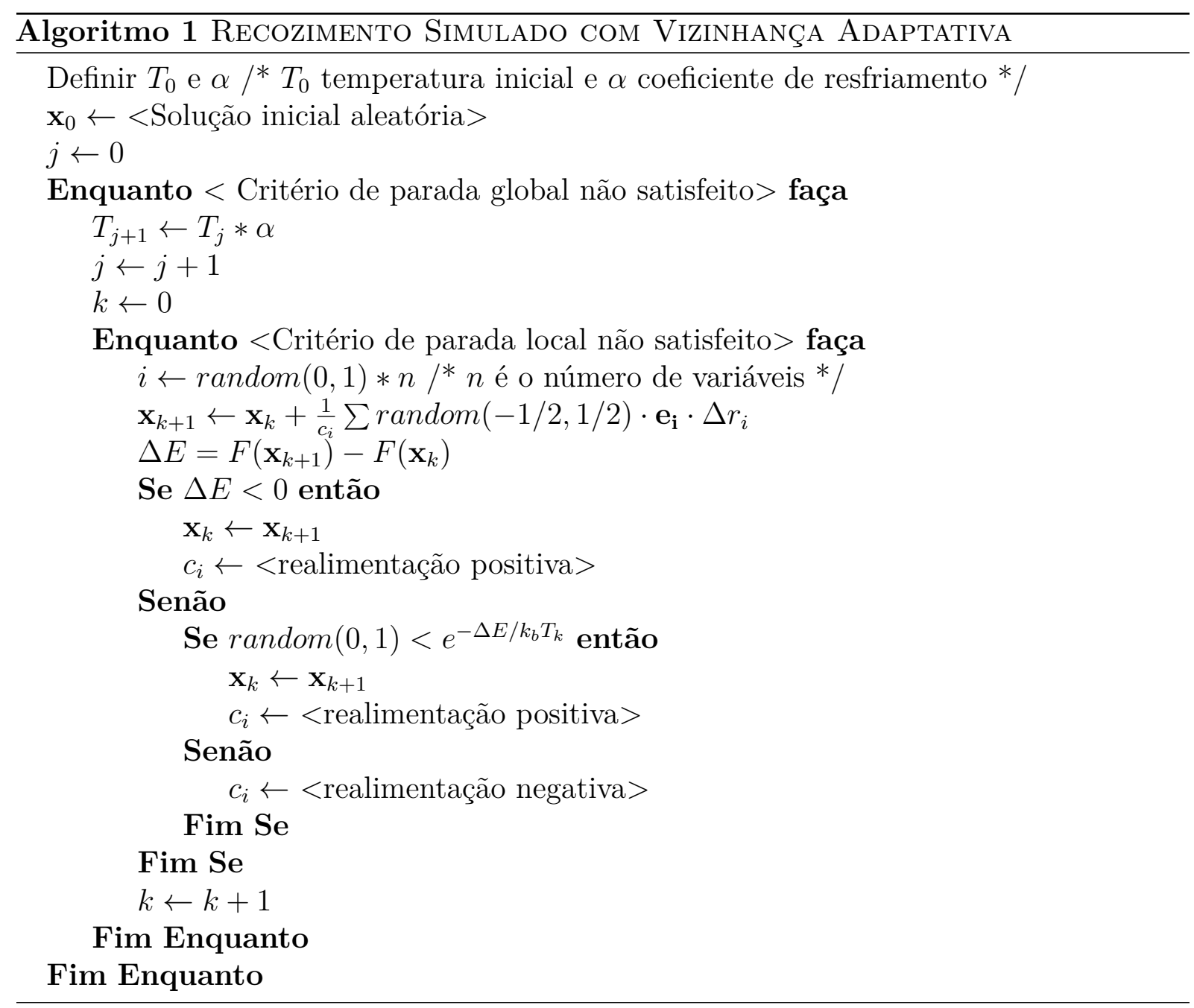

De acordo com Martins et al. [2012], a estratégia utilizada por Corana et al. [1987] pode não ser a melhor estratégia para se avaliar o comportamento da função objetivo em diferentes direções, por isto, Martins et al. [2012] propuseram um algoritmo de recozimento simulado com vizinhança adaptativa (Algoritmo 1). É conhecido que soluções rejeitadas não contribuem para o avanço do algoritmo do recozimento simulado, a distribuição de 
probabilidade é ajustada conforme o número de soluções aceitas. A cada iteração somente um parâmetro é modificado e o novo candidato é gerado por

$$
\mathbf{x}_{k+1}=\mathbf{x}_{k}+\frac{1}{c_{i}} \sum_{1}^{c_{i}} \operatorname{random}(-1 / 2,1 / 2) \cdot \mathbf{e}_{\mathbf{i}} \cdot \Delta r_{i},
$$

onde $c_{i}$ é o fator de cristalização para a variável contínua $i$ que é modificada nesta iteração. A modificação aplicada é uma distribuição de Bates com centro em zero e amplitude de 1/2. A distribuição de Bates [JOHNSON et al., 1995, seção 26.9] é a distribuição probabilística da média de variáveis aleatórias uniformemente distribuídas de forma que são estatisticamente independentes em um intervalo unitário. Assim o desvio padrão desta distribuição é

$$
\sigma=\frac{1}{2 \sqrt{3 c_{i}}}
$$

Durante o processo de otimização, cada variável contínua possui um fator de cristalização correspondente que é ajustado favorecendo a aceitação de novos candidatos. Ao rejeitar um candidato, o desvio padrão da densidade de probabilidade da variável diminui, resultando em uma menor amplitude para a densidade de probabilidade da próxima modificação. Se o candidato é aceito, o desvio padrão aumenta, resultando em uma amplitude maior para a densidade de probabilidade da próxima modificação. Quando um candidato é aceito, ocorre a realimentação positiva e o fator de cristalização $c_{i}$ correspondente à variável $i$ diminui em uma unidade, aumentando o desvio padrão que é calculado pela eq. 3.5, resultando em um aumento da amplitude de busca. Caso contrário, quando ocorre a rejeição de um candidato (realimentação negativa), o fator de cristalização $c_{i}$ aumenta de uma unidade, o desvio padrão diminui resultando em uma menor amplitude de busca. O procedimento de aceitar e rejeitar candidatos pode ser observado na Fig. 3.6. O comportamento do fator de cristalização esperado com a variação da temperatura para a maioria das variáveis contínuas pode ser observado na Fig. 3.7, onde com o decaimento da temperatura o fator de cristalização tende a aumentar passando de uma fase exploratória, onde o fator de cristalização é menor, a amplitude de busca é grande e a temperatura é elevada, para uma fase de resfriamento, onde o fator de cristalização é maior, a amplitude de busca é pequena e a temperatura é baixa.

O recozimento simulado com vizinhança adaptativa considera que o problema a ser minimizado possui $n$ variáveis contínuas, um programa de resfriamento que inicia com uma temperatura inicial $T_{0}$ e utiliza um fator de resfriamento $\alpha$. Este algoritmo utiliza parâmetros de paradas local e global. O critério da parada local controla quantas iterações são realizadas para uma determinada temperatura $T$ e quando ele é satisfeito ocorre uma diminuição da temperatura. O critério da parada global é a verificação de quando ocorre o término do algoritmo. Geralmente é utilizado um número mínimo de soluções aceitas para uma temperatura e quando esse valor for menor que esse mínimo, o algoritmo termina. 


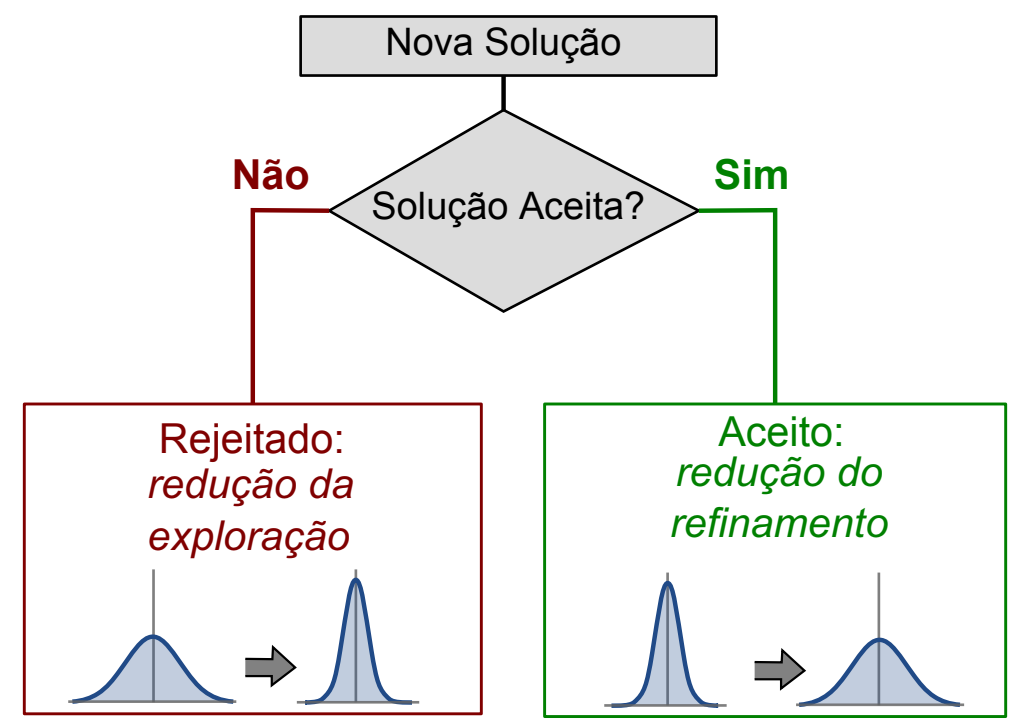

Figura 3.6 - Realimentação do fator de cristalização.

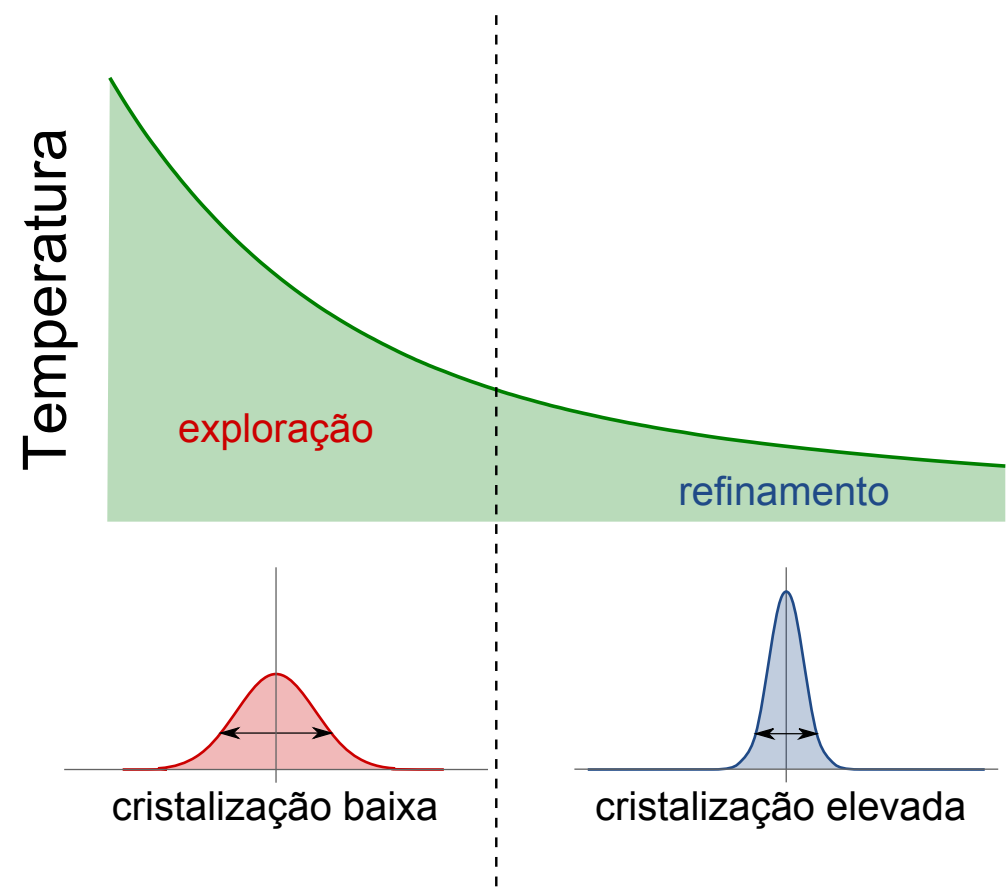

Figura 3.7 - Comportamento do fator de cristalização com a variação da temperatura. 
Ou seja, quando poucos candidatos são aceitos, significa que a amostra está congelada e o algoritmo deve ser terminado.

\subsection{Programa de Resfriamento}

O programa de resfriamento é a função que define como ocorre o decaimento da temperatura durante o algoritmo. A escolha do programa de resfriamento influencia diretamente a qualidade do resultado final, pois como mostra a Fig. 3.7, quando a temperatura é alta a amplitude de busca é grande, correspondendo à fase exploratória do algoritmo, e com a diminuição da temperatura a amplitude de busca diminui, correspondendo à fase de refinamento do algoritmo. Se o algoritmo diminui a temperatura de uma forma muito brusca ele passará pouco tempo na fase de exploração.

Uma função de resfriamento utilizada é o resfriamento geométrico dado pela função $T_{k+1}=T_{k} * \alpha$, com valores de $\alpha$ pertencente ao intervalo ]0, 1[. Se o valor de $\alpha$ for mais próximo de 1 , melhor o resultado final, porém o tempo de processamento do algoritmo é elevado. Com a diminuição do valor de $\alpha$ o algoritmo se torna mais rápido, mas com resultados piores. Isto ocorre, pois quanto menor o valor de $\alpha$ mais rápido ocorre o resfriamento, e a fase de exploração é feita com temperaturas elevadas. Se o algoritmo reduz o tempo da fase exploratória, a qualidade do resultado final é prejudicada. Definir este coeficiente não é uma tarefa fácil, pois é possível que em algumas temperaturas a distribuição da amostra tenha baixo desvio padrão, indicando que a amostra já está congelada para aquela temperatura e consequentemente a próxima temperatura será mais baixa do que o decaimento geométrico e o mesmo efeito pode ocorrer de modo inverso, o desvio padrão é muito elevado e a amostra necessita resfriar de modo mais lento que o decaimento geométrico. Assim, será adotado o resfriamento adaptativo, onde o valor de $\alpha$ que possui relação com o calor específico, que por sua vez possui relação com o desvio padrão $(\sigma(T))$ de todos os custos obtidos em uma determinada temperatura $T$. O valor de $\alpha$ é calculado pela seguinte expressão

$$
\alpha=e^{-\frac{\gamma \cdot T}{\sigma(T)}}
$$

onde $\gamma$ é um coeficiente ajustável e $\sigma(T)$ o desvio padrão da distribuição das funções custo para uma determinada temperatura $T$.

O recozimento simulado a cada temperatura $T$ gera uma série de custos $C_{i}$ e o cálculo do desvio padrão destes custos é feito pela probabilidade de distribuição das funções custo que é dado por

$$
\operatorname{Prob}_{i}(T)=\frac{e^{\frac{-C_{i}(T)}{k_{B} T}}}{\sum_{j} e^{\frac{-C_{j}(T)}{k_{B} T}}}
$$


O custo médio para uma determinada temperatura é calculado como

$$
\langle C(T)\rangle=\sum C_{i}(T) \operatorname{Prob}_{i}(T)
$$

O custo quadrático médio é definido como

$$
\left\langle C^{2}(T)\right\rangle=\sum C_{i}^{2}(T) \operatorname{Prob}_{i}(T) .
$$

Desta forma, a variância, que é o desvio padrão elevado ao quadrado, é expressa por

$$
\sigma^{2}(T)=\left\langle C^{2}(T)\right\rangle-\langle C(T)\rangle^{2} .
$$

Assim o calor específico é expresso por:

$$
S_{H}(T)=\frac{\sigma(T)^{2}}{T^{2} k_{B}^{2}} .
$$

Com o calor específico pode ser observado a mudança de fase, quando houver uma queda do calor específico ocorre uma mudança de fase. O recozimento simulado passa da fase de exploração para a fase de refinamento. 


\section{Aplicação do Recozimento Simulado no Problema de Ajuste de Curvas}

O recozimento simulado com vizinhança adaptativa será aplicado para resolver o problema de ajuste de curvas, onde será utilizada a curva de Bézier por trechos para aproximar uma sequência de pontos.

\subsection{Definição da Função de Custo}

A função de custo ou função objetivo a ser minimizada não será a eq. 2.4 que é a função objetivo utilizada em [HASEGAWA et al., 2013], [PANDUNATA; SHAMSUDDIN, 2010] e [ADI et al., 2010], pois ao utilizá-la o algoritmo pode se tornar instável, uma vez que não existe nenhum controle quanto ao comprimento da curva. Assim, o número de soluções é elevado, sendo necessário redefinir a função objetivo para que o recozimento simulado convirja para uma solução desejada. Para evitar este comportamento, a função objetivo foi modificada de forma que avalie tanto a distância entre $\mathbf{d}_{k}$ e a curva, assim como o comprimento da curva. Desta forma, a função objetivo utilizada será uma soma ponderada da somatória da distância de cada ponto da sequência de pontos até a curva aproximadora e o comprimento da curva que é expressa por

$$
f\left(\mathbf{p}_{\mathbf{0}}, \ldots, \mathbf{p}_{\mathbf{n}}\right)=W 1 \cdot \sum_{k=1}^{m-1}\left|\mathbf{d}_{k}-\mathbf{P}\left(u_{k}\right)\right|+W 2 \cdot L .
$$

onde $W 1$ e $W 2$ são pesos que controlam a influência de cada um dos dois fatores de forma que $W 1+W 2=1$, e L é o comprimento da curva aproximadora.

\subsection{Cálculo da Projeção}

O método para o cálculo da distância de um ponto até a curva aproximadora adotado é um aprimoramento do método em que a curva é discretizada e é feita a comparação entre o ponto $\mathbf{d}_{k}$ e a curva discretizada. Como este método depende diretamente do número de pontos em que a curva é discretizada, uma forma simples de melhorar esse cálculo é determinar a altura de um triângulo formado por um ponto da sequência de pontos e dois pontos da curva discretizada como mostra a Fig. 4.8, onde os pontos mostrados por quadrados são pontos da curva discretizada e o ponto mostrado por um círculo é um ponto da sequência de pontos. Primeiramente é feita a busca do ponto da curva discretizada que possui a menor distância até o ponto da sequência de pontos em avaliação, na Fig. 4.8 este ponto é denominado de $\mathbf{P}\left(u_{k}\right)$, em seguida é avaliado se $\left|\mathbf{P}\left(u_{k-1}\right)-\mathbf{d}_{k}\right|<\left|\mathbf{P}\left(u_{k+1}\right)-\mathbf{d}_{k}\right|$ ou 


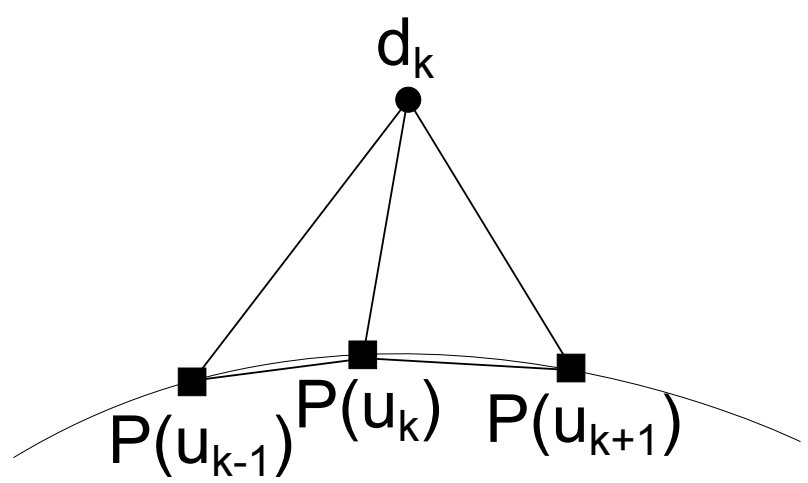

Figura 4.8 - Cálculo da altura de um triângulo.

$\left|\mathbf{P}\left(u_{k-1}\right)-\mathbf{d}_{k}\right|>\left|\mathbf{P}\left(u_{k+1}\right)-\mathbf{d}_{k}\right|$. Se o primeiro caso ocorrer, a área do triângulo definida pelos pontos $\mathbf{d}_{k}, \mathbf{P}\left(u_{k-1}\right)$ e $\mathbf{P}\left(u_{k}\right)$ é calculada e a altura deste triângulo é definida como sendo a distância entre o ponto $\mathbf{d}_{k}$ da sequência de pontos e a curva. Caso contrário a área do triângulo definida pelos pontos $\mathbf{d}_{k}, \mathbf{P}\left(u_{k}\right)$ e $\mathbf{P}\left(u_{k+1}\right)$ é calculada e a altura deste triângulo é a distância procurada.

A área do triângulo é calculada pelo teorema de Herão que é expressa por

$$
A=\sqrt{(s(s-a)(s-b)(s-c))},
$$

onde $a, b$ e $c$ são os comprimentos dos lados do triângulo e $s$ o semiperímetro calculado por $s=(a+b+c) / 2$. Este teorema é facilmente demonstrado pelo teorema dos cossenos da trigonometria.

Esta nova forma de calcular a distância melhora a qualidade do resultado, pois uma curva discretizada nada mais é que vários segmentos de reta e a altura de um triângulo é ortogonal à base do triângulo e a menor distância entre um ponto e uma reta é a projeção ortogonal do ponto sobre a reta.

\subsection{Cálculo do Comprimento}

Quanto ao cálculo do comprimento da curva, uma vez que no método adotado para calcular a distância entre a sequência pontos e a curva a curva foi discretizada, é feita a soma dos comprimentos de todos os segmentos que discretizam a curva. Porém, este não foi o valor a ser minimizado na função objetivo. Sabe-se que o menor comprimento de uma curva de Bézier é uma reta e esse não é o objetivo final do algoritmo. Desta forma foi adotado como comprimento a ser minimizado o módulo da diferença entre o comprimento da curva e o comprimento do polígono formado pelos pontos da sequência de pontos. Esta nova função minimiza o comprimento da curva que se aproxima ao máximo da sequência de pontos. 


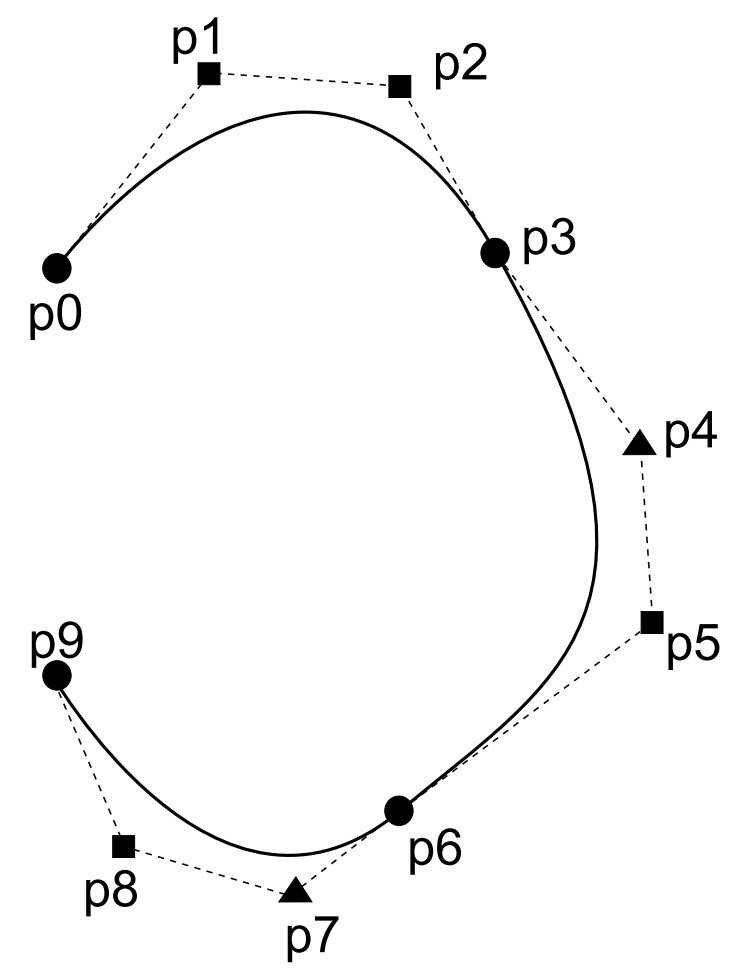

Figura 4.9 - Curva de Bézier por trechos.

\subsection{Representação Paramétrica da Curva de Bézier por Tre- chos}

Existem dois tipos de parâmetros a serem otimizados pelo recozimento simulado; parâmetros contínuos e discretos.

\subsubsection{Parâmetros Contínuos}

Os parâmetros contínuos a serem otimizados pelo recozimento simulado são as coordenadas dos pontos de controle e o fator de continuidade que determina pontos de controle de forma que as curvas possuam continuidade $C^{1}$-fraca.

Utilizando como exemplo a Fig. 4.9, que mostram três curvas de Bézier cúbica conectadas, os parâmetros contínuos a serem determinados pelo recozimento simulado são:

1. Coordenada $\mathrm{x}$ do ponto $\mathbf{p} \mathbf{1}(\mathrm{p} 1 \mathrm{x})$

2. Coordenada y do ponto p1 (p1y)

3. Coordenada $\mathrm{x}$ do ponto $\mathbf{p} 2(\mathrm{p} 2 \mathrm{x})$

4. Coordenada y do ponto p2 (p2y)

5. Fator de continuidade do ponto p4 $(\beta 4)$

6. Coordenada $\mathrm{x}$ do ponto p5 (p5x) 
7. Coordenada y do ponto p5 (p5y)

8. Fator de continuidade do ponto p7 $(\beta 7)$

9. Coordenada $\mathrm{x}$ do ponto $\mathrm{p} 8(\mathrm{p} 8 \mathrm{x})$

10. Coordenada y do ponto $\mathbf{p} 8(\mathrm{p} 8 \mathrm{y})$

Os pontos p0 e p9 são o primeiro e o último pontos da sequência de pontos e os pontos p3 e p6 são pontos da sequência. Os parâmetros correspondentes às coordenadas x e y dos pontos de controle $\mathbf{p} 1, \mathbf{p} \mathbf{2}, \mathbf{p} 5$ e $\mathbf{p} 8$ e os fatores de continuidades $(\beta)$ para a determinação dos pontos p4 e p7 são os parâmetros contínuos a serem otimizados pelo recozimento simulado.

\subsubsection{Parâmetros Discretos}

Como mostrado pela Fig. 4.9 os pontos p3 e p6, que são o início do segundo e do terceiro trecho de curva, correspondem a pontos da sequência e, esta sequência é um conjunto ordenado de pontos. Assim cada ponto possui um índice correspondente, p3 e p6 são associados a dois pontos da sequência de pontos de forma que o índice de p3 seja menor que o índice de p6. Estes índices são parâmetros discretos a serem otimizados pelo recozimento simulado.

Desta forma para cada curva de Bézier acrescentada serão necessários 3 parâmetros contínuos e 1 discreto para a controle desta nova curva cúbica. Os parâmetros contínuos são as coordenadas $x$ e $y$ do terceiro ponto de controle desta nova curva e um fator de continuidade da curva que determinará o segundo ponto de controle da curva por

$$
\mathbf{p}_{3 i+4}=\mathbf{p}_{3 i+3}-\left(\mathbf{p}_{3 i+2}-\mathbf{p}_{3 i+3}\right) * \beta_{3 i+4}, \quad i=0, \ldots, j-1 .
$$

onde $j$ é o número de curvas utilizadas.

O parâmetro discreto é o índice que corresponde a um ponto da sequência que será o primeiro ponto de controle da curva.

\subsection{Determinação do Próximo Candidato}

A geração de novos candidatos para parâmetros contínuos segue o Algoritmo 1 que utiliza o fator de cristalização que modifica a distribuição de probabilidade de cada parâmetro com a diminuição da temperatura. Porém para os parâmetros discretos a forma utilizada para a geração do próximo candidato não é a mesma que a proposta no Algoritmo 1, a utilização do fator de cristalização é possível apenas para parâmetros contínuos. Por isto, foram criadas regras simples toda vez que um parâmetro discreto é modificado. Inicialmente, é gerado um valor aleatório entre $[0,1]$, se o valor for menor que 0.5 diminui-se uma unidade 
o valor deste parâmetro, caso contrário acrescenta-se uma unidade. Porém, foram impostos alguns limites para esta variação, que são:

- a mudança não pode ser maior que quatro unidades em relação à posição original, tanto em incremento e decremento. Isto foi adotado para evitar que surjam parâmetros que modifiquem demasiadamente as posições iniciais e finais de cada trecho de curva de Bézier. Este limite é mostrado na Fig. 4.10, onde o quadrado em azul é a posição inicial de junção de duas curvas e esta posição pode ser modificada por qualquer um dos quadrados em verde.

- cada parâmetro precisa ter uma distância mínima em relação ao parâmetro anterior e posterior, pois desta forma evitará a criação de curvas muito curtas que aproximem poucos pontos da sequência de pontos. Assim foi adotada que a distância mínima é de 4 unidades. Este limite é mostrado na Fig. 4.11, onde o quadrado em azul é a posição inicial de junção de duas curvas e os quadrados em verde mostram as posições possíveis dessa junção, note que de acordo com o primeiro limite, o limite de deslocamento poderia ser maior, mas como o início e o fim das curvas são próximos este deslocamento é menor.

\subsection{Otimização da Busca do Ponto mais Próximo}

Outro benefício da localidade da curva de Bézier por trechos será utilizado no início do algoritmo que obtém a distância de um ponto da sequência de pontos até a curva. Como é necessário no início obter o ponto da curva de Bézier discretizada que é mais próxima a cada ponto da sequência de pontos, pode-se realizar uma busca restrita, uma vez que cada trecho da curva de Bézier aproxima somente uma parte da sequência de pontos. Desta forma, esta busca é realizada conforme mostra a representação da Fig. 4.12. Os pontos $\mathbf{d}_{\mathbf{5}}$ e $\mathbf{d}_{\mathbf{m}-\mathbf{5}}$ são os locais onde ocorrem as divisões das curvas, cada curva possui $v$ pontos e existem $j$ curvas. Assim a busca dos pontos $\mathbf{d}_{\mathbf{1}}, \mathbf{d}_{\mathbf{2}}, \mathbf{d}_{\mathbf{3}}$ e $\mathbf{d}_{\mathbf{4}}$ serão realizadas somente na primeira curva $\left(\mathbf{P} \mathbf{1}_{\mathbf{1}}, \ldots, \mathbf{P} \mathbf{1}_{\mathbf{v}-\mathbf{1}}\right)$, e os pontos $\mathbf{d}_{\mathbf{m}-\mathbf{4}}, \mathbf{d}_{\mathbf{m}-\mathbf{3}}, \mathbf{d}_{\mathbf{m}-\mathbf{2}}$ e $\mathbf{d}_{\mathbf{m}-\mathbf{1}}$ a busca é realizada na última curva $\left(\mathbf{P j}_{\mathbf{1}}, \ldots, \mathbf{P j}_{\mathbf{v}-\mathbf{1}}\right)$. Cada ponto da sequência de pontos $\mathbf{d}_{k}$ possui uma curva de Bézier correspondente para realizar a busca. Assim o tempo de processamento é menor, pois a busca é realizada em um número menor de pontos, e o mais importante, a localidade do cálculo da distância. Esta localidade beneficia principalmente exemplos onde a curva aproximadora é auto-intersectante conforme mostra a Fig. 4.13. Ambos os exemplos possuem comprimentos próximos e a distância entre a sequência de pontos e curva também são próximos, mas na Fig. 4.13(a) a curva é auto-intersectante como desejado, mas na Fig. 4.13(b) o mesmo não ocorre. Ao ser feito uma busca global para determinar o ponto mais próximo para cada $\mathbf{d}_{k}$, os pontos da sequência de pontos 


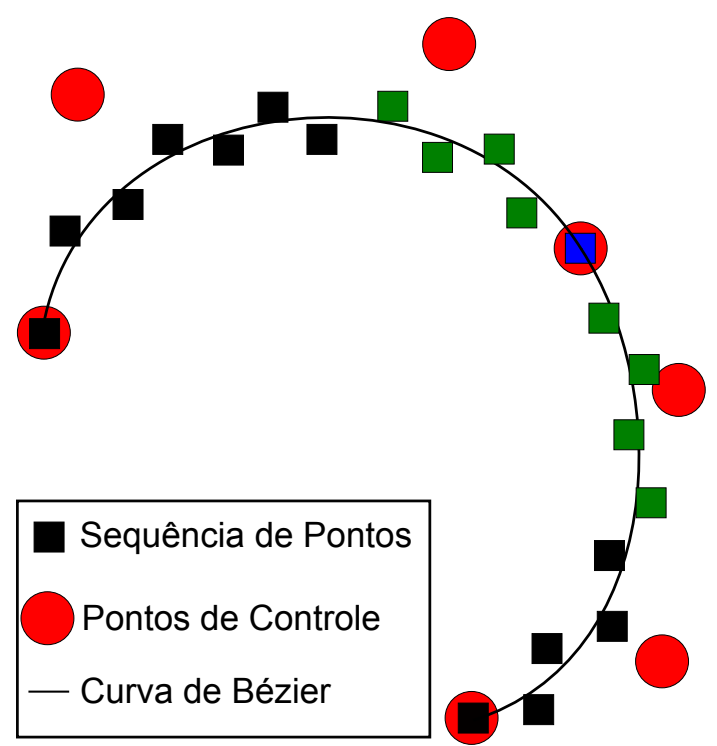

Figura 4.10 - Primeiro limite de deslocamento da junção de curvas.

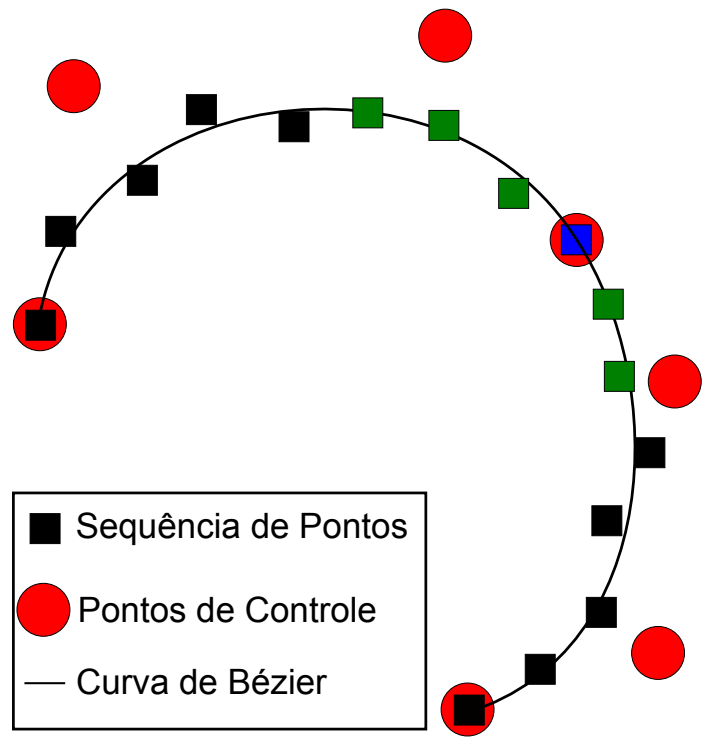

Figura 4.11 - Segundo limite de deslocamento da junção de curvas.

que deveriam se aproximar da curva em vermelho, se aproximam da curva em preto, e os pontos que deveriam se aproximar da curva em preto se aproximam da curva em vermelho. 


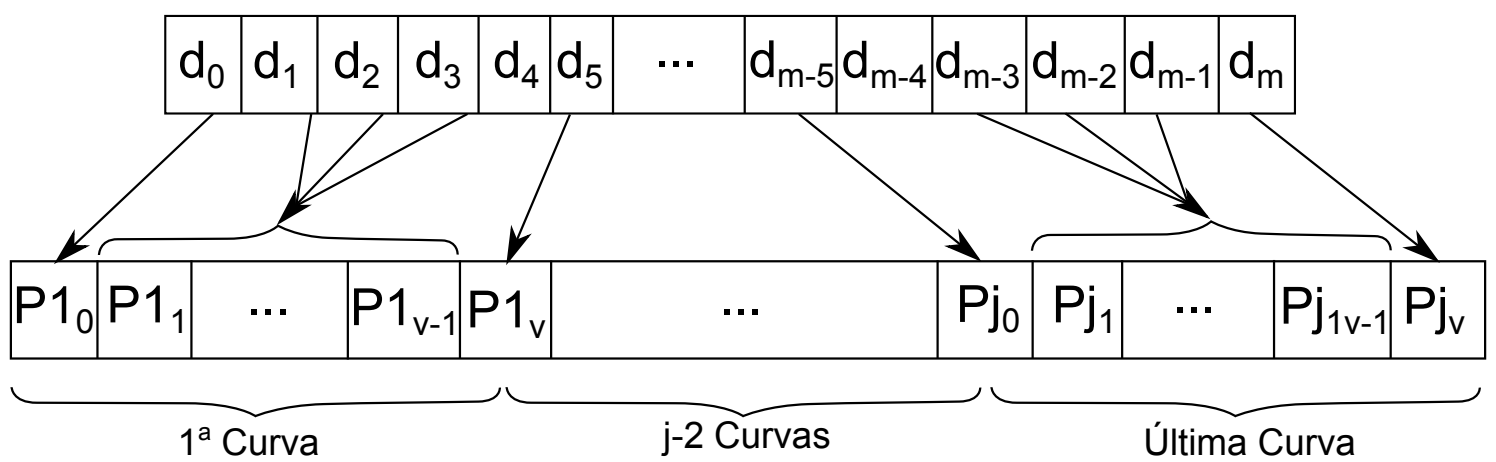

Figura 4.12 - Busca da menor distância entre cada ponto da sequência de pontos e curva gerada.

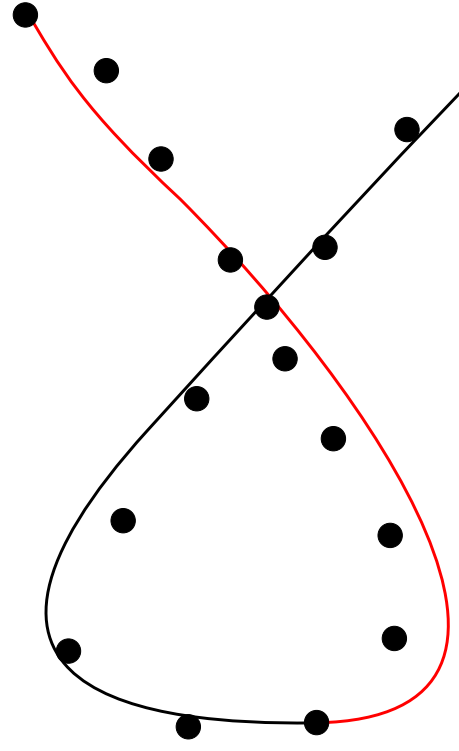

(a)

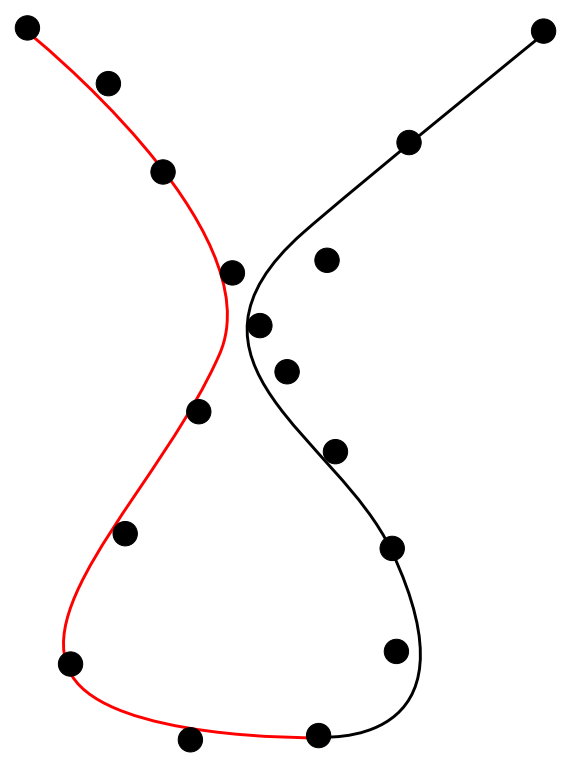

(b)

Figura 4.13 - Exemplo de uma curva com dois trechos. (a) Ocorre auto-intersecção; (b) Não ocorre auto-intersecção. 


\section{Recozimento Simulado Multi-objetivo}

Os algoritmos de otimização multi-objetivo são diferentes dos algoritmos com um único objetivo. Na otimização com um único objetivo existe uma solução ótima global, enquanto na otimização multi-objetivo não existe um ótimo global, exite um conjunto de soluções igualmente importantes, denominado de curva de Pareto ou frente de Pareto, em que cada solução é um ótimo global.

Smith et al. [2004] e Bandyopadhyay et al. [2008] desenvolveram um recozimento simulado multi-objetivo. As principais diferenças entre estes dois algoritmos são na determinação se uma solução é aceita ou não, e o número de soluções que compõem a frente de Pareto. Enquanto Smith et al. [2004] definiram uma única forma de aceitar soluções, Bandyopadhyay et al. [2008] utilizam várias formas para aceitar soluções. Quanto ao tamanho da frente de Pareto, Smith et al. [2004] não impõem um limite, já Bandyopadhyay et al. [2008] utilizam um limite ao utilizar técnicas de clustering. Neste trabalho será utilizado o algoritmo de Bandyopadhyay et al. [2008], denominado por AMOSA (Archive Multiobjetive Simulated Annealing). Porém será utilizado uma forma simplificada, onde não será imposto um limite no tamanho da frente de Pareto, como é exibido no Algoritmo 2 .

Inicialmente é criado um arquivo que são as soluções que formarão a frente de Pareto ao final do algoritmo. Em seguida é escolhida uma solução aleatória do arquivo como ponto inicial do algoritmo. O algoritmo é composto por dois laços, o laço externo possui como critério de parada uma temperatura mínima, enquanto a temperatura for maior que um limite o algoritmo continua. O laço interno possui como critério de parada um número máximo de iterações por temperatura. O algoritmo utiliza um conceito de dominância entre candidatos e dependendo da dominância entre eles pode-se ter três casos para aceitar um candidato. Então, a cada iteração um parâmetro é alterado e em seguida é avaliada a dominância entre os candidatos, e dependendo da dominância, uma ação é realizada. A solução corrente (sol-cor) domina a nova solução (sol-nova), a nova solução domina a solução corrente e o último caso não existe dominância entre a solução corrente e a nova solução.

\subsection{Inicialização do Arquivo}

No início do algoritmo é criado um conjunto com $S L$ soluções aleatórias e cada solução é composta por $n$ parâmetros, então o arquivo é criado com $S L \times n$ parâmetros. O arquivo é modificado no algoritmo onde novas soluções são aceitas ao dominarem as soluções anteriores, e caso ocorra a não dominância entre soluções a nova solução é adicionada ao arquivo. 


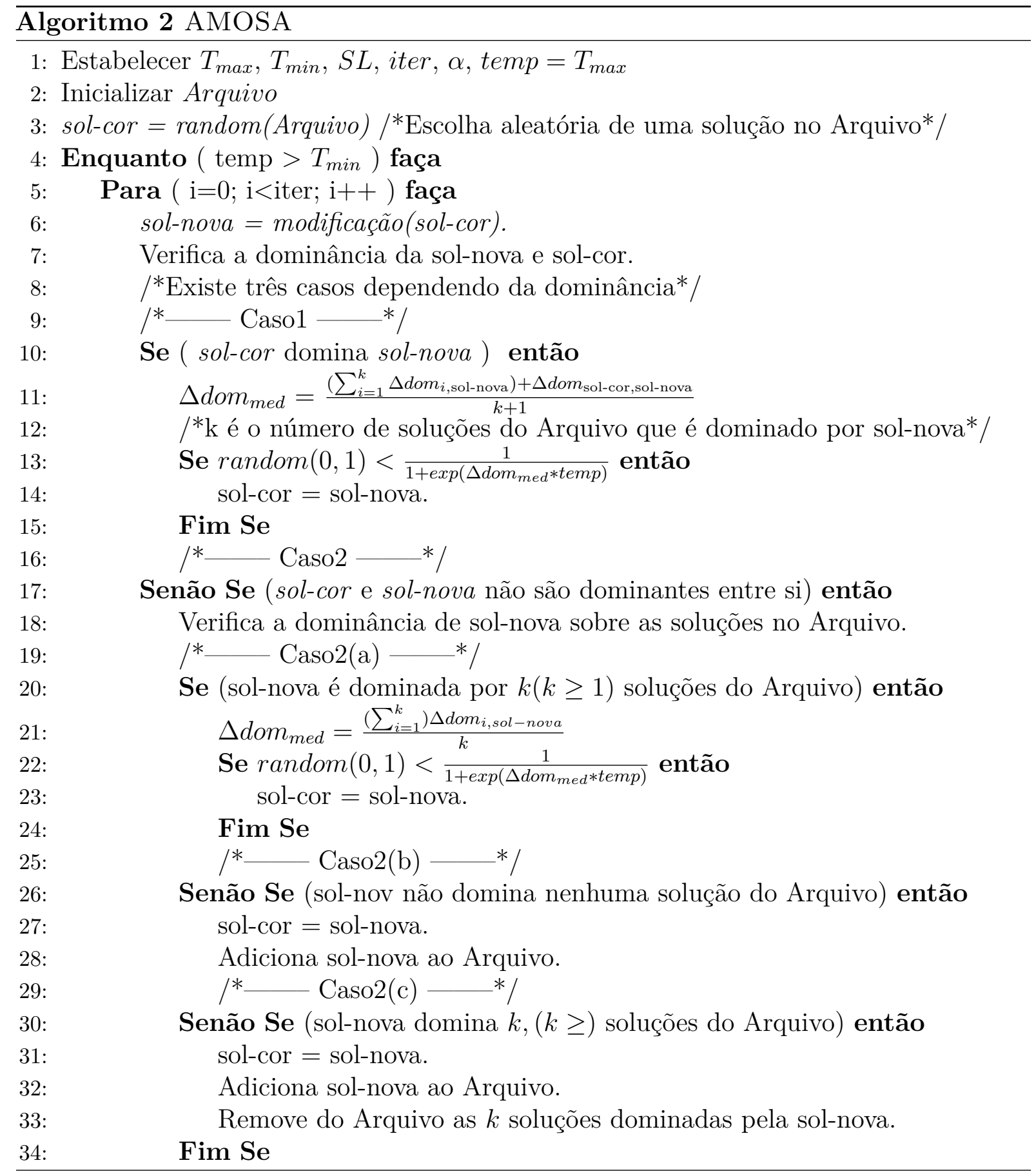




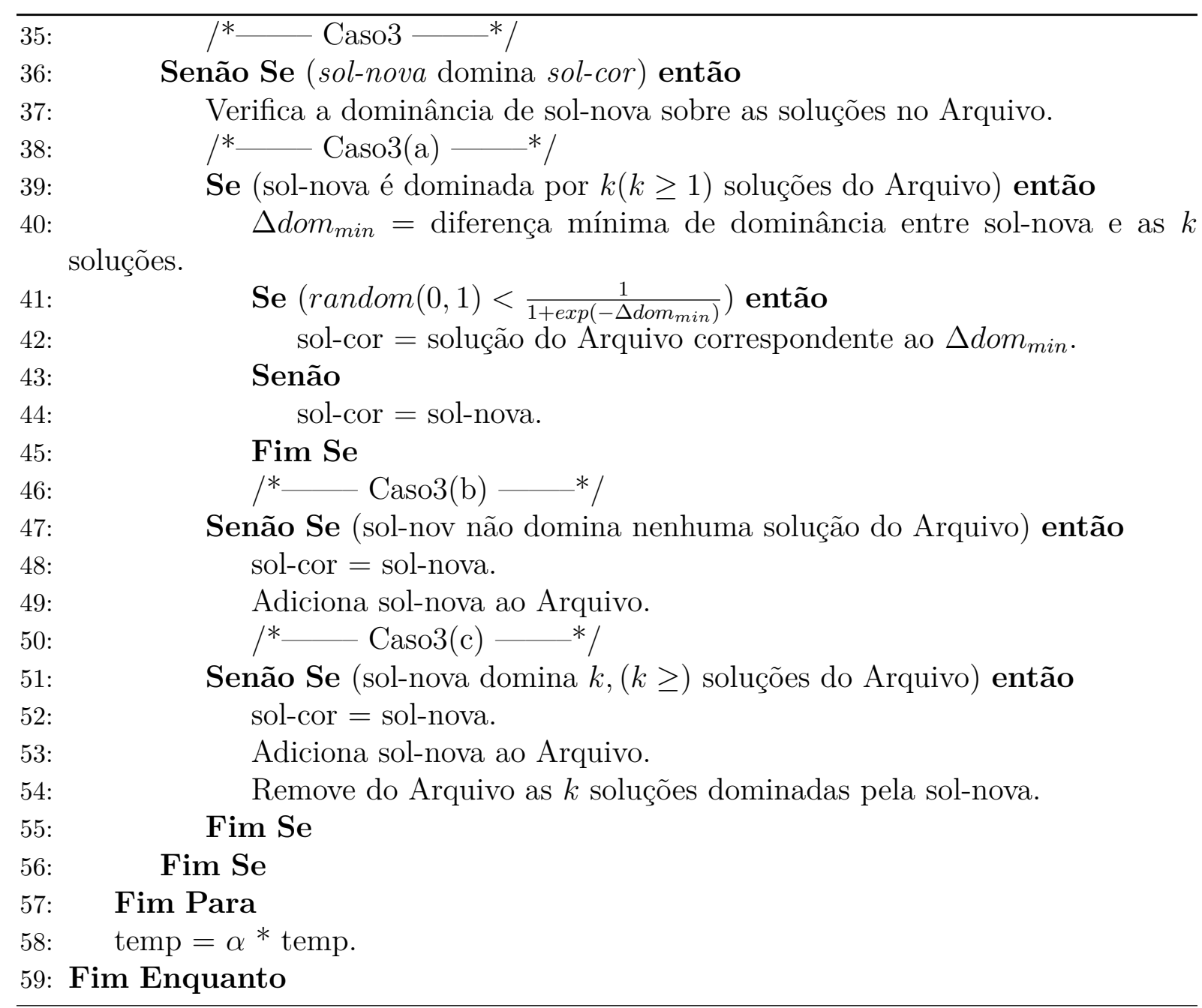

\subsection{Quantidade de Dominância}

O algoritmo AMOSA utiliza o conceito de quantidade de dominância para o cálculo da probabilidade de aceitar uma nova solução. Dadas duas soluções $a$ e $b$, a quantidade de dominância é definida como

$$
\Delta d o m_{a, b}=\prod_{i=1}^{M}\left(\frac{\left|f_{i}(a)-f_{i}(b)\right|}{R_{i}}\right),
$$

onde, $\mathrm{M}$ é número de funções objetivo, $\operatorname{com} f_{i}(a) \neq f_{i}(b)$ e $R_{i}$ é o alcance da i-ésima função objetivo.

\subsection{Casos de Dominância}

A dominância entre duas soluções $a$ e $b$ é avaliada da seguinte forma:

- $a$ domina $b$ - todas as funções objetivo de $a$ são menores que as funções objetivo de $b$.

- $b$ domina $a$ - todas as funções objetivo de $b$ são menores que as funções objetivo de $a$. 
- não existe dominância entre $a$ e $b$ - existem funções objetivo de $a$ que são menores que as funções objetivo de $b$, mas existem funções objetivo de $b$ que são menores que as funções objetivo de $a$.

Assim, como mencionado anteriormente existem três diferentes casos a serem seguidos.

\subsubsection{Caso 1 - a solução corrente domina a nova solução}

Este caso é representado nas Figs. 5.14(a) e 5.14(b), na primeira, a solução nova não domina nenhuma solução do arquivo e, na segunda, a solução nova é dominada por pelo menos uma solução do arquivo (no caso, apenas uma solução do arquivo domina a nova solução). Neste caso a nova solução é adotada como solução corrente (cur-sol = sol-nova) com a seguinte probabilidade

$$
\operatorname{prob}=\frac{1}{1+\exp \left(\Delta d_{\text {domed }} * T\right)}
$$

onde

$$
\Delta d o m_{\text {med }}=\frac{\left(\sum_{i=1}^{k} \Delta d o m_{i, \text { sol-nova }}\right)+\Delta d o m_{\text {sol-cor }, \text { sol-nova }}}{k+1} .
$$

\subsubsection{Caso 2 - não existe dominância entre a solução corrente e a nova solução}

Neste caso podem ocorrer três diferentes situações:

a) A nova solução é dominada por $k$ soluções do arquivo, como mostra a Fig. 5.15(a). Neste caso a nova solução é adotada como solução corrente (cur-sol = sol-nova) com a seguinte probabilidade

$$
\operatorname{prob}=\frac{1}{1+\exp \left(\Delta \text { dom }_{\text {med }} * T\right)}
$$

onde

$$
\Delta d o m_{m e d}=\frac{\left(\sum_{i=1}^{k} \Delta d o m_{i, s o l-n o v a}\right)}{k} .
$$

b) Não existe dominância entre a nova solução e as soluções do arquivo, como mostra a Fig. 5.15(b). Neste caso a nova solução é adotada como solução corrente e é adicionada ao arquivo.

c) A nova solução domina $k$ soluções do arquivo, como mostra a Fig. 5.15(c). Neste caso a nova solução é adotada como solução corrente e é adicionada ao arquivo, e todas as $k$ soluções que foram dominadas pela nova solução são excluídas do arquivo. 


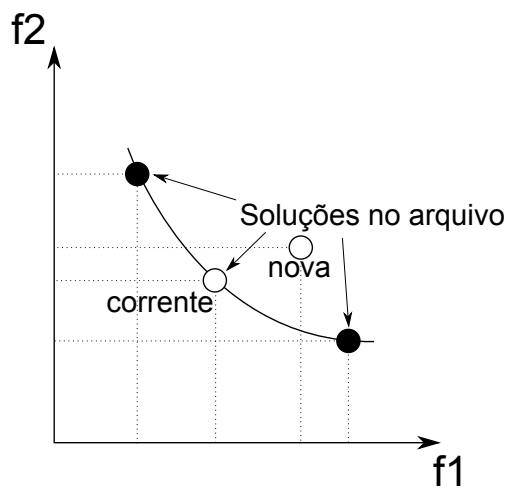

(a)

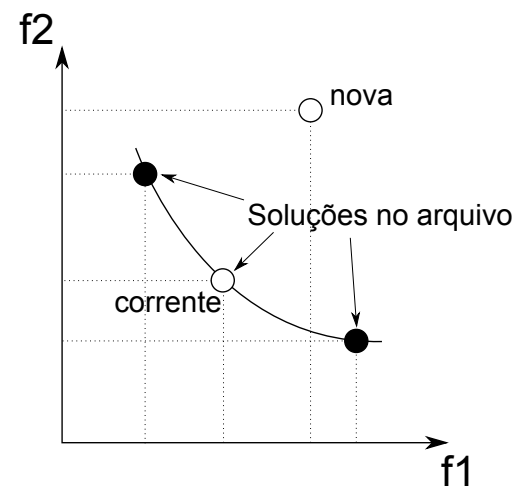

(b)

Figura 5.14 - A solução nova é dominada pela solução corrente. (a) A solução nova e as soluções do arquivo são não dominantes; (b) Algumas soluções do arquivo dominam a solução nova.

\subsubsection{Caso 3 - a nova solução domina a solução corrente}

Neste caso podem ocorrer três diferentes situações:

a) A nova solução é dominada por $k$ soluções do arquivo, como mostra a Fig. 5.16(a). Este caso pode somente acontecer se a solução corrente não pertencer ao arquivo. Nesta situação é calculada a mínima quantidade de dominância entre a solução nova e as $k$ soluções do arquivo. Esta quantidade de dominância é denominada de $\Delta d d_{\text {min }}$ e a solução correspondente à mínima quantidade de dominância é adotada como solução corrente com a seguinte probabilidade

$$
\operatorname{prob}=\frac{1}{1+\exp \left(-\Delta d o m_{\min }\right)} .
$$

Se a nova solução é que possui a mínima quantidade de dominância, então ela é adotada como solução corrente.

b) Não existe dominância entre a nova solução e as soluções do arquivo, como mostra a Fig. 5.16(b). Neste caso, a nova solução é adotada como solução corrente e é adicionada ao arquivo. Caso a solução corrente faça parte do arquivo ela é removida do arquivo.

c) A nova solução domina $k$ soluções do arquivo, como mostra a Fig. 5.16(c). Neste caso a nova solução é adotada como solução corrente e é adicionada ao arquivo, mas todas as $k$ soluções que foram dominadas são excluídas do arquivo. 


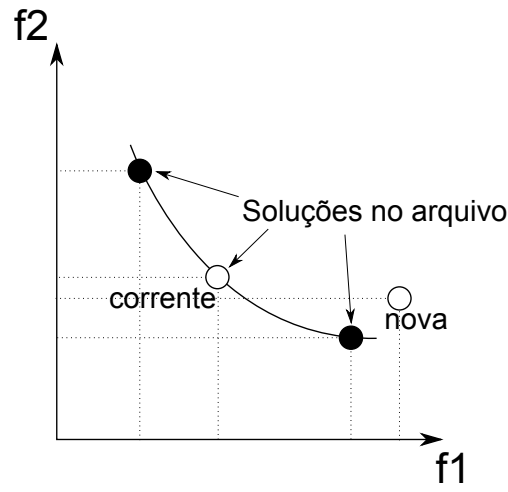

(a)

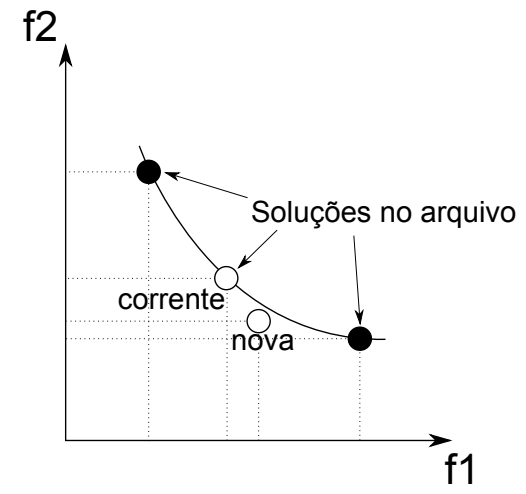

(b)

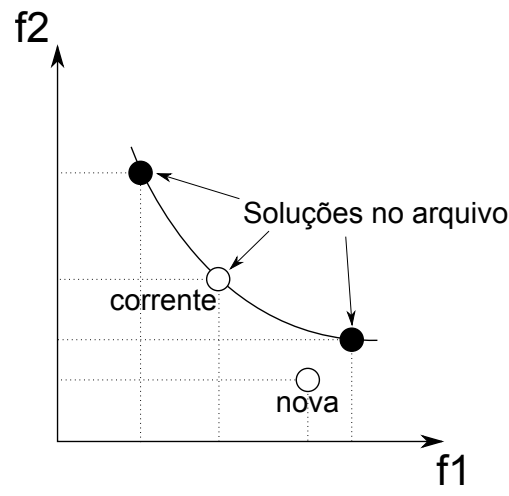

(c)

Figura 5.15 - A nova solução e a solução corrente são não dominantes. (a) Algumas soluções do arquivo dominam a nova solução; (b) A nova solução e as soluções do arquivo são não dominantes; (c) A nova solução domina $k(k \geq 1)$ soluções do arquivo.

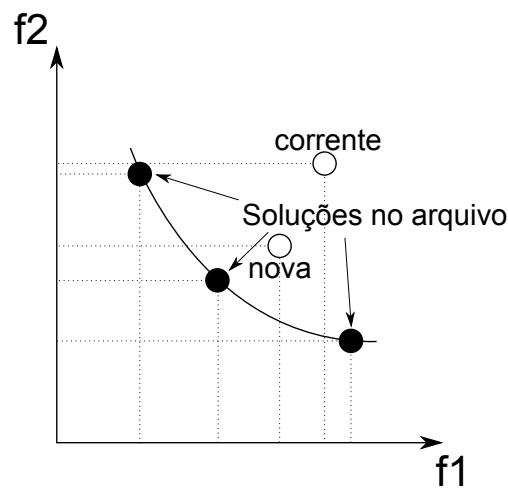

(a)

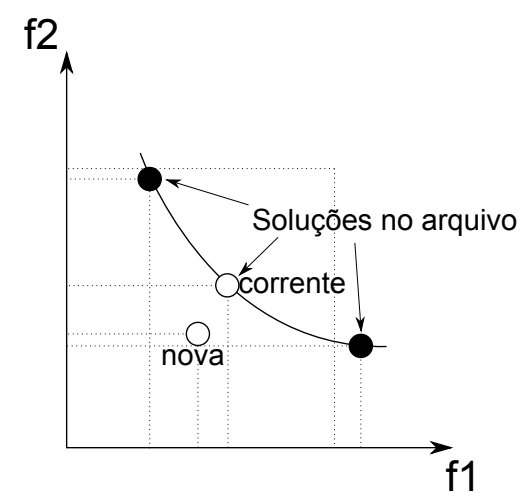

(b)

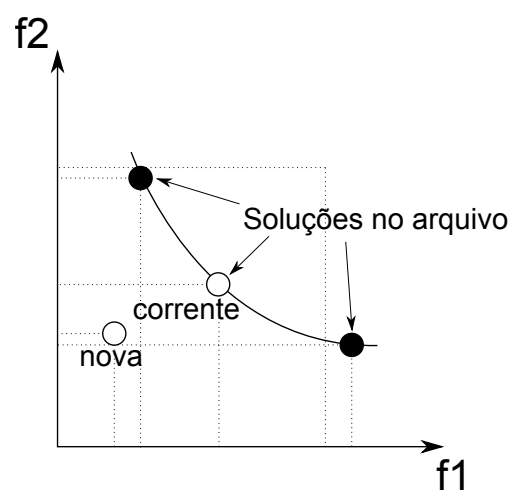

(c)

Figura 5.16 - A nova solução domina a solução corrente. (a) Algumas soluções do arquivo dominam a nova solução; (b) A nova solução e as soluções do arquivo são não dominantes, com exceção da solução corrente; (c) A nova solução domina algumas soluções do arquivo, excluindo a solução corrente. 


\section{Aplicação da AMOSA no Problema de Ajuste de Curvas}

O AMOSA será aplicado para resolver o problema de ajuste de curvas, onde será utilizada a curva de Bézier por trechos para aproximar uma curva a uma sequência de pontos.

\subsection{Funções objetivo}

As funções objetivo adotadas para resolver este problema serão cada uma das componentes da eq. 4.1. Assim:

$$
\begin{aligned}
f 1\left(\mathbf{p}_{\mathbf{0}}, \ldots, \mathbf{p}_{\mathbf{n}}\right) & =\sum_{k=1}^{m-1}\left|\mathbf{d}_{k}-\mathbf{P}\left(\mathbf{u}_{\mathbf{k}}\right)\right|, \\
f 2\left(\mathbf{p}_{\mathbf{0}}, \ldots, \mathbf{p}_{\mathbf{n}}\right) & =L .
\end{aligned}
$$

Desta forma, o cálculo da função $f 1$ é feita da mesma forma que é feito no recozimento simulado com um objetivo, com está explicado na seção 4.2, porém a função f2 não é a mesma utilizada no recozimento simulado com um objetivo (seção 4.3). Será minimizado o comprimento absoluto da curva aproximadora.

A parametrização da curva é a mesma que foi utilizada para o recozimento simulado com um objetivo, como foi descrito na seção 4.4

\subsection{Determinação do Próximo Candidato}

Para os parâmetros discretos pode-se utilizar as mesmas regras descritas na seção 4.5, porém para os parâmetros contínuos, não é possível utilizar a mesma regra, pois o AMOSA não utiliza o fator de cristalização para modificar a distribuição de probabilidade da busca. Desta forma é adotado o método utilizado por Corana et al. [1987], descrito na eq. 3.3 


\section{Resultados}

São utilizadas três sequências de pontos para testar os algoritmos. Os exemplos foram obtidos ao criar uma curva no formato desejado e discretizando-os com 50 pontos, e foram adicionados a um ruído de $3 \%$ na coordenada $x$ e na coordenada $y$. Os formatos escolhidos para teste foram uma parábola, uma curva com inflexão e uma curva com auto-intersecção. Primeiramente, cada exemplo é testado com o algoritmo geométrico de interpolação (descrito no Apêndice B), em seguida é utilizado o recozimento simulado com um objetivo e por último é utilizado o recozimento simulado multi-objetivo.

Na otimização com um objetivo, cada exemplo é testado com diferentes números de curvas de Bézier, onde cada uma é discretizada com 100 pontos, e também são variados os valores dos pesos $W 1$ e $W 2$ para cada exemplo. Para cada exemplo, é comparado o valor do custo, assim como os valores do comprimento da curva e da distância entre a sequência de pontos e a curva. Também é avaliado o comportamento dos fatores de cristalização, calor específico, coeficiente de resfriamento $\alpha$, energia máxima, energia mínima e energia média com a variação da temperatura. Os critérios de parada local utilizados são que o número de candidatos é no máximo 1000 ou que o número de candidatos aceitos é no máximo 500 para cada temperatura. Para o critério de parada global é utilizado um número mínimo de candidatos aceitos, se o número de candidatos aceitos for menor que $1 \%$ do total de candidatos para uma temperatura o processo é terminado, ou seja, para uma dada temperatura caso ocorram menos que 10 candidatos aceitos para 1000 iterações o algoritmo é finalizado.

Na otimização multi-objetivo, novamente cada exemplo é testado com diferentes números de curvas de Bézier, onde cada uma é discretizada com 100 pontos. O número de curvas por exemplo são os mesmos utilizados na otimização com um objetivo.

\subsection{Parábola}

\subsubsection{Interpolação}

São realizados dois testes utilizando o algoritmo geométrico de interpolação de curvas. Na Fig. 7.17(a), todos os pontos da sequência de pontos são interpolados, e pode ser observado que a curva interpoladora gerada possui uma grande e indesejada tortuosidade. Na Fig. 7.17(b) a curva interpoladora é definida utilizando somente alguns pontos da sequência de pontos. São consideradas para a interpolação o primeiro e o último ponto da sequência de pontos e 1 ponto a cada 4 pontos da sequência de pontos, totalizando 13 pontos. Desta forma é possível observar que a curva interpoladora possui uma menor tortuosidade, e que na parte superior da curva existem pontos da sequência de pontos que 


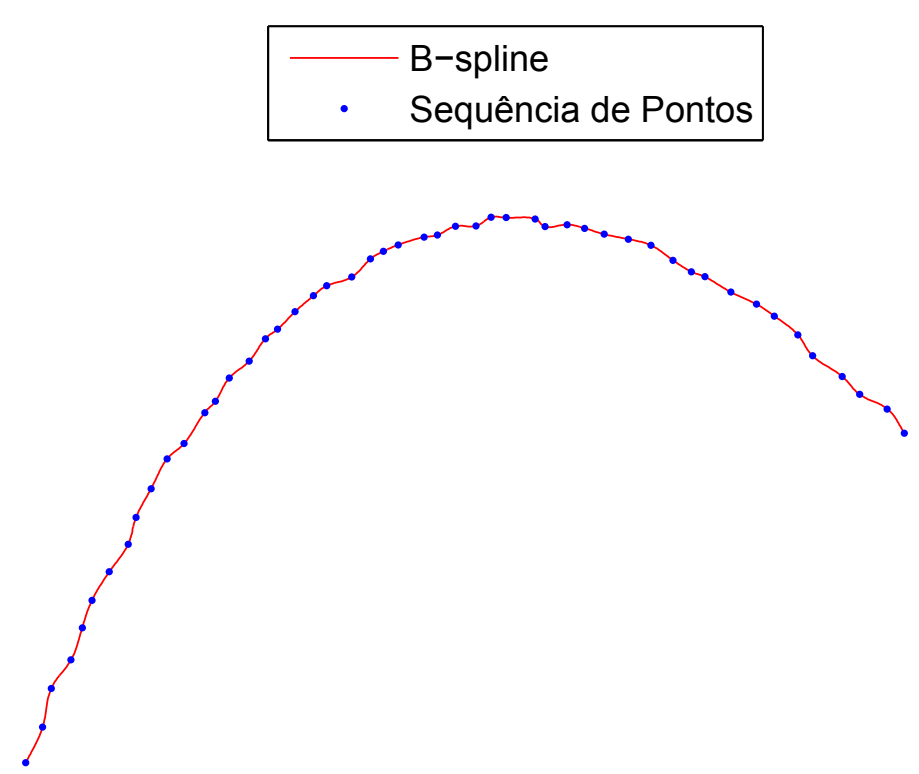

(a)

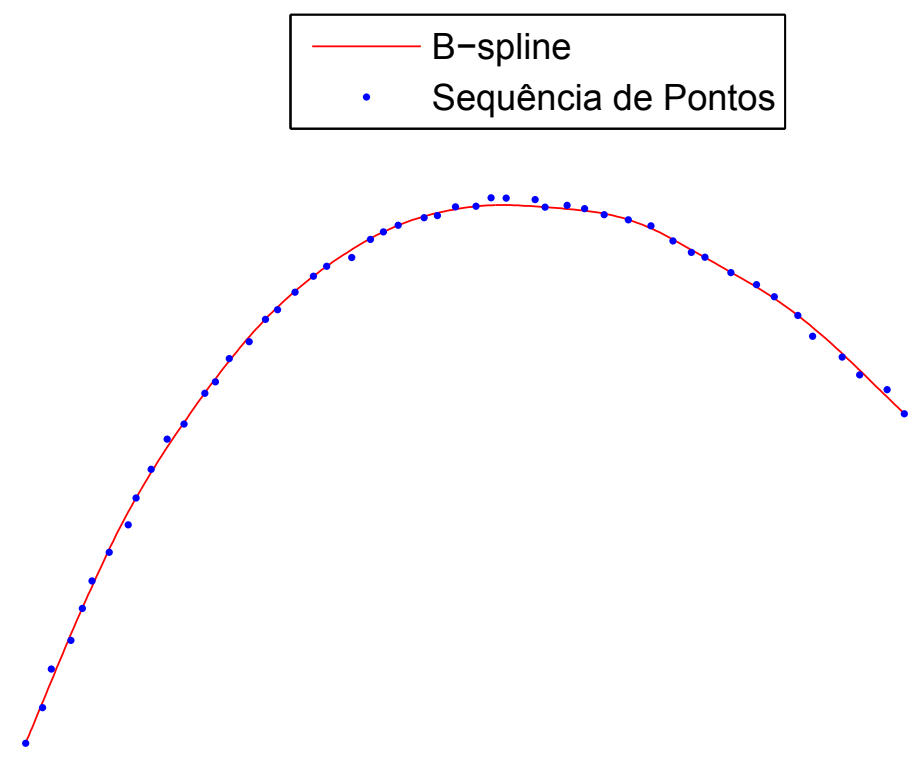

(b)

Figura 7.17 - Resultado da interpolação no exemplo da parábola. (a) Todos os pontos são interpolados; (b) 13 pontos são interpolados.

ficaram um pouco distante da curva. Isto ocorre pois não existe uma forma de avaliar quais são os melhores pontos que devem ser escolhidos e nem a quantidade de pontos a serem interpolados.

\subsubsection{Recozimento Simulado com Vizinhança Adaptativa}

Este exemplo é de uma sequência de pontos que será aproximada por 1, 2 e 3 curvas de Bézier cúbicas como mostram, respectivamente, as Figs. 7.18(a), 7.18(b) e 7.18(c). A Fig.7.19(a) mostra os valores da distância entre a sequência de pontos e a curva com a variação do peso $W 1$, e é possível observar que com a variação de $W 1$, o valor da 
distância pouco se altera, mas com o aumento do número de curvas, a distância diminui. Inicialmente essa diminuição pode ser incorretamente associada ao maior número de pontos em que a curva foi discretizada, como foi mencionado que quanto maior o número de pontos de discretização melhor o cálculo da distância entre a sequência de pontos e a curva gerada. Mas testes com 1 curva que possuía 300 pontos de discretização não foram obtidos resultados melhores que os testes com 3 curvas com 100 pontos cada. Assim, de fato, o que resulta em um menor valor da distância é o maior número de pontos de controle que pode controlar localmente regiões da curva. A Fig.7.19(b) mostra a diferença entre os comprimentos com a variação do peso $W 1$, e nela é possível observar que pouco se altera este valor para as diversas configurações. A Fig.7.19(c) mostra a variação do custo com a variação do peso $W 1$, e é possível observar que com o aumento de $W 1$ o custo também aumenta, o que é esperado. Os valores referentes às Figs. 7.19(a), 7.19(b) e 7.19(c), se encontra na Tabela 1 do Apêndice C.

\subsubsection{Recozimento Simulado Multi-objetivo}

A Fig.7.20 mostra a frente de Pareto referente ao exemplo da parábola. É possível observar que na aproximação com apenas uma curva foram obtidas curvas com comprimento muito baixo e elevada distância entre a sequência de pontos e a curva aproximadora, e estes valores não foram obtidos utilizando 2 ou 3 curvas, pois as curvas são geradas interpolando necessariamente alguns pontos da sequência de pontos evitando a determinação de curvas mais curtas. As Figs. 7.21(a), 7.21(b) e 7.21(c) mostram os resultados de algumas curvas da frente de Pareto. A Fig. 7.21(a) é referente ao exemplo com 1 curva de Bézier, a Fig. 7.21(b) referente ao exemplo com 2 curvas de Bézier e a Fig. 7.21(c) ao exemplo com 3 curvas. Em todas as figuras a curva em vermelho é a curva que apresenta o menor valor para da distância entre sequência de pontos e curva gerada, e a curva em verde é a que apresenta o menor valor de comprimento de curva gerada.

\subsection{Curva com Inflexão}

\subsubsection{Interpolação}

Novamente foram realizados dois testes utilizando o algoritmo geométrico de interpolação de curvas. Na Fig. 7.22(a) todos os pontos da sequência de pontos foram interpolados, e pode ser observado que a curva interpoladora gerada possui uma grande e indesejada tortuosidade. Na Fig. 7.22(b), a curva interpoladora é definida utilizando somente alguns pontos da sequência de pontos. Foram utilizados os mesmos critérios de escolha que os do exemplo da parábola, resultando na interpolação de 13 pontos. Novamente é observada uma curva com menor tortuosidade, mas não é possível determinar que esta é a melhor curva que pode ser gerada a partir da sequência de pontos. 


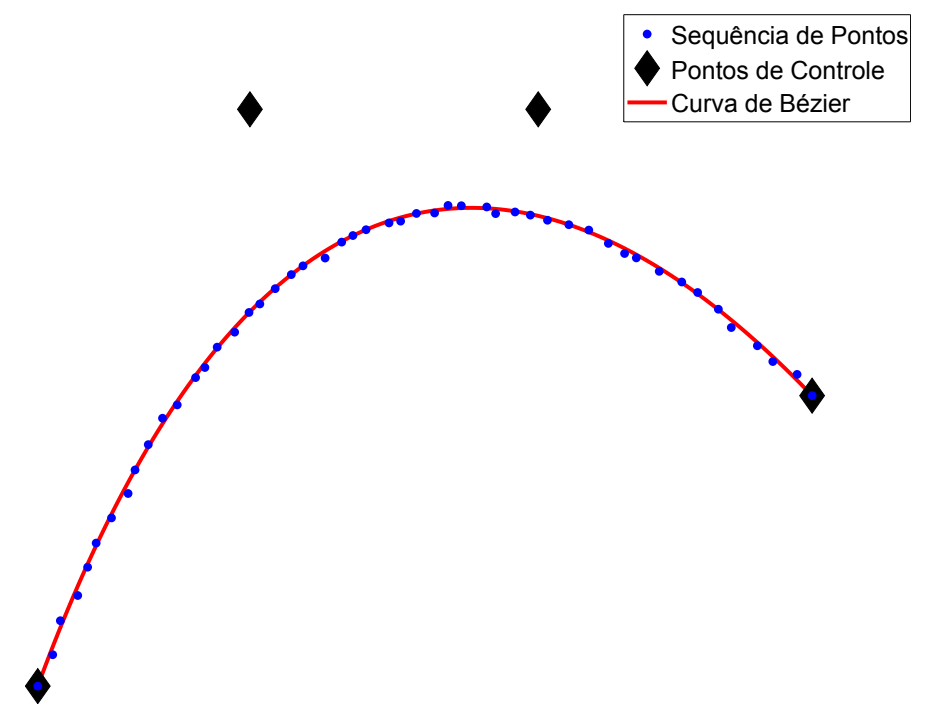

(a)

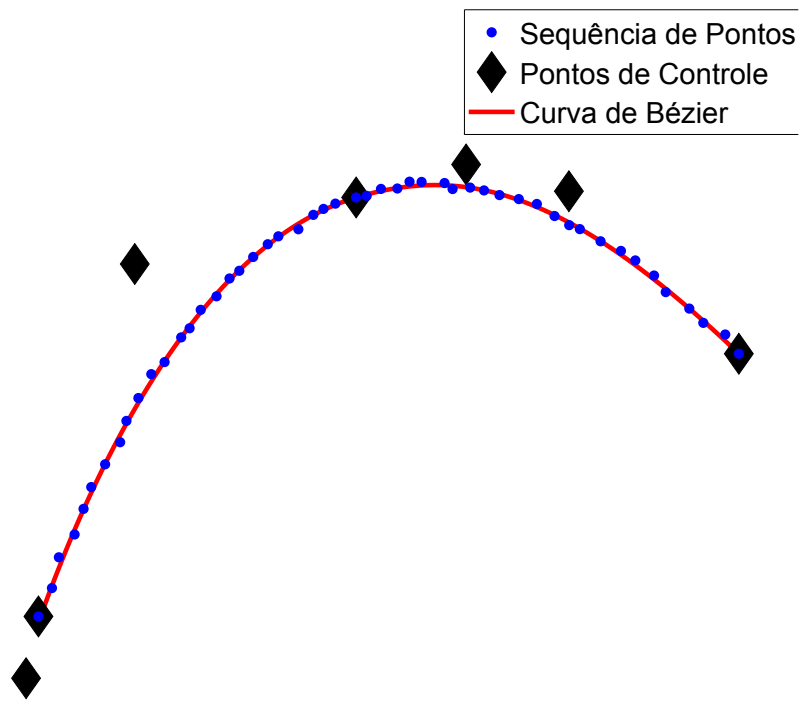

(b)

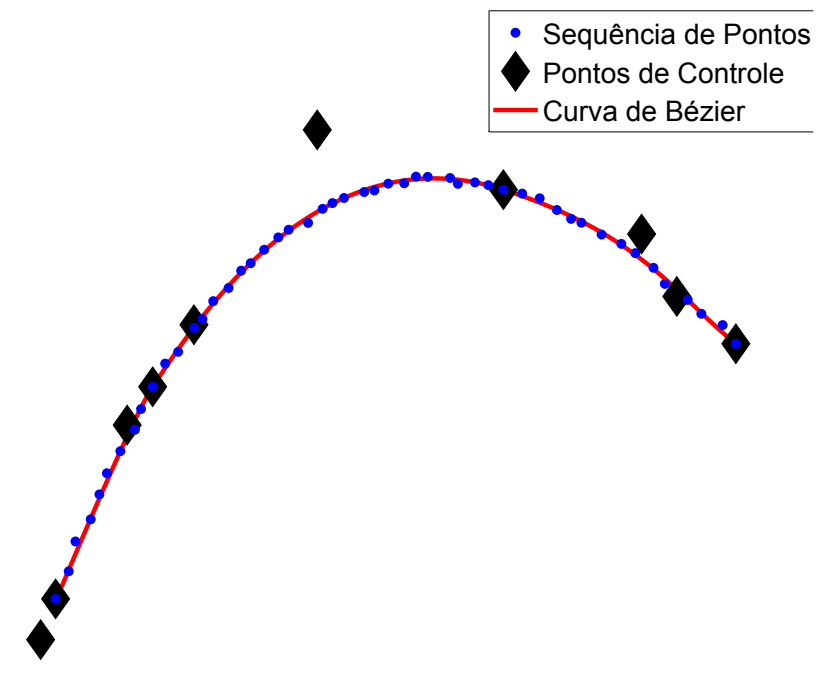

(c)

Figura 7.18 - Exemplo de uma parábola com: (a) 1 curva de Bézier; (b) 2 curvas de Bézier; (c) 3 curvas de Bézier. 


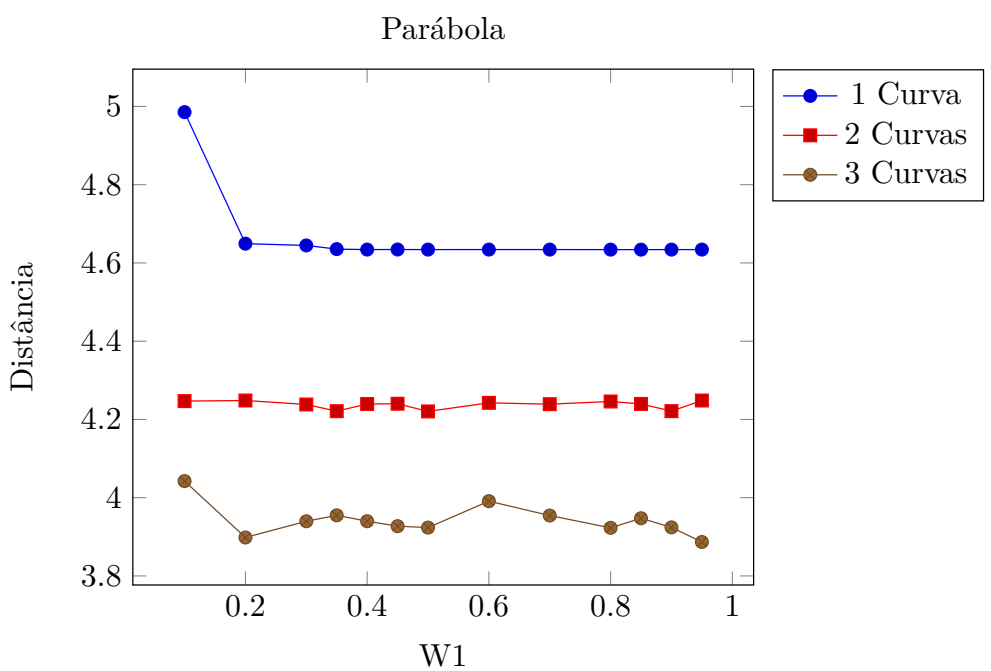

(a)

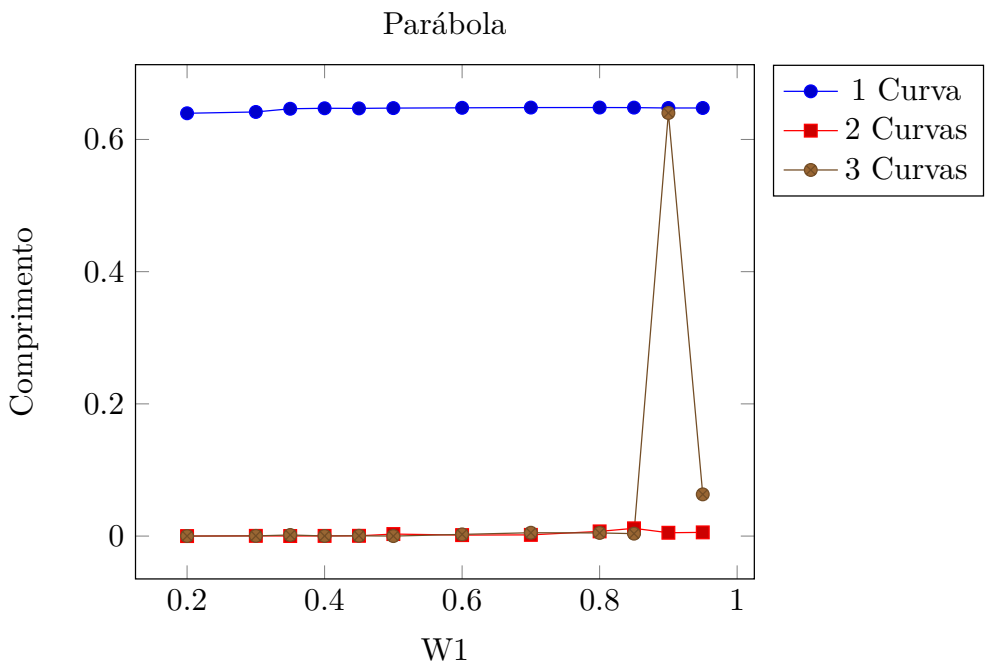

(b)

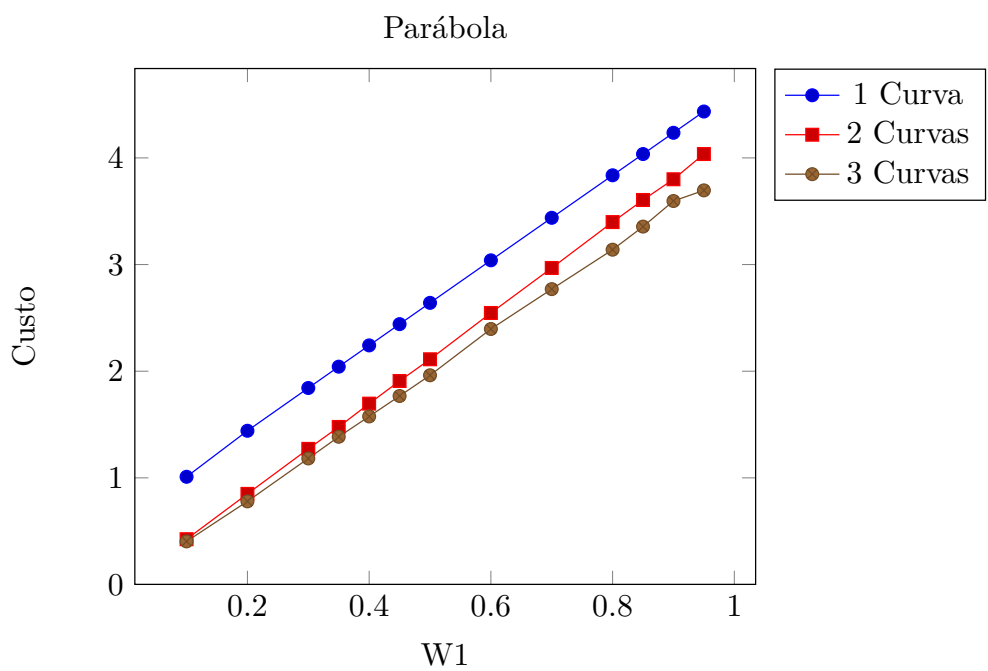

(c)

Figura 7.19 - Resultados do exemplo da parábola: (a) W1 x Distância; (b) W1 x Comprimento; (c) W1 x Custo. 


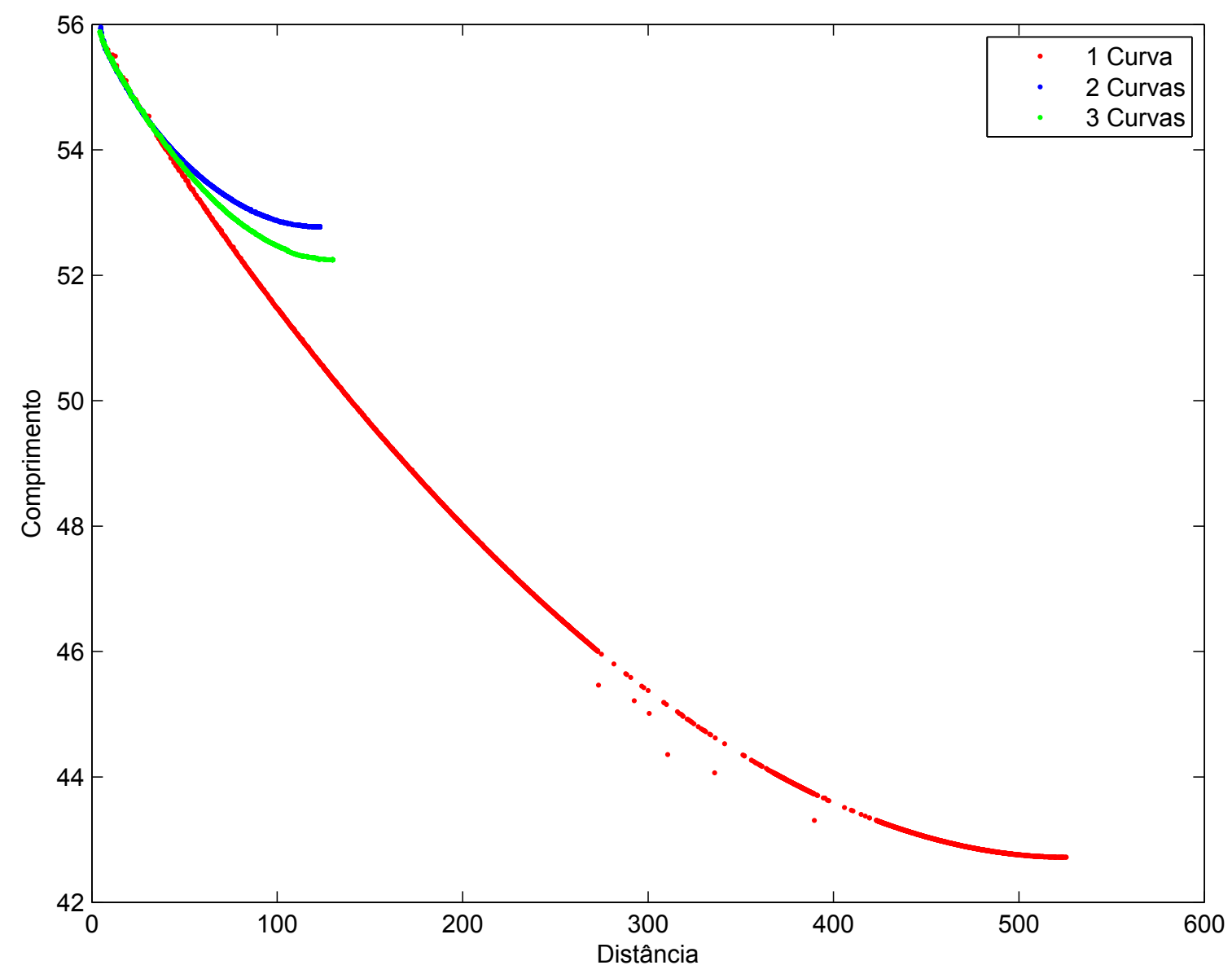

Figura 7.20 - Frente de Pareto do exemplo da curva parabólica.

\subsubsection{Recozimento Simulado com Vizinhança Adaptativa}

Neste segundo exemplo, a sequência de pontos é aproximada por 2, 3 e 4 curvas de Bézier cúbicas como mostram, respectivamente, as Figs. 7.23(a), 7.23(b) e 7.23(c). A Fig.7.24(a) mostra os valores da distância entre a sequência de pontos e a curva com a variação do peso $W 1$, e assim como no exemplo da parábola é possível observar que com o aumento do número de curvas a distância diminui. E para as configurações com 3 e 4 curvas ocorre uma pequena diminuição da distância com o aumento de $W 1$. A Fig. 7.24(b) mostra a diferença entre os comprimentos com a variação do peso $W 1$, e é possível observar que quase não há alterações no valor do comprimento. A única exceção foi em uma configuração onde foi utilizado 3 curvas e $W 1=0,95$. Nesta configuração, a diferença entre os comprimentos é elevada, porém o valor da distância não é maior que em outras configurações que utilizam 3 curvas. Assim, como o peso que controla o comprimento da curva é muito baixo, ocorreu a criação de uma curva que se aproxima da sequência de pontos com comprimento elevado, como pode ser observado na Fig.7.25. A Fig. 7.24(c) mostra a variação do custo com a varição do peso $W 1$, e assim como no exemplo da parábola é possível observar que com o aumento de $W 1$ o custo também aumenta. Os valores referentes às Figs. 7.24(a), 7.24(b) e 7.24(c), se encontra na Tabela 2 do Apêndice C. 


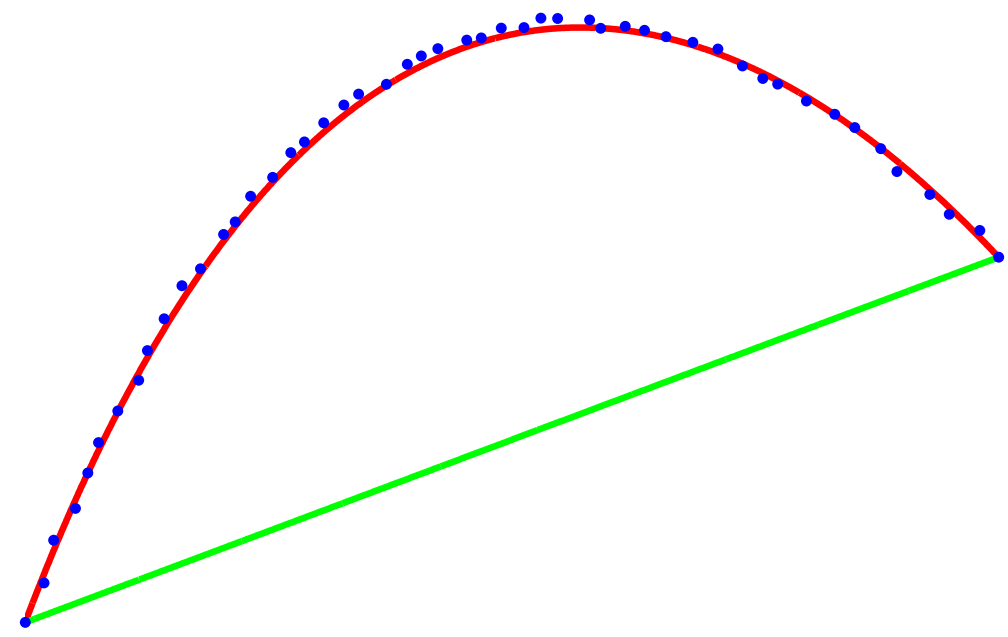

(a)

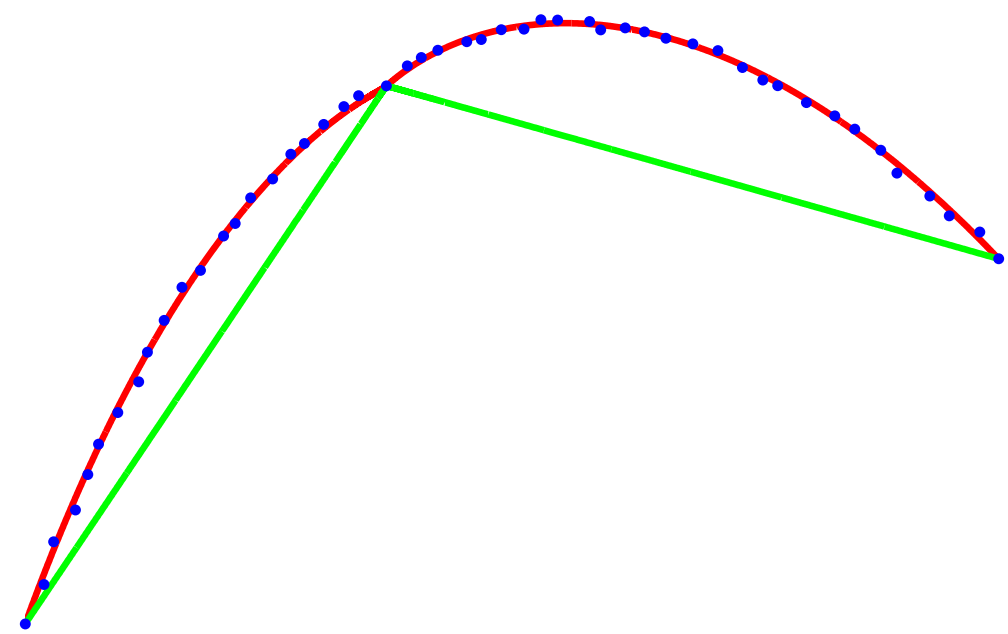

(b)

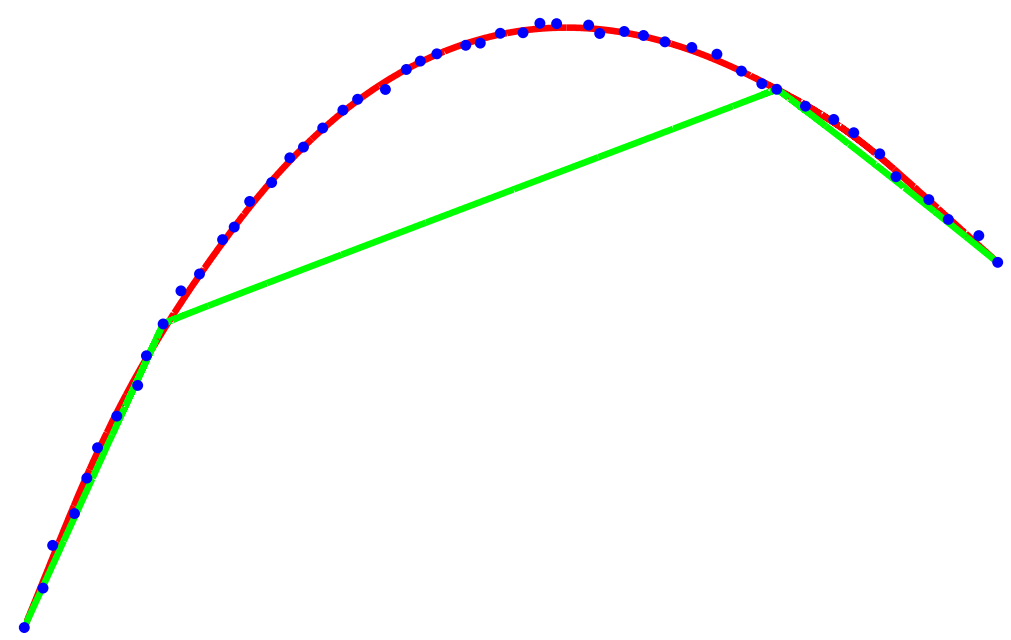

(c)

Figura 7.21 - Alguns resultados da frente de Pareto referente ao exemplo da parábola com: (a) 1 curva de Bézier; (b) 2 curvas de Bézier; (c) 3 curvas de Bézier. A curva em vermelho é a curva que apresenta a menor distância entre sequência de pontos e curva aproximadora, e a curva em verde a curva que apresenta o menor comprimento. 


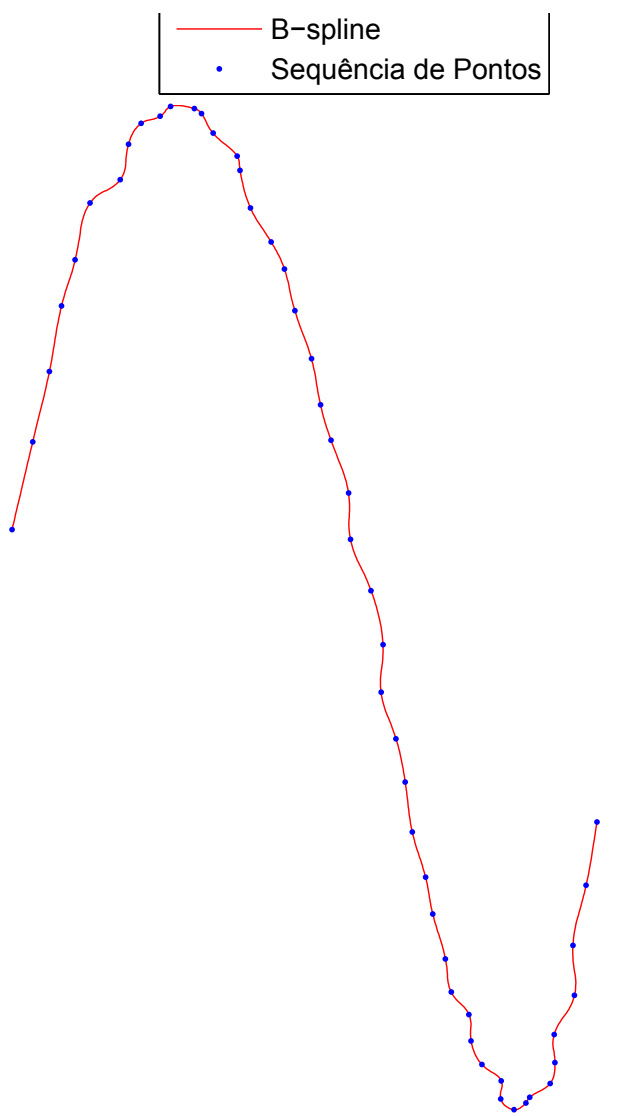

(a)

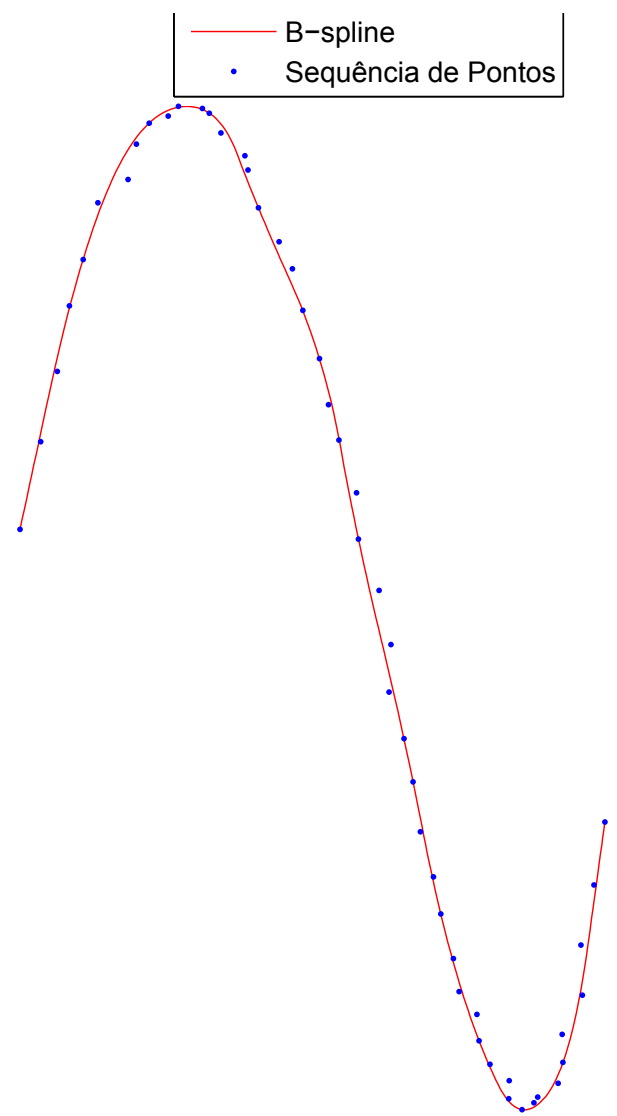

(b)

Figura 7.22 - Resultado da interpolação no exemplo de uma curva com inflexão. (a) Todos os pontos são interpolados; (b) 13 pontos são interpolados.

\subsubsection{Recozimento Simulado Multi-objetivo}

A Fig.7.26 mostra a frente de Pareto referente ao exemplo da curva com inflexão. É possível observar que quanto maior a distância entre a sequência de pontos e a curva aproximadora gerada, menor o comprimento da curva aproximadora. Com a diminuição do comprimento, pode-se observar que para cada configuração existe um comprimento mínimo. Ao atingir este comprimento mínimo a diminuição do comprimento não pode ser observada nesta figura por ser muito pequena. Nota-se que para este exemplo, quanto menor o número de curvas de Bézier menor o comprimento mínimo, pois o comprimento mínimo ocorre quando a curva de Bézier criar uma reta entre o primeiro e o último ponto de controle de cada trecho de curva. E como estes pontos fazem parte da sequência de pontos quanto menor o número de curvas menor é o comprimento mínimo. As curvas com menor comprimento podem ser observadas nas Figs. 7.27(a), 7.27(b) e 7.27(c), onde as curvas em verde são as curvas de menor comprimento e as curvas em vermelho são as curvas de menor distância entre a sequência de pontos e curva aproximadora. Na Fig. 7.27(a) é utilizado 2 curvas de Bézier, na Fig. 7.27(b) 3 curvas de Bézier e na Fig. 7.27(c) 4 curvas de Bézier. 


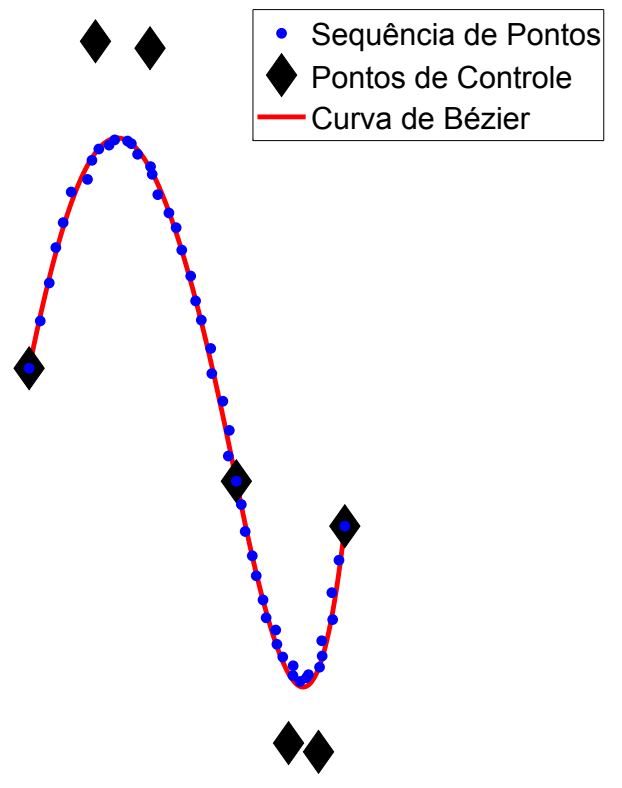

(a)

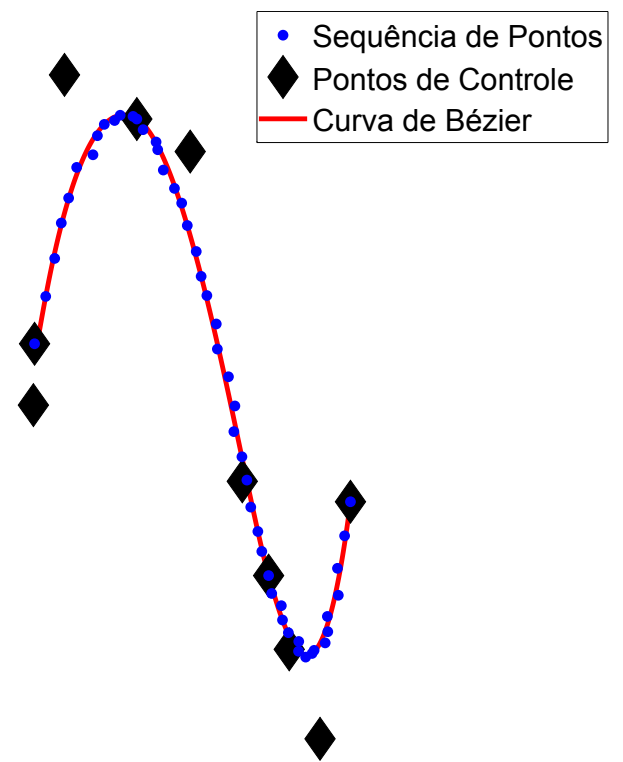

(b)

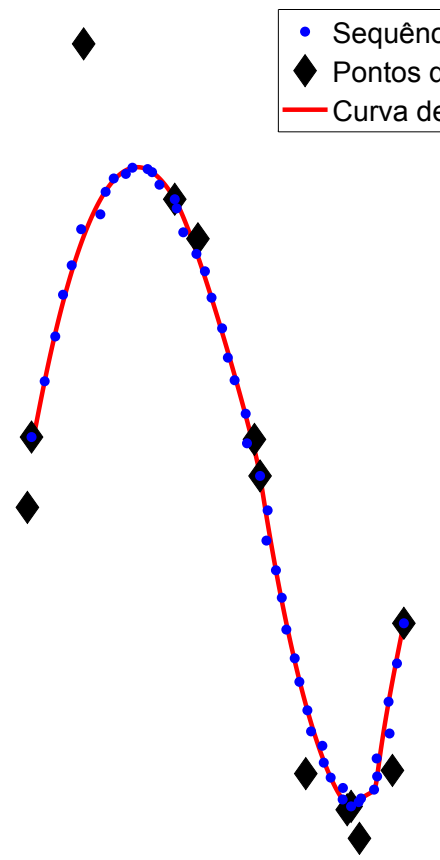

(c)

Figura 7.23 - Exemplo de uma curva com inflexão com: (a) 2 curvas de Bézier; (b) 3 curvas de Bézier; (c) 4 curvas de Bézier. 


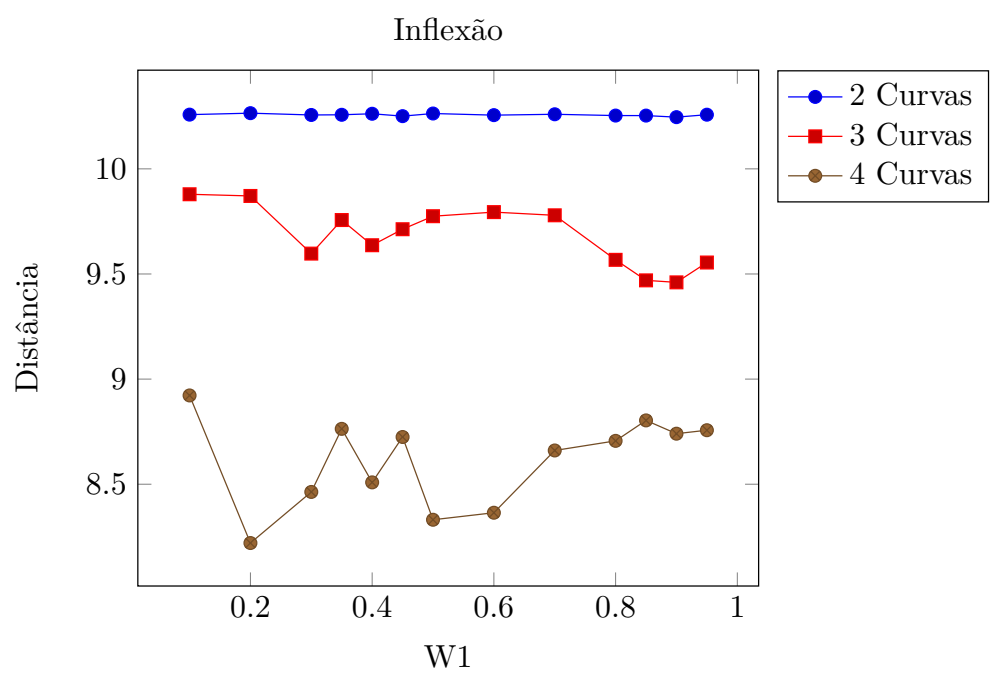

(a)

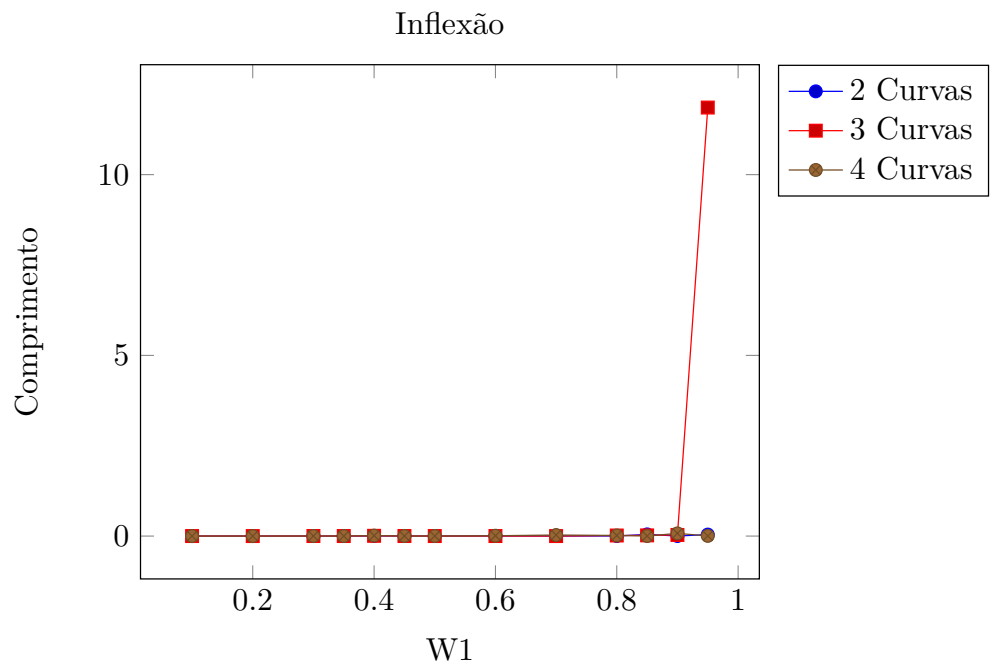

(b)

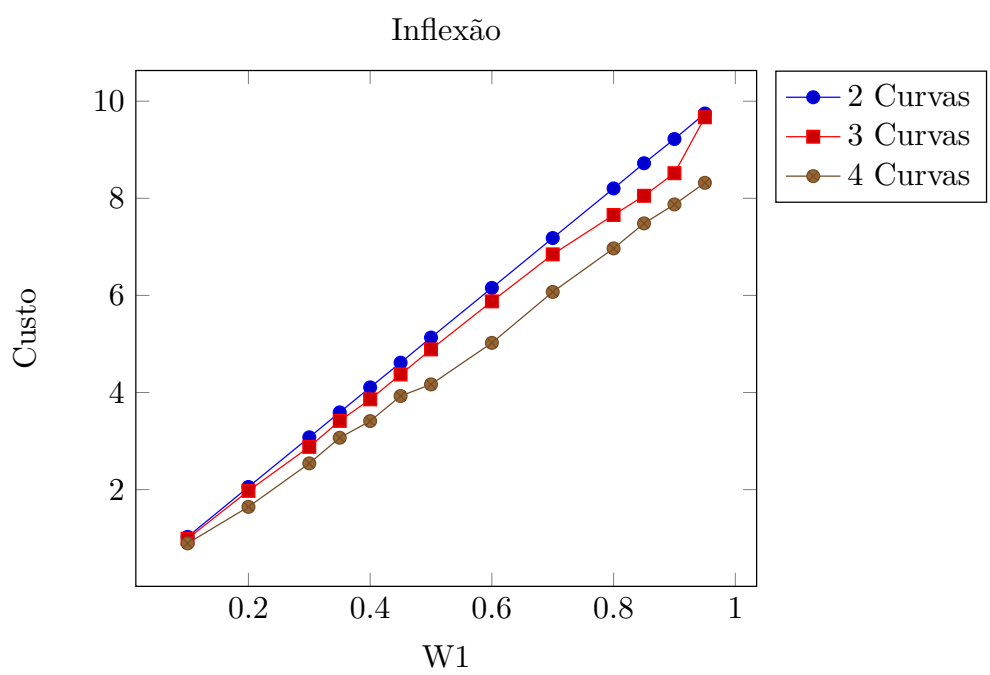

(c)

Figura 7.24 - Resultados do exemplo da curva com inflexão: (a) W1 x Distância; (b) W1 x Comprimento; (c) W1 x Custo. 


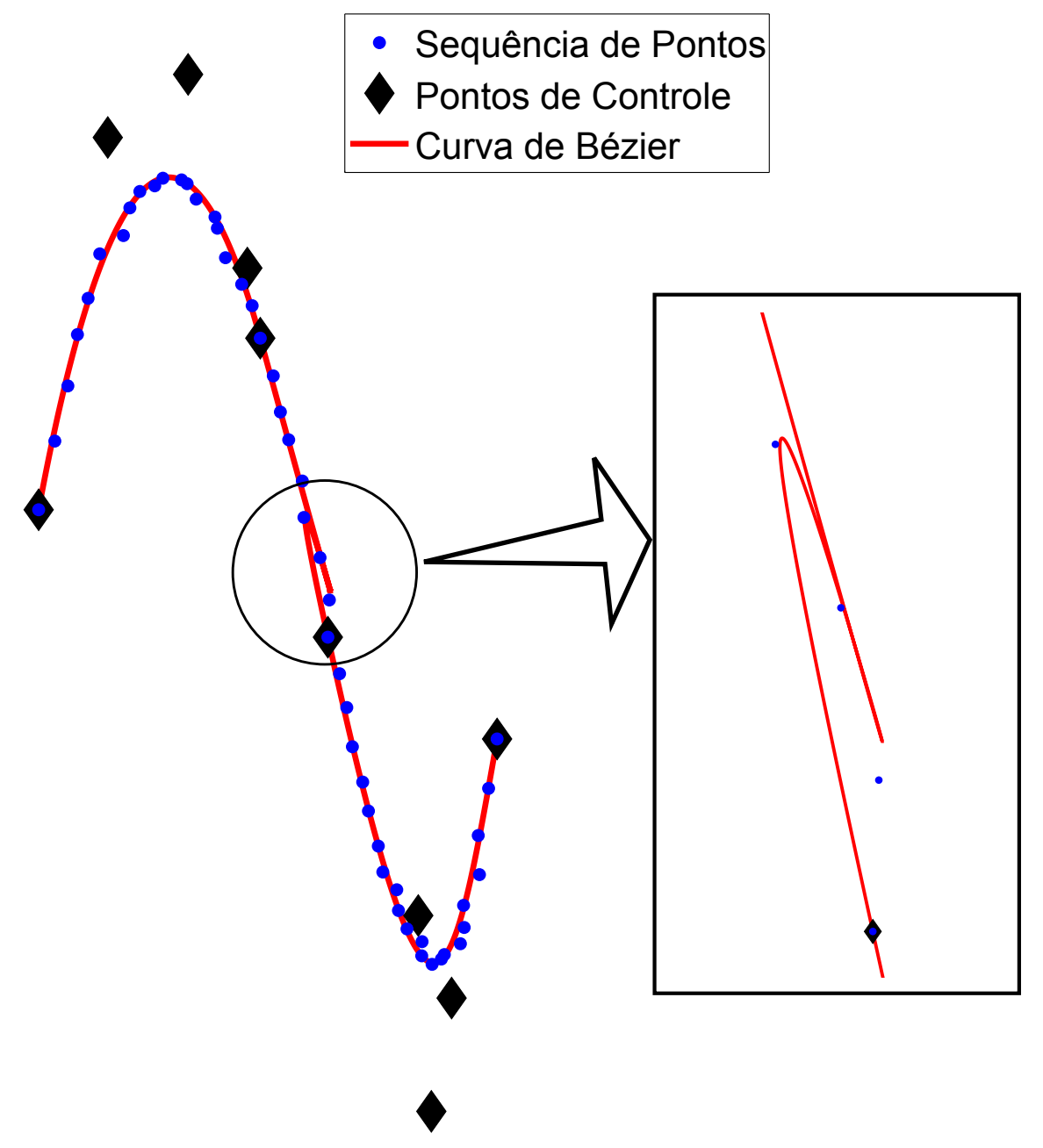

Figura 7.25 - Curva com inflexão com comprimento elevado.

\subsection{Curva com Auto-Intersecção}

\subsubsection{Interpolação}

Novamente foram realizados dois testes utilizando o algoritmo geométrico de interpolação de curvas. As Fig. 7.28(a) e Fig. 7.28(b) são novamente geradas utilizando as mesmas regras que os exemplos anteriores. Na primeira figura todos os pontos foram interpolados enquanto na segunda figura somente alguns pontos foram interpolados. Novamente, com a interpolação de todos os pontos a curva apresenta uma grande e indesejada tortuosidade, mas diferente dos exemplos anteriores o resultado da interpolação de somente alguns pontos não foi boa, principalmente no início e fim da curva. Devido à maior complexidade da curva é necessário interpolar um maior número de pontos da sequência de pontos ou modificar os pontos de escolha. Novamente, isto ocorre pois não existe uma forma de avaliar quais são os melhores pontos que devem ser escolhidos e nem a quantidade de pontos a serem interpolados. 


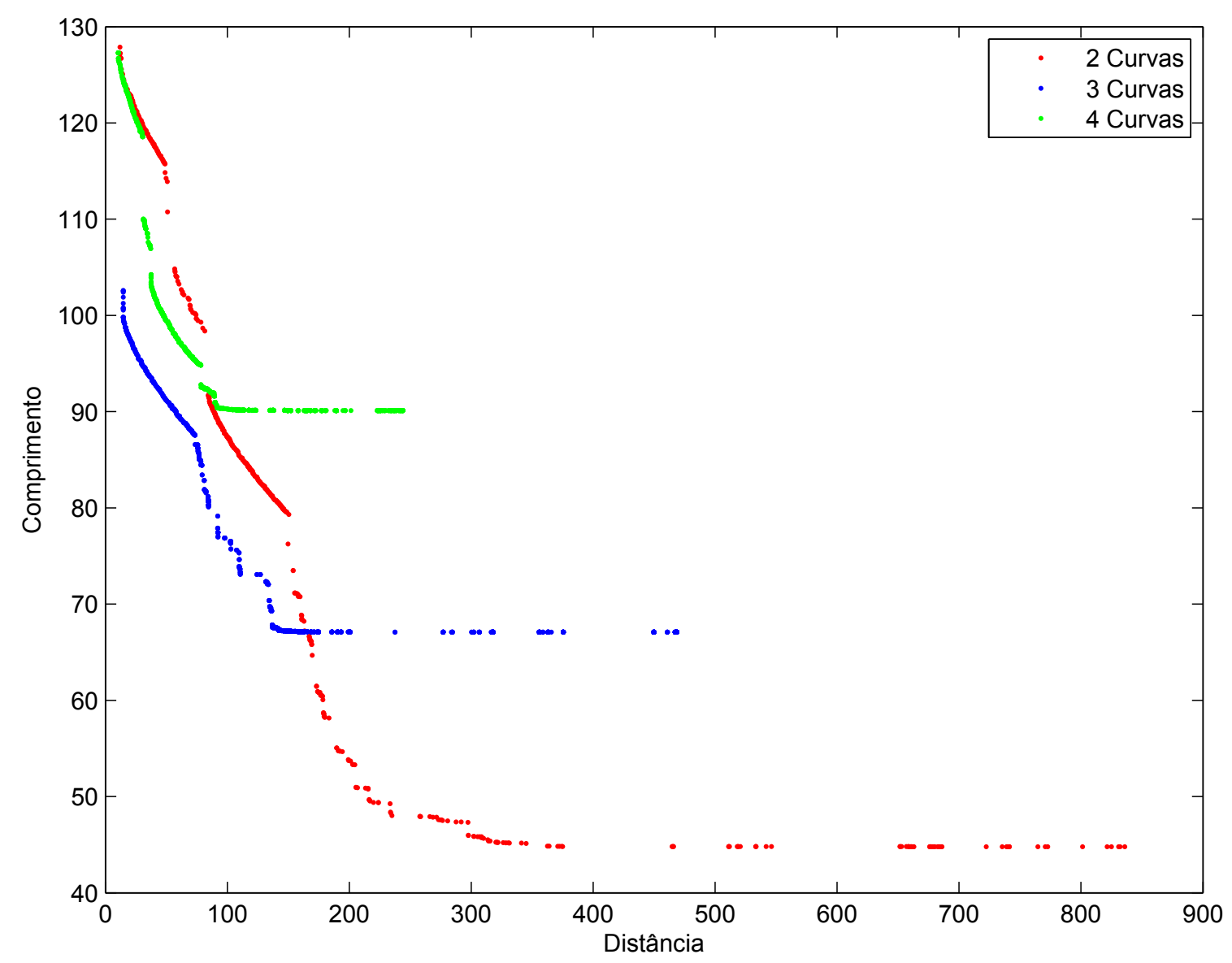

Figura 7.26 - Frente de Pareto do exemplo da curva com inflexão.

\subsubsection{Recozimento Simulado com Vizinhança Adaptativa}

O terceiro exemplo é de uma sequência de pontos que é aproximada por 5, 6 e 7 curvas de Bézier cúbicas como mostram, respectivamente, as Figs. 7.29(a), 7.29(b) e 7.29(c). A Fig.7.30(a) mostra os valores da distância entre a sequência de pontos e a curva com a variação da peso $W 1$. Novamente, quanto maior o número de curvas, menor a distância, mas neste exemplo nas três configurações ocorre uma diminuição da distância com a aumento do peso $W 1$. Ao observar os três exemplos é possível notar que, nos dois primeiros exemplos, os pontos da sequência apresentam um menor espaçamento em comparação com a terceira sequência de pontos, além do terceiro exemplo apresentar um grau de complexidade maior em relação aos anteriores. Desta forma, neste terceiro exemplo, todas as configurações obtiveram um menor valor da distância com o aumento do peso $W 1$, pois cada curva aproxima um conjunto menor de pontos da sequência de pontos. A Fig.7.30(b) mostra a diferença entre os comprimentos com a variação do peso $W 1$ e a Fig.7.30(c) mostra a variação do custo com a variação do peso $W 1$. Os valores referentes às Figs. 7.30(a), 7.30(b) e 7.30(c), se encontra na Tabela 3 do Apêndice C. 


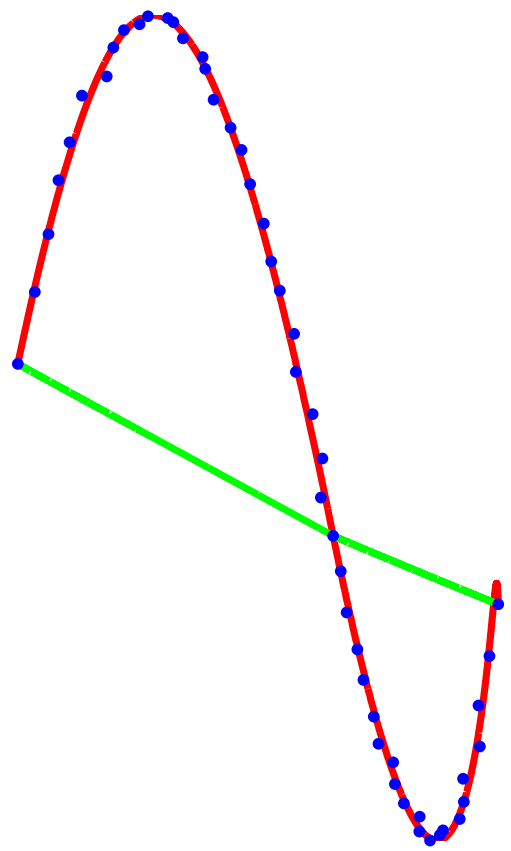

(a)

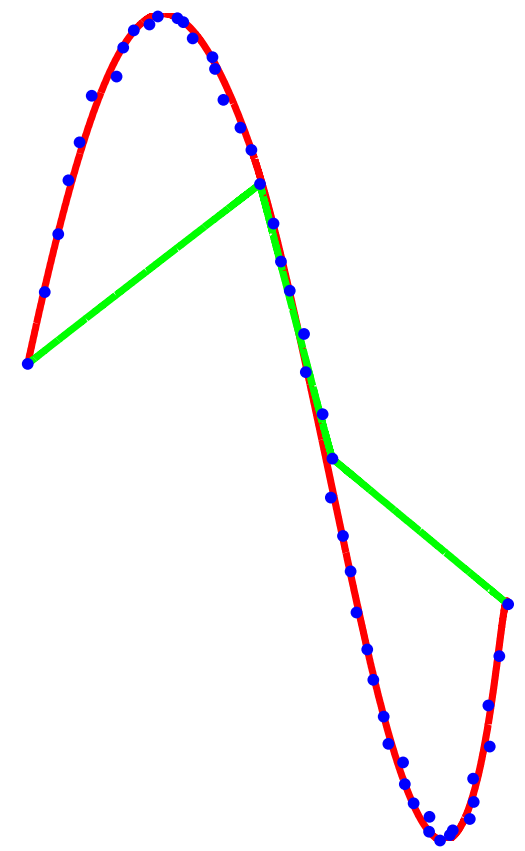

(b)

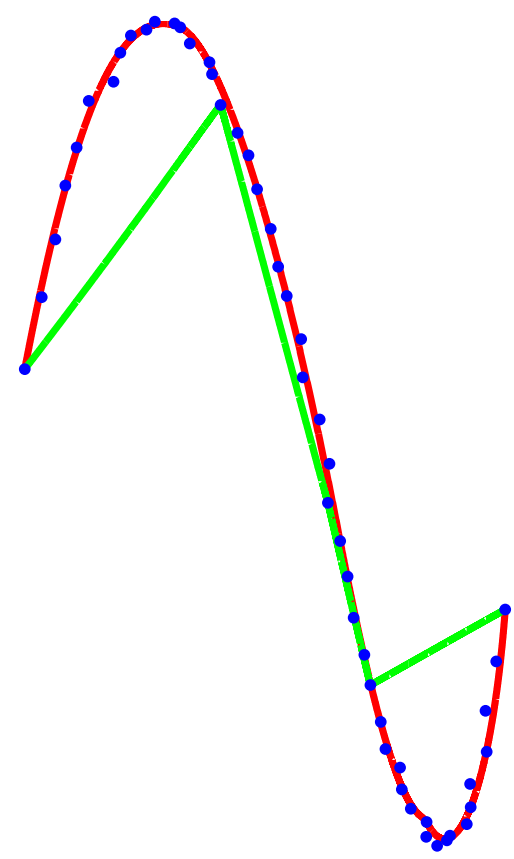

(c)

Figura 7.27 - Alguns resultados da frente de Pareto referente ao exemplo da curva com inflexão com: (a) 2 curvas de Bézier; (b) 3 curvas de Bézier; (c) 4 curvas de Bézier. A curva em vermelho é a curva que apresenta a menor distância entre sequência de pontos e curve aproximadora, e a curva em verde a curva que apresenta o menor comprimento. 


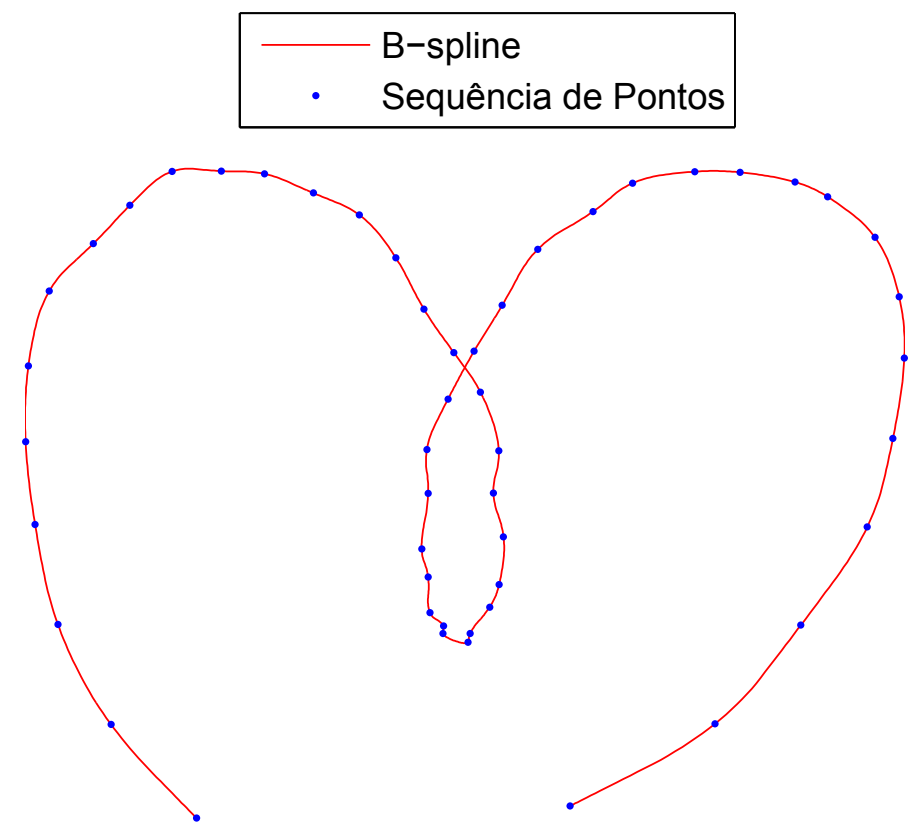

(a)

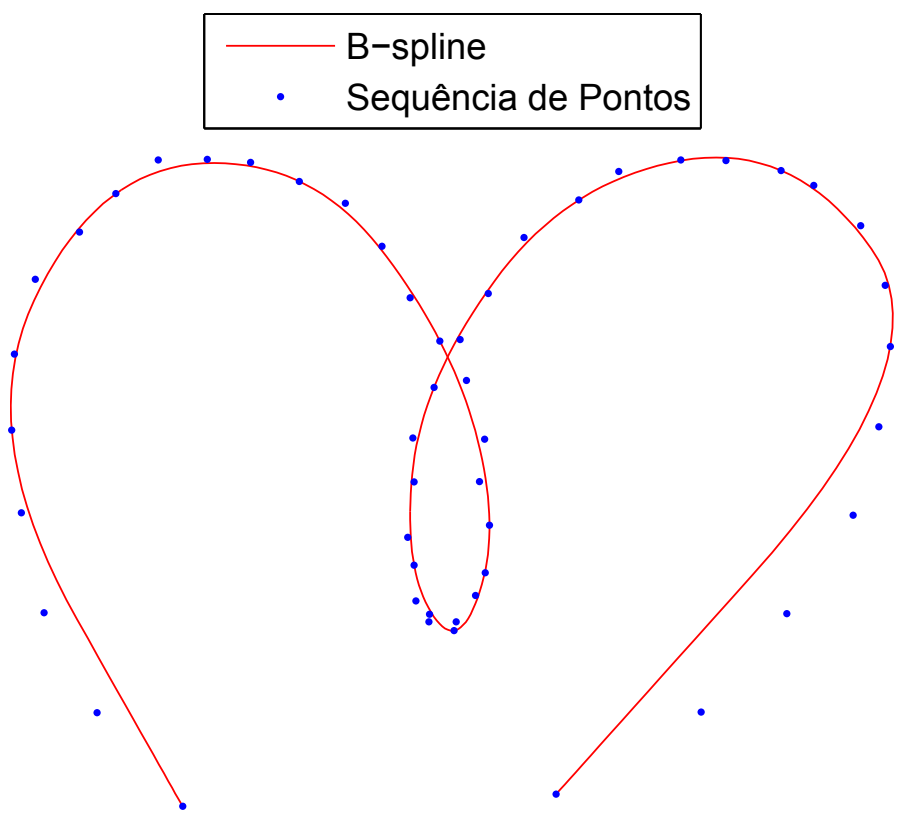

(b)

Figura 7.28 - Resultado da interpolação no exemplo de uma curva com auto-intersecção. (a) Todos os pontos são interpolados; (b) 13 pontos são interpolados. 


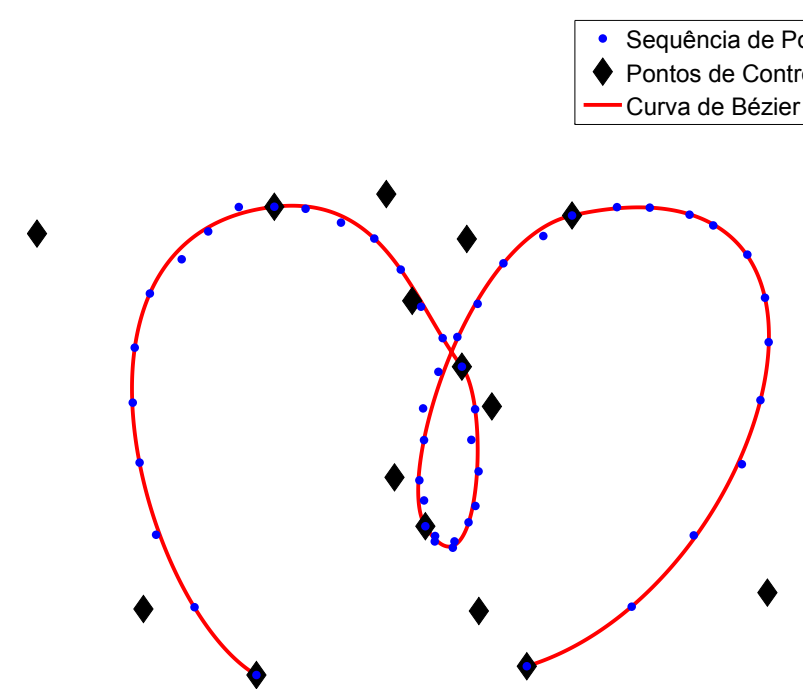

(a)

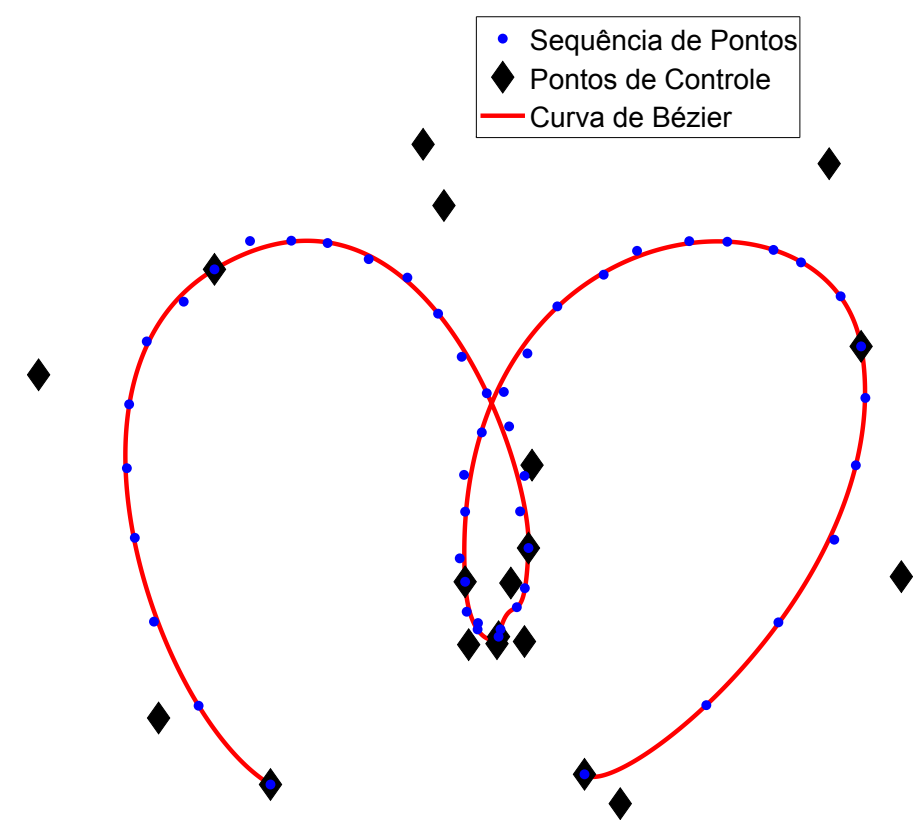

(b)

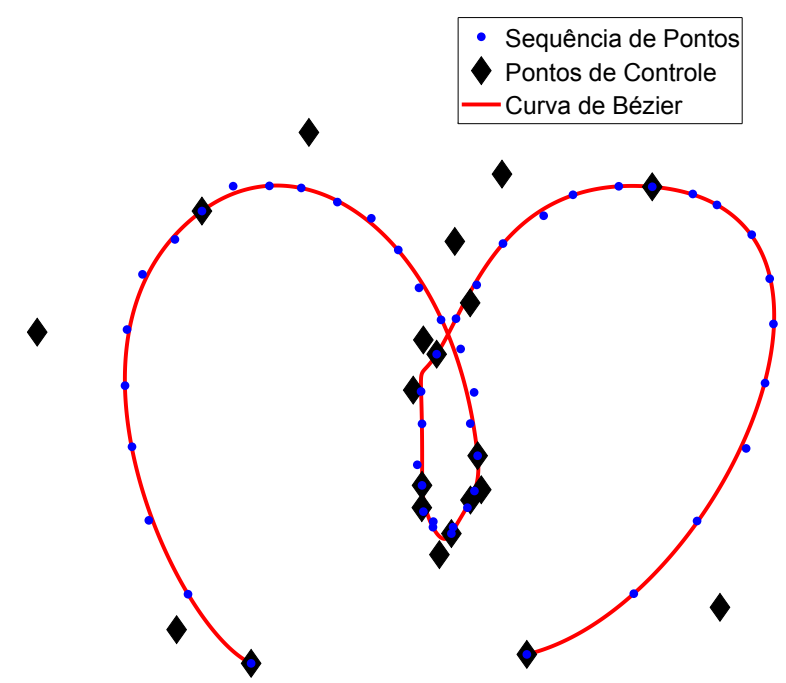

(c)

Figura 7.29 - Exemplo de uma curva com auto-intersecção com: (a) 5 curvas de Bézier; (b) 6 curvas de Bézier; (c) 7 curvas de Bézier. 


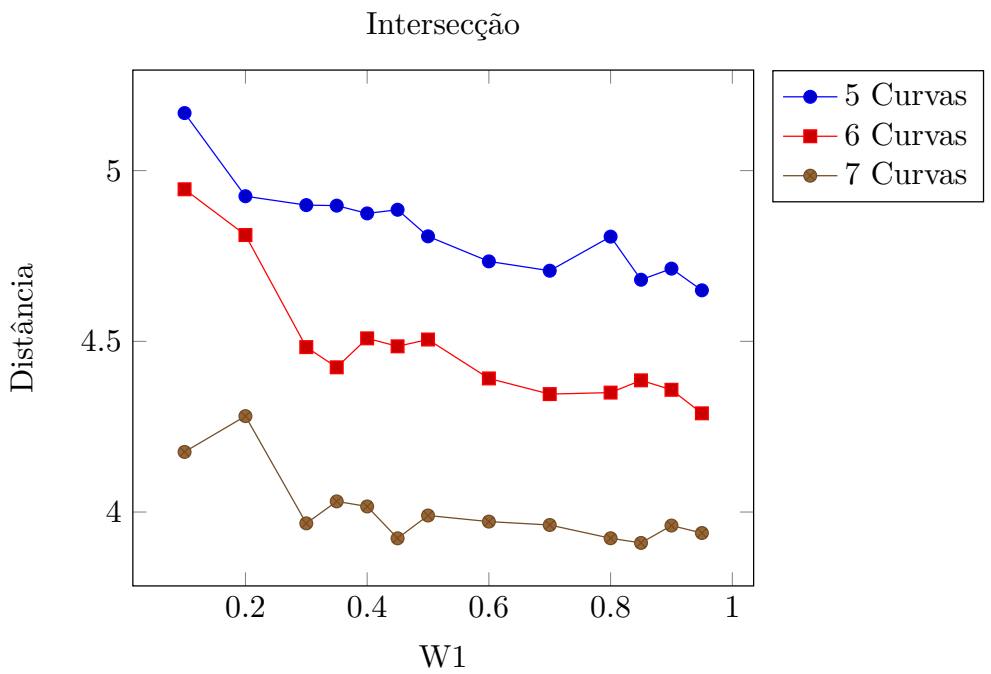

(a)

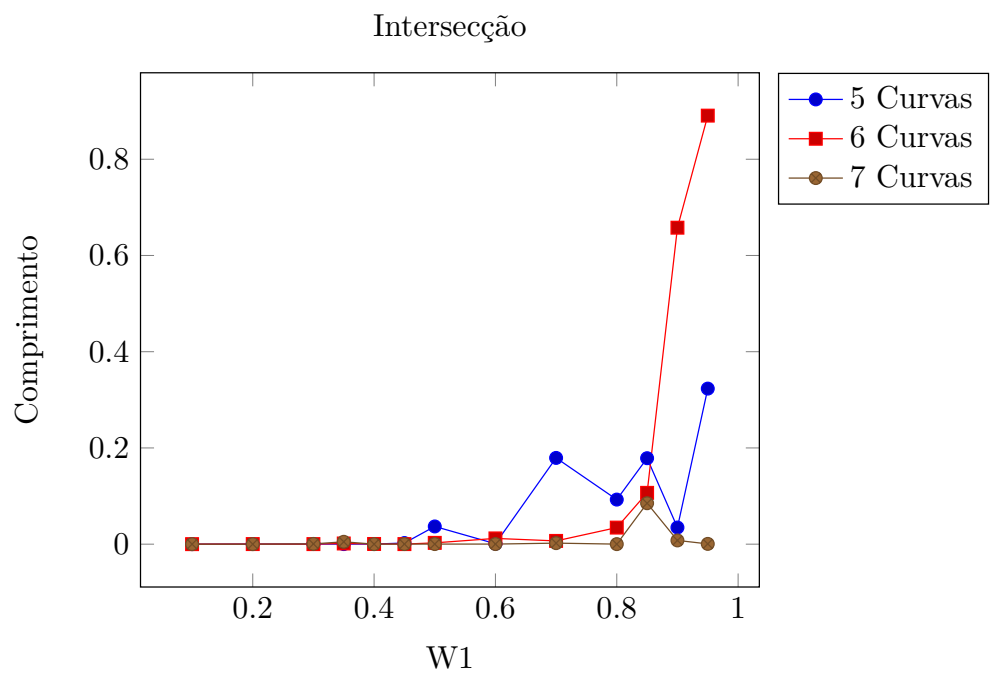

(b)

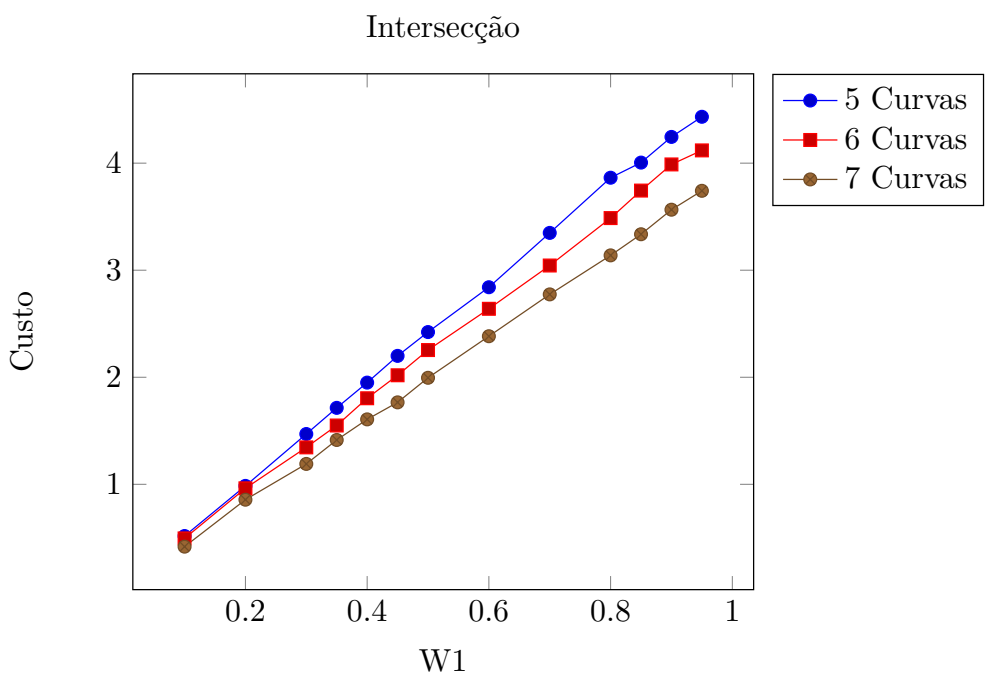

(c)

Figura 7.30 - Resultados do exemplo da curva com auto-intersecção : (a) W1 x Distância; (b) W1 x Comprimento; (c) W1 x Custo. 


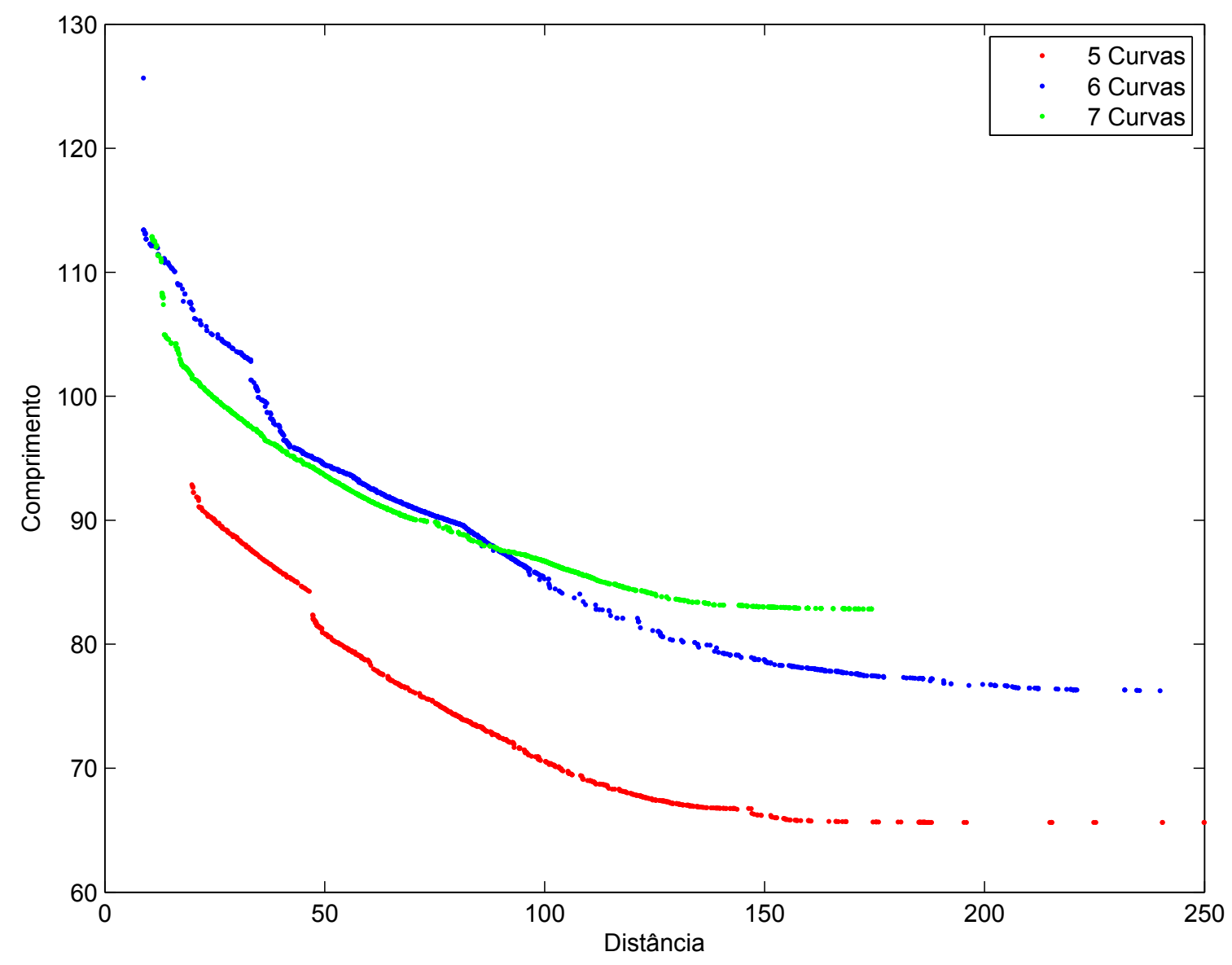

Figura 7.31 - Frente de Pareto do exemplo da curva com auto-intersecção.

\subsubsection{Recozimento Simulado Multi-objetivo}

A Fig.7.31 mostra a frente de Pareto referente ao exemplo da curva com auto-intersecção. Novamente nota-se que quanto menor o comprimento maior a distância entre a sequência de pontos e a curva aproximadora. Ao comparar a frente de Pareto e os resultados obtidos com o recozimento simulado com um objetivo é possível notar que os resultados obtidos com um objetivo se concentram na região onde a distância é mínima, pois ao utilizar poucos pontos de controle não é possível criar curvas com comprimento elevado e baixo valor na distância. As Figs. 7.32(a), 7.32(b) e 7.32(c) são respectivamente exemplos com 5, 6 e 7 curvas. As curvas em vermelho são as curvas que apresentam a menor distância entre sequência de pontos e curva aproximadora e as curvas em verde são as curvas aproximadoras que apresentam o menor comprimento.

\subsection{Fator de Cristalização, Calor Específico, Coeficiente de Resfriamento e Custos}

A partir do exemplo mais simples, que é uma curva parabólica aproximada com 1 curva de Bézier, foi levantada a relação dos fatores de cristalização com a temperatura, calor 


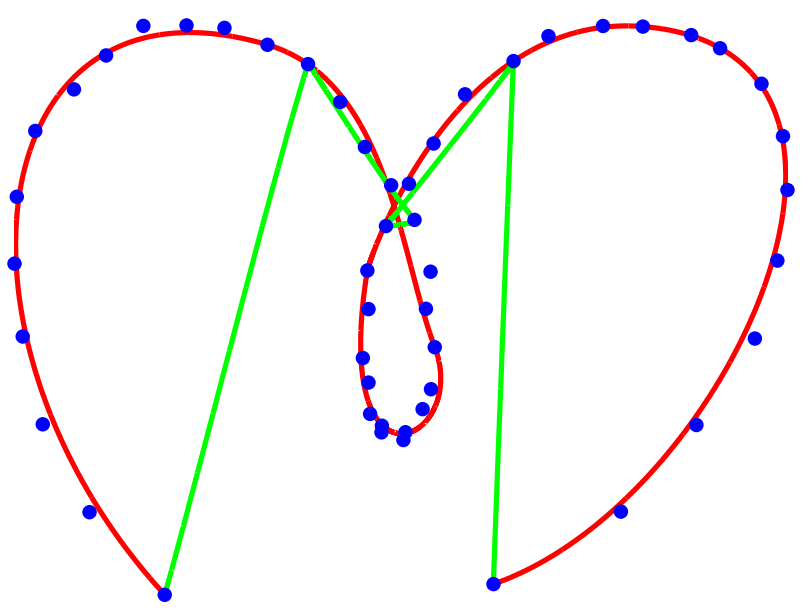

(a)

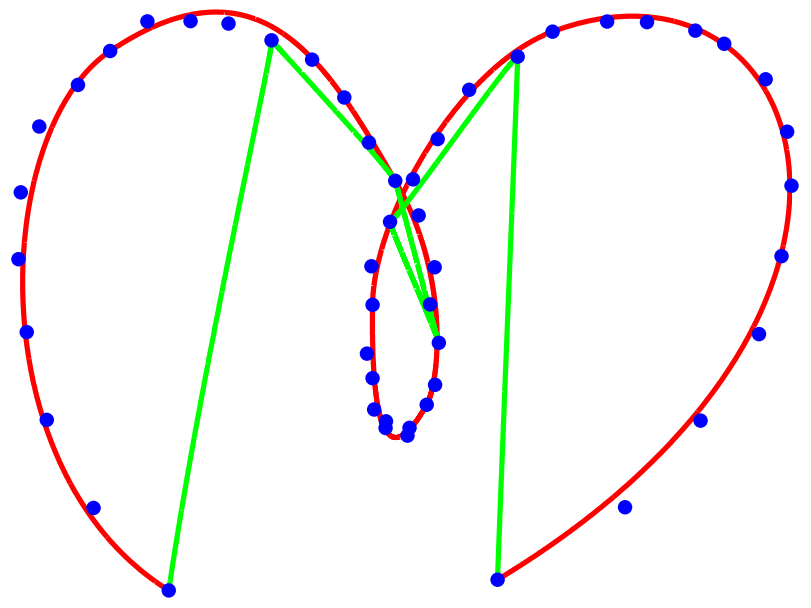

(b)

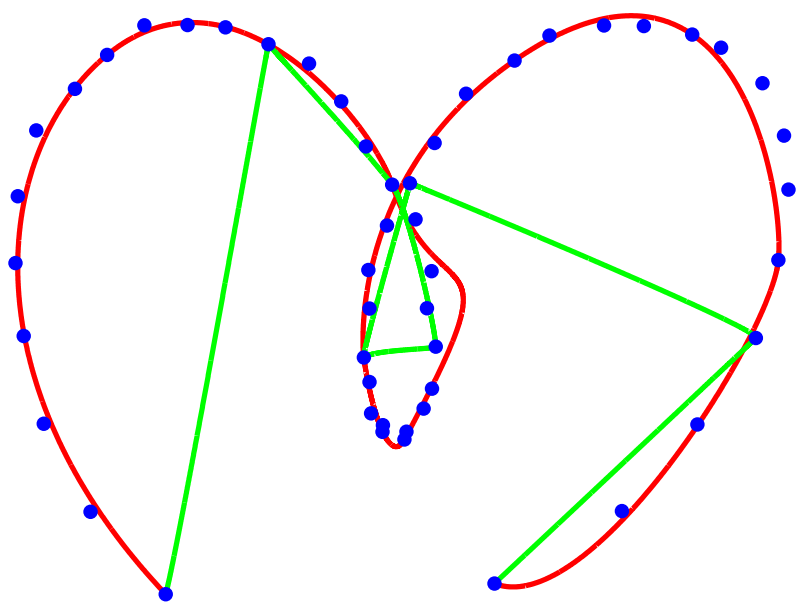

(c)

Figura 7.32 - Alguns resultados da frente de Pareto referente ao exemplo da curva com auto-intersecção com: (a) 5 curvas de Bézier; (b) 6 curvas de Bézier; (c) 7 curvas de Bézier. A curva em vermelho é a curva que apresenta a menor distância entre sequência de pontos e curva aproximadora, e a curva em verde a curva que apresenta o menor comprimento. 
específico com a temperatura, coeficiente de resfriamento $\alpha$ com a temperatura e custo máximo, mínimo e médio com a temperatura.

A Fig. 7.33 é um gráfico di-log, onde no eixo $x$ são valores da temperatura e no eixo $y$ os valores do fator de cristalização de uma variável. A Fig. 7.33(a) exibe o fator $c_{0}$ correspondente à coordenada $x$ do segundo ponto de controle, a Fig. 7.33(b) exibe o fator $c_{1}$ correspondente à coordenada $y$ do segundo ponto de controle, a Fig. 7.33(c) exibe o fator $c_{2}$ correspondente à coordenada $x$ do terceiro ponto de controle e a Fig. 7.33(d) exibe o fator $c_{3}$ correspondente à coordenada $y$ do terceiro ponto de controle. Todas os fatores de cristalização tiveram o mesmo comportamento, com o decaimento da temperatura os fatores de cristalização aumentaram. Comprovando que na temperatura elevada corresponde à fase de exploração do recozimento simulado e o fator de cristalização é mantido baixo, e com a diminuição da temperatura o fator de cristalização se eleva, correspondendo à fase de refinamento do método.

A Fig. 7.34 é um gráfico do valor da função custo no eixo y pela temperatura no eixo $x$. A curva em azul é o custo máximo para cada temperatura, a curva em preto é o custo mínimo e a curva em vermelho é o custo médio. Pode se verificar que para temperaturas altas o custo mínimo, máximo e médio são altos, além da amplitude do custo compreendido entre o custo máximo e mínimo ser grande, e com o decaimento da temperatura todos os valores do custo diminuem e a amplitude também diminui. Isto comprova que o desvio padrão e a variância do custo diminuem com a diminuição da temperatura o que pode ser observado na Fig. 7.35.

O calor específico e o coeficiente de resfriamento são apresentados respectivamente nas Figs. 7.36 e 7.37. No gráfico do calor específico pode-se notar que quando o valor da temperatura era aproximadamente 8 ocorreu um queda do calor específico que mostra uma mudança de fase. Já no gráfico do coeficiente de resfriamento $\alpha$ pode-se notar que inicialmente o valor de $\alpha$ se encontra baixo e se eleva rapidamente. 


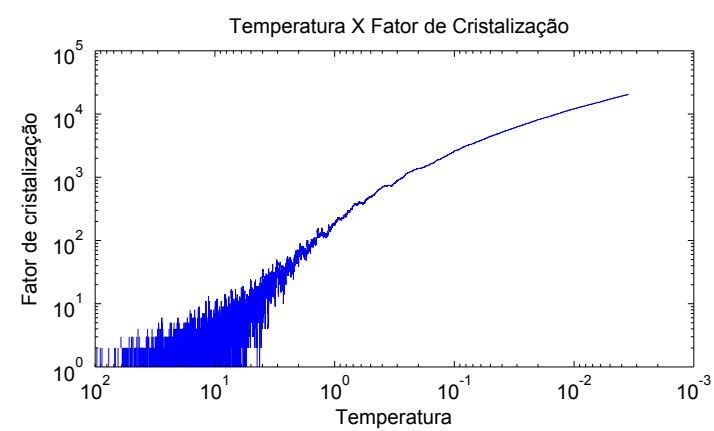

(a)

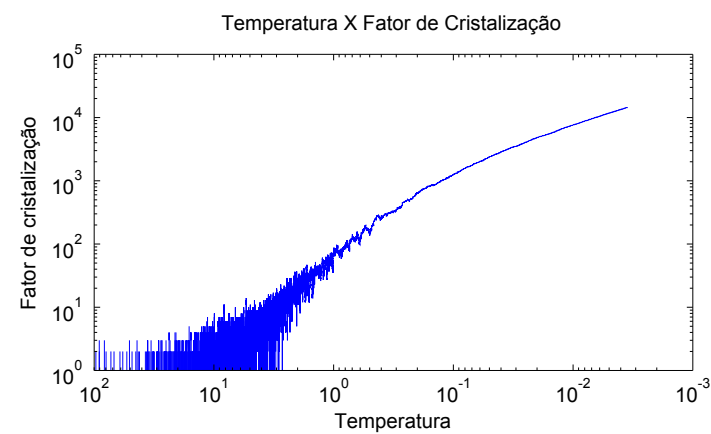

(c)

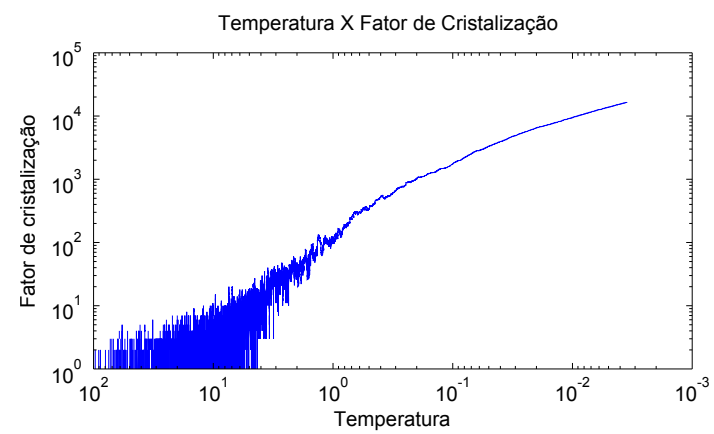

(b)

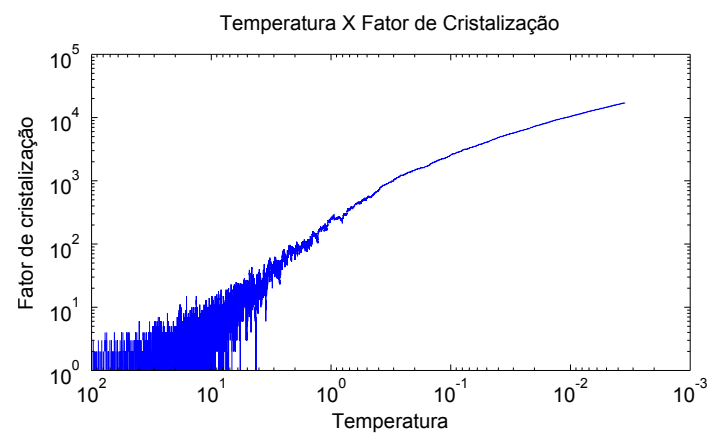

(d)

Figura 7.33 - Fatores de cristalização para um exemplo com 4 parâmetros. (a) Fator $c_{0}$; (b) Fator $c_{1}$; (c) Fator $c_{2}$; (d) Fator $c_{3}$.

\section{Temperatura X Custo}

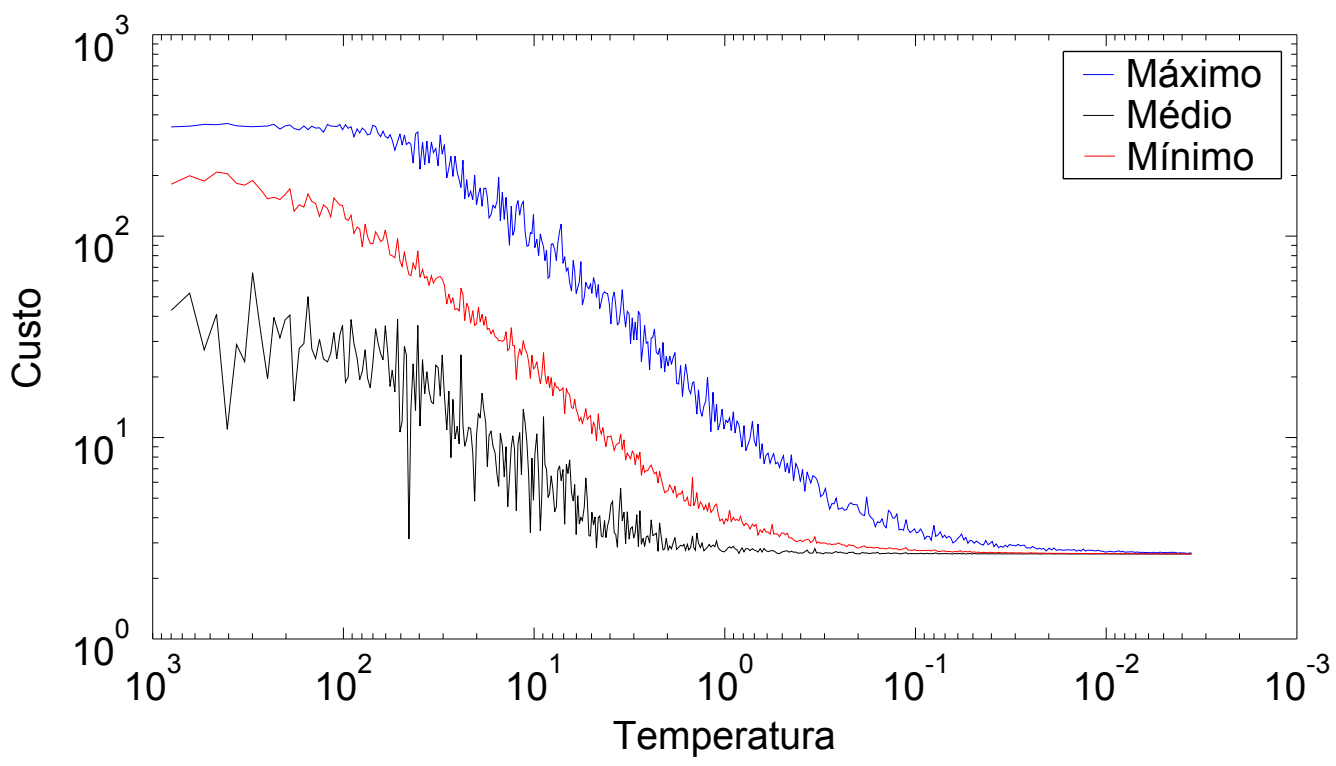

Figura 7.34 - Curva de custo máximo, mínimo e médio por temperatura. 


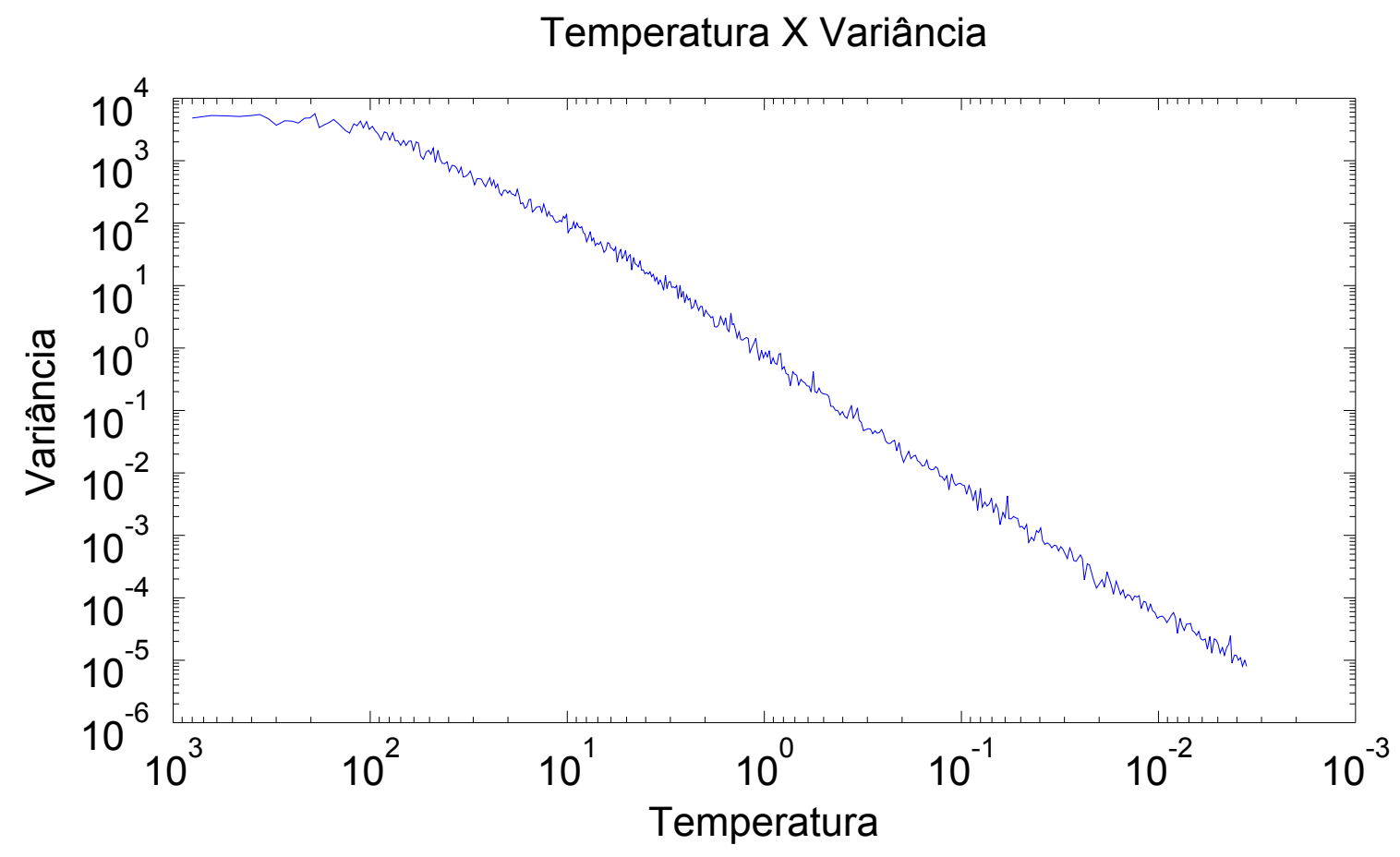

Figura 7.35 - Curva da variância por temperatura.

Temperatura X Calor Específico

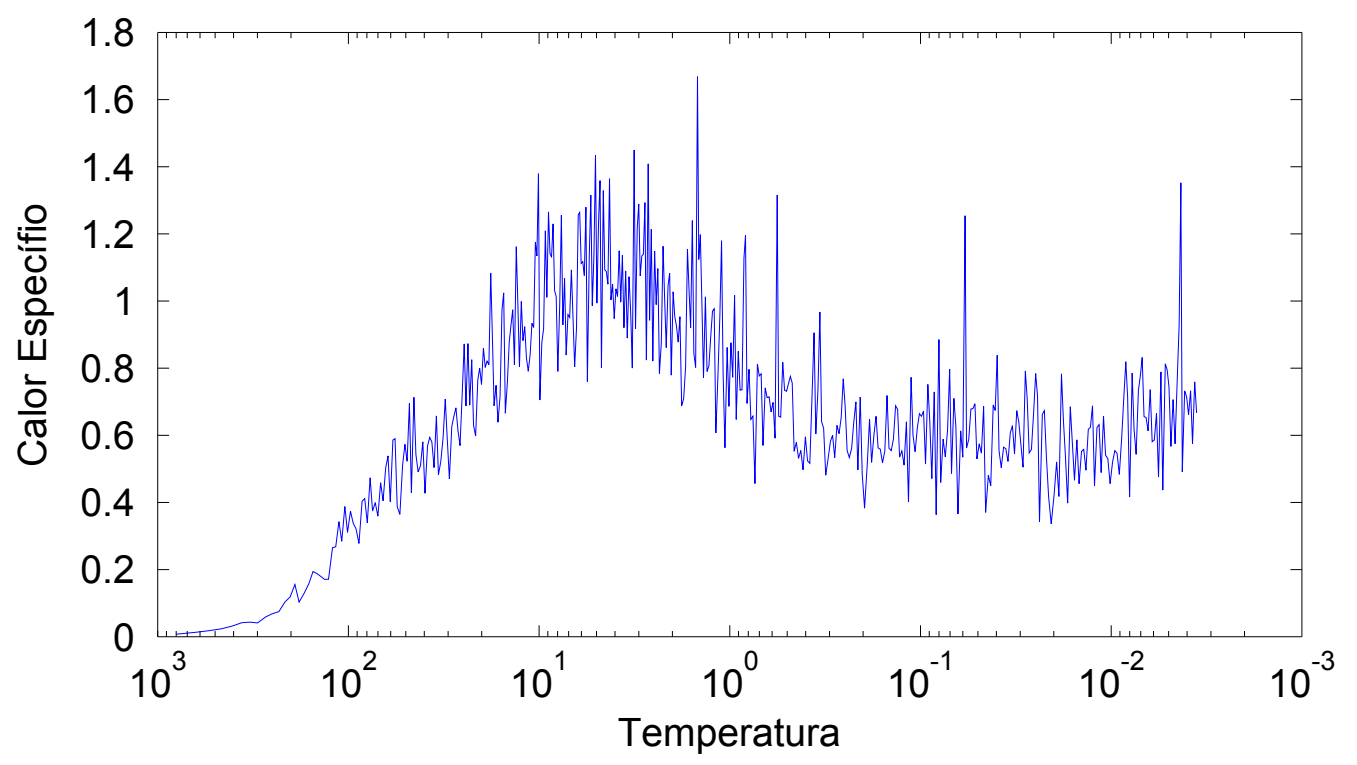

Figura 7.36 - Curva do calor específico por temperatura. 


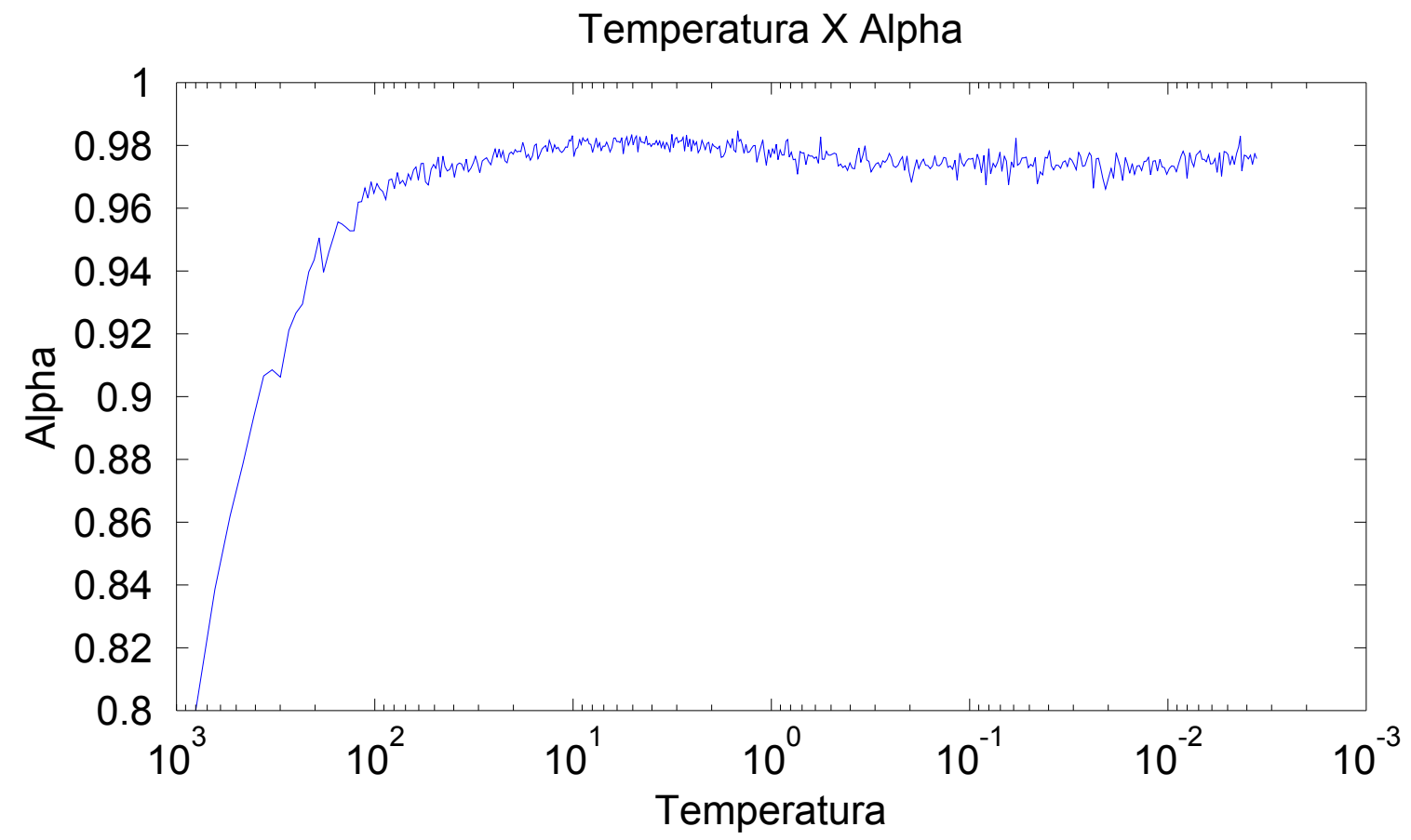

Figura 7.37 - Curva do fator de resfriamento $\alpha$ por temperatura. 


\section{Conclusões}

Neste trabalho foi proposto um método para resolver o problema de ajuste de curvas. Para resolver o problema foram utilizados o recozimento simulado com vizinhança adaptativa e o AMOSA, um recozimento simulado multi-objetivo. Para aplicar estas meta-heurísticas foi proposto um método de parametrização para criar uma sequência de curvas. Este método define parâmetros contínuos e discretos que criam curvas de Bézier de forma que elas possuam continuidade $C^{1}$-fraca. Na função objetivo da heurística com um objetivo foi utilizado o comprimento da curva aproximadora gerada como regularização, evitando a criação de curvas com grande tortuosidade.

O método proposto foi testado em três exemplos onde cada exemplo foi testado com diversas configurações, ao modificar o número de curvas. No teste com recozimento simulado com um objetivo foi analisada a influência do comprimento da curva sobre a função objetivo e o resultado final. Em um exemplo, diversas características do recozimento simulado com vizinhança adaptativa foram analisadas: a variação dos fatores de cristalização com o decaimento da temperatura; a variação do custo com o decaimento da temperatura; e a variação do calor específico com o decaimento da temperatura. Com estes testes, foi possível verificar que curvas aproximadoras com baixo comprimento e tortuosidade foram criadas.

Foi feito uma comparação entre os resultados obtidos utilizando o recozimento simulado com um objetivo e o multi-objetivo, e também foi feita uma comparação visual entre os resultados utilizando técnicas de ajuste de curvas, onde se encontra uma curva aproximadora, com resultados utilizando técnicas de interpolação de curvas. As técnicas de interpolação de curvas criam curvas que apresentam uma grande tortuosidade o que não é desejado, e ao diminuir a quantidade de pontos a serem interpolados, escolhendo apenas alguns pontos a serem interpolados, não é possível avaliar se a curva criada é a melhor, ou seja, que possui a menor distância entre a sequência de pontos e a curva gerada. Desta forma ao utilizar o método proposto, é possível avaliar que a curva gerada possui a menor distância assim como uma menor tortuosidade ao criar curvas com menor comprimento.

\subsection{Trabalhos futuros}

Apesar dos bons resultados deste trabalho, existem algumas melhorias que ainda podem ser feitas.

Pode-se adicionar um termo na função objetivo que avalia a segunda derivada da curva, pois apesar da curva apresentar continuidade $C^{1}$-fraca e valores da distância e do comprimento baixos, em algumas curvas foi possível observar imperfeições, que inicialmente pareciam que a continuidade $C^{1}$-fraca não foi atendida, mas ao aproximar a visualização 
da curva foi possível notar que a curva possui continuidade $C^{1}$-fraca, mas que a segunda derivada não era constante, criando uma inflexão na curva em um pequeno trecho.

Uma segunda melhoria seria criar um método para avaliar qual seria a melhor quantidade de trechos de curva. Testes foram feitos para cada exemplo com várias quantidades de trechos de curvas, e apesar de verificar que quanto maior a quantidade de trechos melhor o resultado, não foi determinado a quantidade de curvas ótima. 


\section{Referências}

ADI, D.; SHAMSUDDIN, S.; HASHIM, S. Z. M. NURBS curve approximation using particle swarm optimization. Computer Graphics, Imaging and Visualization (CGIV), 2010 Seventh International Conference on, p. 73-79, 2010. Citado 2 vezes nas páginas 14 e 25 .

BANDYOPADHYAY, S.; SAHA, S.; MAULIK, U.; DEB, K. A simulated annealing-based multiobjective optimization algorithm: AMOSA. Evolutionary Computation, IEEE Transactions on, v. 12, n. 3, p. 269-283, 2008. Citado na página 32.

BOHACHEVSKY, I. O.; JOHNSON, M. E.; STEIN, M. L. Generalized simulated annealing for function optimization. Technometrics, v. 28, n. 3, p. 209-217, 1986 . Citado na página 19.

CHIYOKURA, H. Solid Modeling with Designbase: Theory and Implementation. Boston, MA, USA: Addison-Wesley Longman Publishing Co., Inc., 1988. ISBN 0201192454. Citado na página 15.

CORANA, A.; MARCHESI, M.; MARTINI, C.; RIDELLA, S. Minimizing multimodal functions of continuous variables with the simulated annealing algorithm. ACM Transactions on Mathematical Software, v. 13, p. 262-280, 1987. Citado 3 vezes nas páginas 19, 20 e 38.

GOFUKU, S.; TAMURA, S.; MAEKAWA, T. Point-tangent/point-normal B-spline curve interpolation by geometric algorithms. Computer-Aided Design, v. 41, p. 412-422, 2009. Citado 3 vezes nas páginas 13, 16 e 68.

HASEGAWA, A. Y.; JR., R. S. U. R.; TSUZUKI, M. S. G. Differential evolution optimization for Bezier curve fitting. 11th IFAC Workshop on Intelligent Manufacturing Systems, p. 233-238, 2013. Citado 5 vezes nas páginas 9, 14, 16, 17 e 25.

HU, S.-M.; WALLNER, J. A second order algorithm for orthogonal projection onto curves and surfaces. Computer-Aided Geometric Design, v. 22, p. 251-260, 2005. Citado 2 vezes nas páginas 13 e 17.

JOHNSON, N.; KOTZ, S.; BALAKRISHNAN, N. Continuous univariate distributions. Nova York: Wiley \& Sons, 1995. (Wiley series in probability and mathematical statistics: Applied probability and statistics, v. 2). Citado na página 21.

KIRKPATRICK, S.; GELATT, C. D.; VECCHI, M. P. Optimization by simulated annealing. Science, v. 220, n. 4598, p. 671-680, 1983. Citado na página 19.

MAEKAWA, T.; MATSUMOTO, Y.; NAMIK, K. Interpolation by geometric algorithm. Computer-Aided Design, v. 39, p. 313-323, 2007. Citado 6 vezes nas páginas 11, 13, 16, 68,69 e 70.

MARTINS, T.; SATO, A.; TSUZUKI, M. Adaptive neighborhood heuristics for simulated annealing over continuous variables. Simulated Annealing - Advances, Applications and Hybridizations, InTech, 2012. Citado na página 20. 
METROPOLIS, N.; ROSENBLUTH, A.; ROSENBLUTH, M.; TELLER, A.; TELLER, E. Equation of state calculations by fast computing machines. The Journal of Chemical Physics, v. 21, p. 1087, 1953. Citado na página 19.

OKANIWA, S.; NASRI, A.; LIN, H.; ABBAS, A.; KINERI, Y.; MAEKAWA, T. Uniform b-spline curve interpolation with prescribed tangent and curvature vectors. IEEE Educational Activities Department, v. 18, n. 9, p. 1474-1487, 2012. Citado na página 13.

PANDUNATA, P.; SHAMSUDDIN, S. Differential evolution optimization for Bezier curve fitting. Computer Graphics, Imaging and Visualization (CGIV), 2010 Seventh International Conference on, p. 68-72, 2010. Citado 3 vezes nas páginas 14, 16 e 25.

PATRIKALIS, N. M.; MAEKAWA, T. Shape Interrogation for Computer Aided Design and Manufacturing, Springer-Verlag, 2001. Citado na página 66.

PIEGL, L.; TILLER, W. Algorithm for approximate NURBS skinning. Computer-Aided Design, v. 28, n. 9, p. 699 - 706, 1996. Citado na página 12.

PIEGL, L.; TILLER, W. The NURBS book: Seccond Ediction, Springer-Verlag, 1997. Citado 3 vezes nas páginas 13, 14 e 66.

SHAMSUDDIN, S.; AHMED, M.; SMIAN, Y. NURBS skinning surface for ship hull design based on new parameterization method. The International Journal of Advanced Manufacturing Technology, v. 28, n. 9-10, p. 936-941, 2006. Citado na página 12.

SMITH, K.; EVERSON, R.; FIELDSEND, J. Dominance measures for multi-objective simulated annealing. Evolutionary Computation, 2004. CEC2004. Congress on, v. 1, p. 23-30 Vol.1, 2004. Citado na página 32.

SOBRINHO, E.; SANOMYA, R.; UEDA, R.; TIBA, H.; TSUZUKI, M. S. G.; ADAMOWSKI, J. C.; SILVA, E. C. N.; CARNOBARI, R. C.; BUIOCHI, F. Development of a methodology for evaluation of a structural damage in turbine blades from hydropower generators. Proceedings of the 20th International Congress of Mechanical Engineering., Gramado, Brazil, 2009. Citado na página 14.

TAVARES, R.; MARTINS, T.; TSUZUKI, M. Simulated annealing with adaptive neighborhood: A case study in off-line robot path planning. Expert Systems with Applications, v. 38, n. 4, p. 2951 - 2965, 2011. Citado 2 vezes nas páginas 14 e 17.

UEDA, E. K.; TSUZUKI, M. de S. G.; SIlVA, E. C. N.; MARTINS, T. de C.; GALLO, G. B.; MARQUES, M. A.; TAKIMOTO, R. Y. Geometric algorithm for curve interpolation with non uniform B-splines. Anais do XI Simpósio Brasileiro de Automação Inteligente., Fortaleza, Brazil, 2013. Citado na página 69.

YAMAGUCHI, F. Curves and surfaces in computer aided geometric design, Springer-Verlag, 1988. Citado na página 18. 
Apêndices 


\section{APÊNDICE A - Curva B-spline}

A curva B-spline é definida como uma combinação linear dos pontos de controle e das funções base $N_{i, k}(t)$ expressas por

$$
\mathbf{P}(t)=\sum_{i=0}^{n} \mathbf{p}_{i} N_{i, k}(t), t \in\left[t_{k-1}, t_{n+1}\right]
$$

onde, $\mathbf{T}=\left(t_{0}, t_{1}, \ldots, t_{n}\right)$; com $t_{i} \in[0,1], \forall i=1, \ldots, n$, é o vetor de nós e as funções base $N_{i, k}(t)$ são expressas por

$$
N_{i, 1}(t)= \begin{cases}1, & \text { for } t_{i} \leq t<t_{i+1} \\ 0, & \text { caso contrário, }\end{cases}
$$

para $k=1$, e

$$
N_{i, k}(t)=\frac{t-t_{i}}{t_{i+k-1}-t_{i}} N_{i, k-1}(t)+\frac{t_{i+k}-t}{t_{i+k}-t_{i+1}} N_{i+1, k-1}(t)
$$

para $k>1$, e $i=0,1, \ldots, n-k$.

Piegl e Tiller [1997] e Patrikalis e Maekawa [2001] utilizam um método recursivo para o cálculo das derivadas da curva B-spline. A primeira derivada é dada pela expressão

$$
\dot{\mathbf{P}}(t)=\sum_{i=1}^{n}(k-1)\left(\frac{\mathbf{p}_{i}-\mathbf{p}_{i-1}}{t_{i+k-1}-t_{i}}\right) N_{i, k-1}(t),
$$

Para os extremos, a primeira derivada é expressa por

$$
\begin{gathered}
\dot{\mathbf{P}}(0)=\frac{(k-2)(k-1)}{t_{k}}\left(\mathbf{p}_{1}-\mathbf{p}_{0}\right), \\
\dot{\mathbf{P}}(1)=\frac{k-1}{t_{n+k-1}-1}\left(\mathbf{p}_{n}-\mathbf{p}_{n-1}\right),
\end{gathered}
$$

A Fig. A.38 mostra uma curva B-spline com sua primeira derivada, os pontos em vermelho são os pontos de controle. 


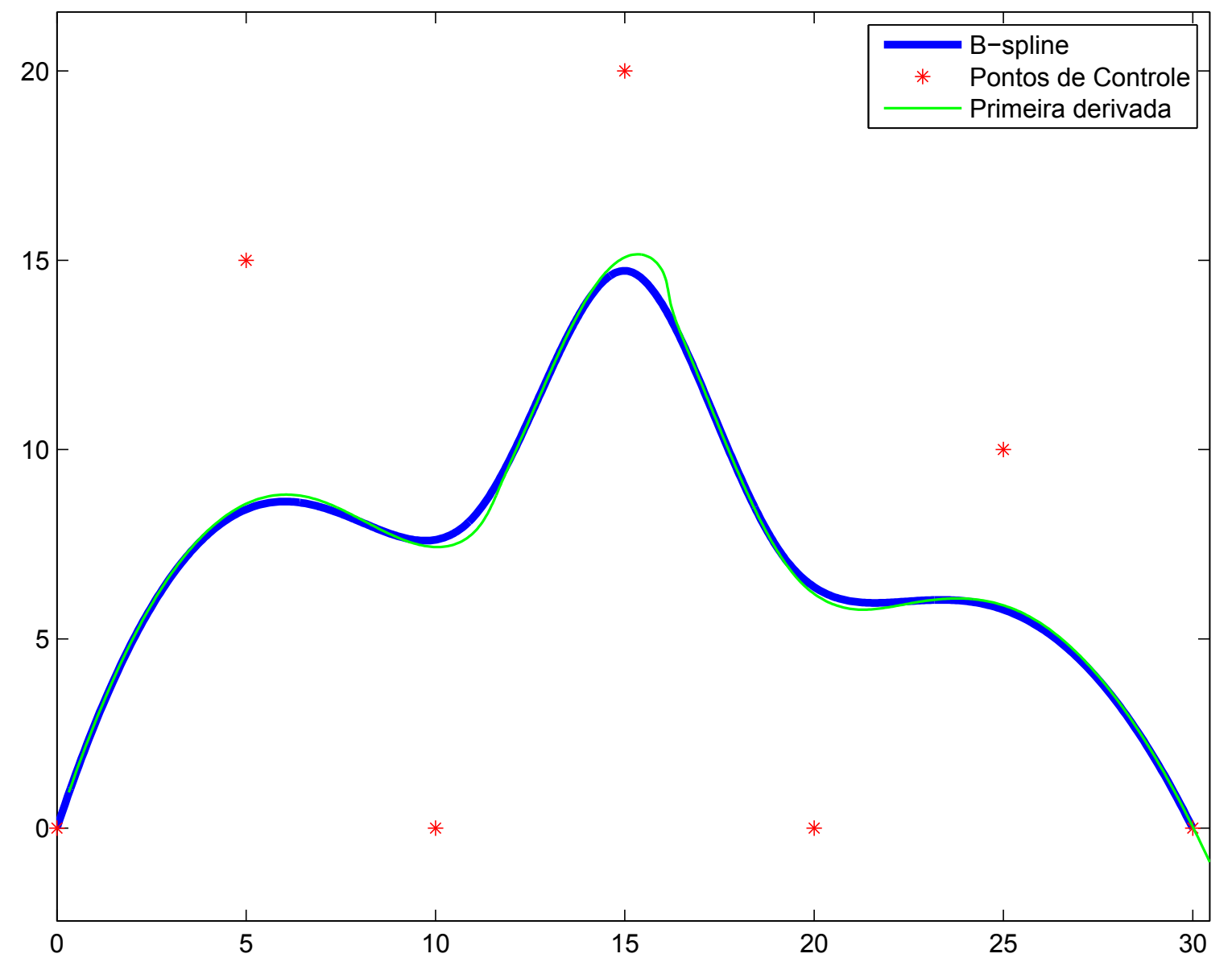

Figura A.38 - B-spline com a primeira derivada. 


\section{APÊNDICE B - Interpolação de Curvas por Algoritmo Geométrico}

A partir de uma sequência de pontos $\mathbf{d}_{k} \operatorname{com} m+1$ elementos o algoritmo geométrico de interpolação de curvas desenvolvido por Maekawa et al. [2007] tem como finalidade resolver a seguinte expressão

$$
\mathbf{P}\left(\tau_{i}\right)=\sum_{j=0}^{m} \mathbf{p}_{j} N_{j, k}\left(\tau_{i}\right)=\mathbf{d}_{\mathbf{i}}, 0 \leq i \leq m
$$

Ao resolver a eq. B.1, encontra-se um conjunto com $m+1$ pontos de controle $\mathbf{p}_{j}$ de forma que a B-spline definida por estes pontos interpola a sequência de pontos $\mathbf{d}_{k}$.

O algoritmo de Maekawa et al. [2007] é composto por dois passos. Inicialmente, os pontos da sequência de pontos $\left(\mathbf{d}_{\mathbf{0}}, \ldots, \mathbf{d}_{\mathbf{m}}\right)$ são utilizados como pontos de controle da B-spline expressa por

$$
\mathbf{P}^{(1)}(t)=\sum_{i=0}^{m} \mathbf{p}_{i}^{(1)} N_{i, k}(t)
$$

onde, $\mathbf{p}_{i}^{(1)}=\mathbf{d}_{\mathbf{i}}, i=0, \ldots, m$.

Neste primeiro passo, é possível observar que a curva não interpola a sequência de pontos. Assim, é necessário calcular para todos os pontos $\mathbf{d}_{k}$ da sequência de pontos, o ponto mais próximo da curva interpoladora, que é a projeção ortogonal do ponto sobre a curva. Formas de calcular a projeção de um ponto sobre uma curva são explicados na seção 2.1. Maekawa et al. [2007] utiliza o método de Newton-Raphson para realizar esta operação ao resolver a seguinte equação não linear

$$
\left(\mathbf{d}_{\mathbf{i}}-\left(\mathbf{P}^{(1)}(t)\right)\right) \cdot \dot{\mathbf{P}}^{(1)}(t)=0 .
$$

Gofuku et al. [2009] realizam uma linearização da curva na j-ésima iteração do método de Newton-Raphson, ao projetar o ponto $\mathbf{d}_{i}$ na reta tangente da curva no ponto que corresponde à parametrização $t_{i, j}$, determinando o parâmetro $\Delta t$ ao resolver a seguinte equação:

$$
\left(\mathbf{d}_{\mathbf{i}}-\left(\mathbf{P}^{(1)}\left(t_{i, j}\right)+\dot{\mathbf{P}}\left(t_{i, j}\right) \Delta t\right)\right) \cdot \dot{\mathbf{P}}^{(1)}\left(t_{i, j}\right)=0 .
$$

O segundo passo do algoritmo é transladar os pontos de controle da B-spline. O deslocamento de cada ponto de controle $\left(\mathbf{p}_{\mathbf{i}}^{(1)}\right)$ é dado por um vetor erro denominado por $\mathbf{e}_{\mathbf{i}}^{(1)}$ que gera novos pontos de controle $\left(\mathbf{p}_{\mathbf{i}}{ }^{(2)}\right)$. Este vetor erro é a distância entre 
um ponto $\mathbf{d}_{\mathbf{i}}$ da sequência de pontos e a projeção ortogonal deste ponto sobre a curva $\mathbf{f}_{i}$. Desta forma na $\alpha$-ésima iteração, o cálculo dos pontos de controle é dado por

$$
\mathbf{p}_{i}^{(\alpha+1)}=\mathbf{p}_{i}^{(\alpha)}+\mathbf{e}_{i}^{(\alpha)}=\mathbf{p}_{i}^{(\alpha)}+\mathbf{d}_{i}-\mathbf{f}_{i}^{(\alpha)}, i=1, \ldots, m-1
$$

$\operatorname{com} \mathbf{p}_{\mathbf{0}}{ }^{(\alpha)}=\mathbf{d}_{\mathbf{0}}$ e $\mathbf{p}_{\mathbf{m}}{ }^{(\alpha)}=\mathbf{d}_{\mathbf{m}}$.

Esse algoritmo se repete até que a magnitude do erro seja menor que uma tolerância. Maekawa et al. [2007] utilizam uma tolerância de 0.05\% da diagonal da caixa formada pela sequência de pontos. A Fig. B.39 mostra algumas partes do algoritmo. A Fig. B.39(a) mostra a primeira B-spline gerada ao utilizar a sequência de pontos como pontos de controle. Na Fig. B.39(b) é feito o deslocamento dos pontos de controle ao adicionar a cada ponto de controle uma distância $e_{i}=\left\|\overline{\mathbf{p}_{i} \mathbf{f}_{i}}\right\|$. A Fig. B.39(c) mostra a curva gerada com os novos pontos de controle e a Fig. B.39(d) mostra a curva interpoladora na k-ésima iteração.

Maekawa et al. [2007] desenvolveram o algoritmo geométrico utilizando uma B-spline quadrática uniforme, expressa por

$$
\mathbf{P}(t)=\left(\frac{1}{2}(1-t)^{2}\right) \mathbf{p}_{i-1}+\left(\frac{1}{2}+t-t^{2}\right) \mathbf{p}_{i}+\frac{1}{2} t^{2} \mathbf{p}_{i+1}, i=1, \ldots, n-1
$$

Mas, Ueda et al. [2013] utilizaram este algoritmo com B-splines não uniformes. A diferença entre estes tipos de B-spline são quanto ao vetor de nós. Na B-spline uniforme a diferença entre dois nós é constante para todo o vetor, na não uniforme essa diferença não é constante, desta forma foram utilizadas as eqs. A.1 -A.5 apresentadas no apêndice A no algoritmo geométrico. 


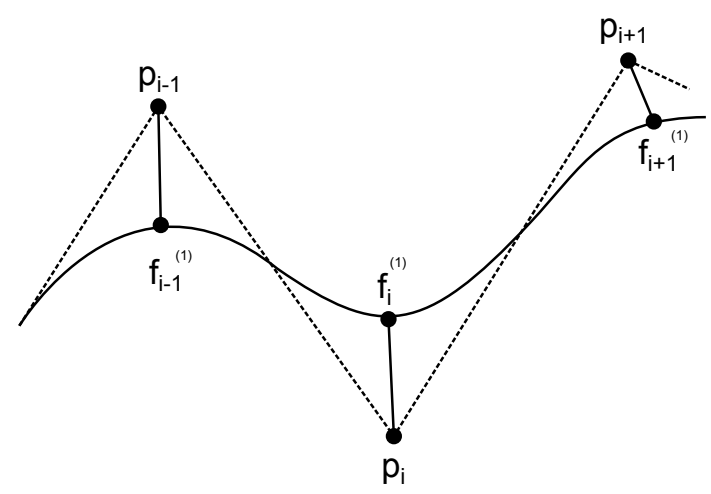

(a)

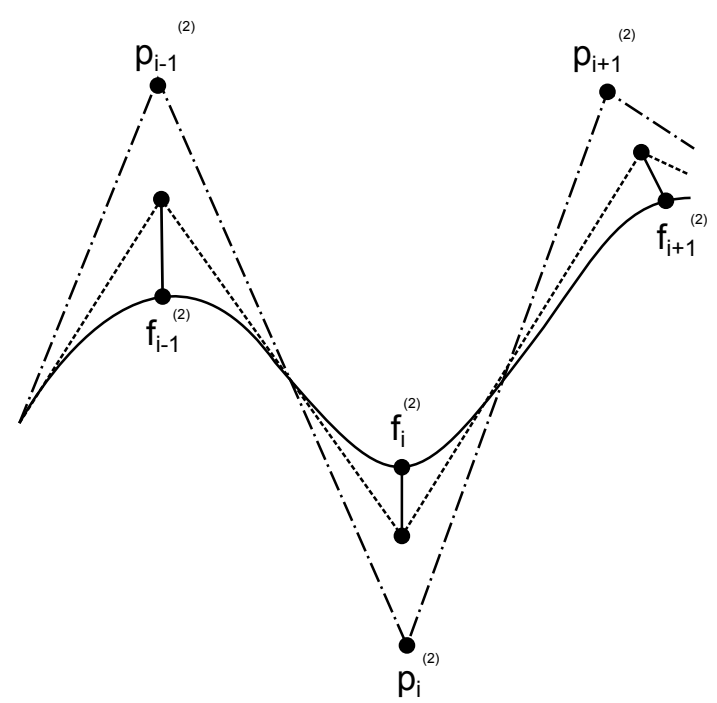

(c)

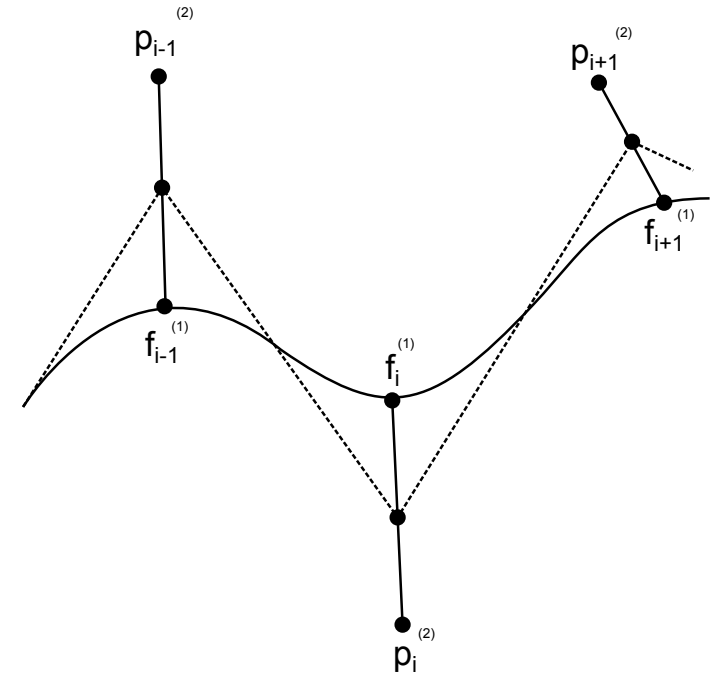

(b)

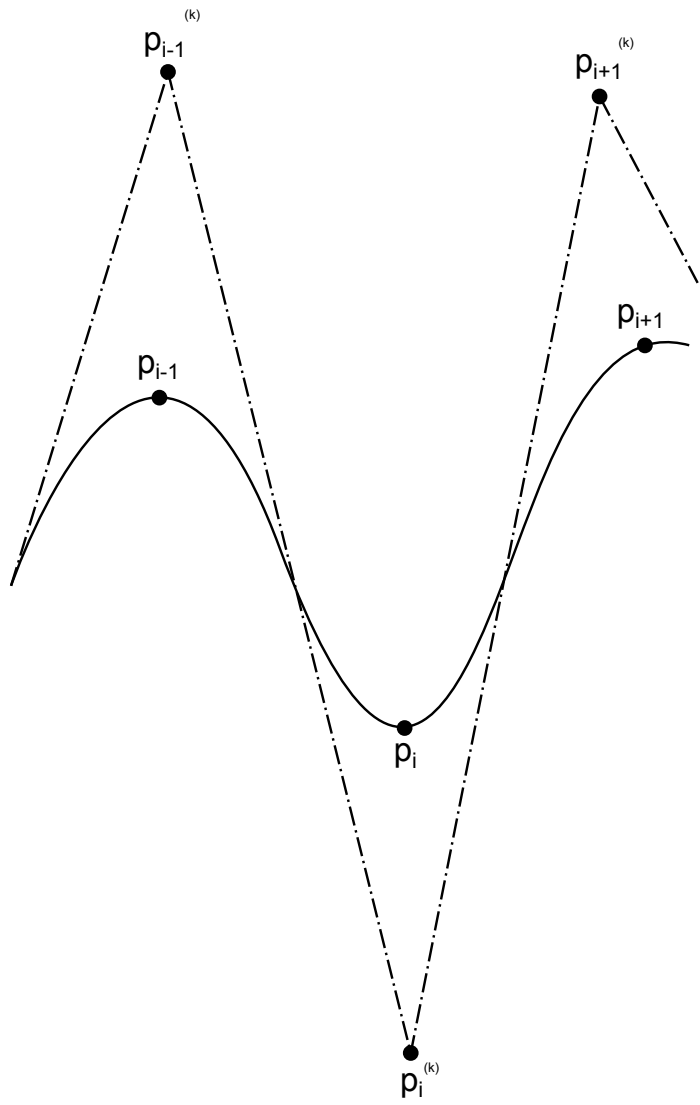

(d)

Figura B.39 - Interpolação de curvas. (a) primeira curva utilizando a sequência de pontos como pontos e controle; (b) primeiro deslocamento dos pontos de controle; (c) curva gerada após o primeiro deslocamento dos pontos de controle; (d) curva interpoladora ao final do processo. (Extraído de Maekawa et al. [2007]) 


\section{APÊNDICE C - Valores de Cada Parcela da Função Custo Utilizando o recozimento simulado com Vizinhança Adaptativa}

Estas tabelas são valores referentes as Figs. 7.19, 7.24 e 7.30 que apresentam os valores de cada parcela da função objetivo para cada exemplo. 
Tabela 1 - Resultados de uma parábola

\begin{tabular}{|c|c|c|c|c|c|c|c|c|c|}
\hline Número de curvas & \multicolumn{3}{|c|}{1} & \multicolumn{3}{|c|}{2} & \multicolumn{3}{|c|}{3} \\
\hline Peso (W1-W2) & Distância & Comprimento & Custo & Distância & Comprimento & Custo & Distância & Comprimento & Custo \\
\hline $0,1-0,9$ & 4,98546 & 0,56838 & 1,01009 & 4,24685 & 0,00014 & 0,42481 & 4,04242 & 0,00013 & 0,40436 \\
\hline $0,2-0,8$ & 4,64930 & 0,63961 & 1,44154 & 4,24845 & 0,00001 & 0,84970 & 3,89829 & 0,00004 & 0,77969 \\
\hline $0,3-0,7$ & 4,64475 & 0,64160 & 1,84254 & 4,23825 & 0,00035 & 1,27172 & 3,93977 & 0,00027 & 1,18212 \\
\hline $0,35-0,65$ & 4,63536 & 0,64643 & 2,04256 & 4,22115 & 0,00009 & 1,47746 & 3,95495 & 0,00169 & 1,38533 \\
\hline $0,4-0,6$ & 4,63418 & 0,64717 & 2,24197 & 4,23942 & 0,00030 & 1,69595 & 3,93986 & 0,00017 & 1,57605 \\
\hline $0,45-0,55$ & 4,63435 & 0,64700 & 2,44130 & 4,24014 & 0,00042 & 1,90829 & 3,92724 & 0,00044 & 1,76750 \\
\hline $0,5-0,5$ & 4,63414 & 0,64745 & 2,64079 & 4,22053 & 0,00306 & 2,11179 & 3,92360 & 0,00001 & 1,96180 \\
\hline $0,6-0,4$ & 4,63419 & 0,64786 & 3,03966 & 4,24245 & 0,00147 & 2,54606 & 3,99113 & 0,00257 & 2,39571 \\
\hline $0,7,0,3$ & 4,63418 & 0,64823 & 3,43840 & 4,23903 & 0,00183 & 2,96787 & 3,95442 & 0,00506 & 2,76961 \\
\hline $0,8-0,2$ & 4,63407 & 0,64829 & 3,83692 & 4,24593 & 0,00710 & 3,39817 & 3,92297 & 0,00475 & 3,13932 \\
\hline $0,85-0,15$ & 4,63401 & 0,64817 & 4,03614 & 4,23965 & 0,01173 & 3,60547 & 3,94747 & 0,00367 & 3,35590 \\
\hline $0,9-0,1$ & 4,63414 & 0,64760 & 4,23549 & 4,22125 & 0,00504 & 3,79963 & 3,92413 & 0,64005 & 3,59572 \\
\hline $0,95-0,05$ & 4,63417 & 0,64761 & 4,43484 & 4,24841 & 0,00561 & 4,03627 & 3,88676 & 0,06312 & 3,69557 \\
\hline Média & 4,66325 & 0,64042 & 2,82171 & 4,23781 & 0,00286 & 2,31486 & 3,94254 & 0,05554 & 2,15452 \\
\hline Max & 4,98546 & 0,64829 & 4,43484 & 4,24845 & 0,01173 & 4,03627 & 4,04242 & 0,64005 & 3,69557 \\
\hline Min & 4,63401 & 0,56838 & 1,01009 & 4,22053 & 0,00001 & 0,42481 & 3,88676 & 0,00001 & 0,40436 \\
\hline
\end{tabular}


Tabela 2 - Resultados de uma curva com inflexão

\begin{tabular}{|c|c|c|c|c|c|c|c|c|c|}
\hline Número de curvas & \multicolumn{3}{|c|}{2} & \multicolumn{3}{|c|}{3} & \multicolumn{3}{|c|}{4} \\
\hline Peso (W1-W2) & Distância & Comprimento & Custo & Distância & Comprimento & Custo & Distância & Comprimento & Custo \\
\hline $0,1-0,9$ & 10,25793 & 0,00021 & 1,02598 & 9,87914 & 0,00062 & 0,98847 & 8,92227 & 0,00029 & 0,89249 \\
\hline $0,2-0,8$ & 10,26491 & 0,00105 & 2,05382 & 9,87115 & 0,00026 & 1,97444 & 8,22031 & 0,00018 & 1,64421 \\
\hline $0,3-0,7$ & 10,25632 & 0,00049 & 3,07724 & 9,59688 & 0,00152 & 2,88013 & 8,46324 & 0,00194 & 2,54033 \\
\hline $0,35-0,65$ & 10,25719 & 0,00111 & 3,59074 & 9,75652 & 0,00110 & 3,41550 & 8,76337 & 0,00100 & 3,06783 \\
\hline $0,4-0,6$ & 10,26207 & 0,00108 & 4,10547 & 9,63668 & 0,00735 & 3,85908 & 8,50879 & 0,01267 & 3,41112 \\
\hline $0,45-0,55$ & 10,25070 & 0,00335 & 4,61466 & 9,71283 & 0,00215 & 4,37195 & 8,72467 & 0,00248 & 3,92746 \\
\hline $0,5-0,5$ & 10,26325 & 0,00107 & 5,13216 & 9,77475 & 0,00073 & 4,88774 & 8,33099 & 0,00205 & 4,16652 \\
\hline $0,6-0,4$ & 10,25549 & 0,00334 & 6,15463 & 9,79425 & 0,00120 & 5,87703 & 8,36437 & 0,00928 & 5,02234 \\
\hline $0,7,0,3$ & 10,25962 & 0,00085 & 7,18199 & 9,77906 & 0,00025 & 6,84542 & 8,66052 & 0,02938 & 6,07118 \\
\hline $0,8-0,2$ & 10,25347 & 0,00194 & 8,20316 & 9,56733 & 0,01571 & 7,65700 & 8,70624 & 0,01688 & 6,96837 \\
\hline $0,85-0,15$ & 10,25336 & 0,04647 & 8,72233 & 9,46966 & 0,01941 & 8,05212 & 8,80353 & 0,00151 & 7,48323 \\
\hline $0,9-0,1$ & 10,24593 & 0,00164 & 9,22150 & 9,46014 & 0,03108 & 8,51723 & 8,74034 & 0,07422 & 7,87373 \\
\hline $0,95-0,05$ & 10,25763 & 0,04101 & 9,74680 & 9,55454 & 11,85686 & 9,66966 & 8,75687 & 0,00517 & 8,31928 \\
\hline Média & 10,25676 & 0,00797 & 5,60234 & 9,68099 & 0,91833 & 5,30737 & 8,61273 & 0,01208 & 4,72216 \\
\hline Max & 10,26491 & 0,04647 & 9,74680 & 9,87914 & 11,85686 & 9,66966 & 8,92227 & 0,07422 & 8,31928 \\
\hline Min & 10,24593 & 0,00021 & 1,02598 & 9,46014 & 0,00025 & 0,98847 & 8,22031 & 0,00018 & 0,89249 \\
\hline
\end{tabular}


Tabela 3 - Resultados de uma curva com auto-intersecção

\begin{tabular}{|c|c|c|c|c|c|c|c|c|c|}
\hline Número de curvas & \multicolumn{3}{|c|}{5} & \multicolumn{3}{|c|}{6} & \multicolumn{3}{|c|}{7} \\
\hline Peso (W1-W2) & Distância & Comprimento & Custo & Distância & Comprimento & Custo & Distância & Comprimento & Custo \\
\hline $0,1-0,9$ & 5,16862 & 0,00007 & 0,51693 & 4,94536 & 0,00005 & 0,49458 & 4,17605 & 0,00002 & 0,41763 \\
\hline $0,2-0,8$ & 4,92503 & 0,00026 & 0,98521 & 4,81139 & 0,00018 & 0,96242 & 4,28093 & 0,00002 & 0,85621 \\
\hline $0,3-0,7$ & 4,89899 & 0,00021 & 1,46984 & 4,48305 & 0,00012 & 1,34500 & 3,96684 & 0,00057 & 1,19045 \\
\hline $0,35-0,65$ & 4,89746 & 0,00015 & 1,71421 & 4,42387 & 0,00142 & 1,54928 & 4,03116 & 0,00492 & 1,41411 \\
\hline $0,4-0,6$ & 4,87467 & 0,00021 & 1,95000 & 4,50876 & 0,00042 & 1,80375 & 4,01632 & 0,00004 & 1,60655 \\
\hline $0,45-0,55$ & 4,88541 & 0,00235 & 2,19973 & 4,48535 & 0,00013 & 2,01848 & 3,92305 & 0,00019 & 1,76548 \\
\hline $0,5-0,5$ & 4,80759 & 0,03682 & 2,42220 & 4,50532 & 0,00271 & 2,25402 & 3,98981 & 0,00019 & 1,99500 \\
\hline $0,6-0,4$ & 4,73417 & 0,00091 & 2,84087 & 4,39131 & 0,01197 & 2,63957 & 3,97198 & 0,00019 & 2,38327 \\
\hline $0,7,0,3$ & 4,70680 & 0,17926 & 3,34854 & 4,34543 & 0,00677 & 3,04384 & 3,96203 & 0,00215 & 2,77407 \\
\hline $0,8-0,2$ & 4,80666 & 0,09266 & 3,86386 & 4,34985 & 0,03445 & 3,48677 & 3,92318 & 0,00009 & 3,13857 \\
\hline $0,85-0,15$ & 4,68041 & 0,17867 & 4,00515 & 4,38573 & 0,10665 & 3,74387 & 3,90950 & 0,08508 & 3,33584 \\
\hline $0,9-0,1$ & 4,71294 & 0,03464 & 4,24511 & 4,35808 & 0,65774 & 3,98805 & 3,96042 & 0,00778 & 3,56516 \\
\hline $0,95-0,05$ & 4,64942 & 0,32330 & 4,43312 & 4,28908 & 0,89064 & 4,11916 & 3,93855 & 0,00057 & 3,74166 \\
\hline Média & 4,82678 & 0,06535 & 2,61498 & 4,48328 & 0,13179 & 2,41914 & 4,00383 & 0,00783 & 2,16800 \\
\hline Max & 5,16862 & 0,32330 & 4,43312 & 4,94536 & 0,89064 & 4,11916 & 4,28093 & 0,08508 & 3,74166 \\
\hline Min & 4,64942 & 0,00007 & 0,51693 & 4,28908 & 0,00005 & 0,49458 & 3,90950 & 0,00002 & 0,41763 \\
\hline
\end{tabular}

